عدد خاص من مجلة "بحوث في العلوم والقنون النوعيه" العزيه

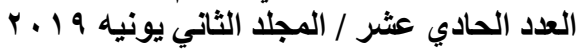

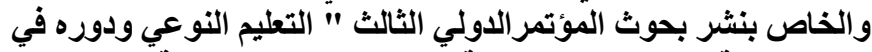

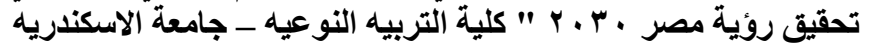

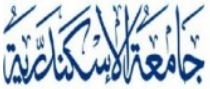

ALEXANDRIA

U N I VER S I T Y

AlexUPress

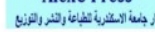

(9) (9) - (9) - (9)

\title{
مميزات وعيوب التسوق عبر الإنترنت لعينة من الأسر بمحافظتى البحيرة \\ والإسكندرية فى ضوء بعض المتغيرات الإجتماعية والإقتصادية
}

د./ سحر أمين حميدة سليمان

مدرس إدارة المنزل وإقتصاديات الاسرة

كلية التربية النوعية/ جامعة الأسكندرية
أ.د./ فاتن مصطفى كمال لطفى

أستاذ إدارة المنزل وإقتصاديات الأسرة

عميد كلية التربية النوعية/ جامعة الإسكندرية

$$
\text { إيمان محمد إبراهيم العرجاوى }
$$

مدرس مساعد بقسم الإقتصاد المنزلى

تخصص إدارة المنزل وإقتصاديات الأسرة

كلية التربية النوعية/ جامعة الاسكندرية 


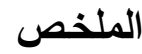

يهدف البحث إلى التعرف على مديزات وعيوب التسوق عبر الإنترنت لدي عينة مـن الأسر بمحافظتى البحيرة والإسكندرية في ضوء بعض المتغيرات الإجتماعية والإقتصـادية،

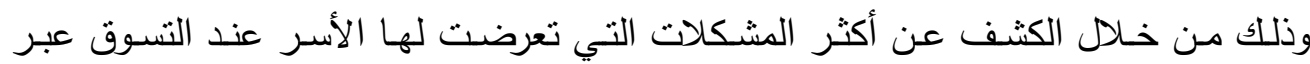
الإنترنـت، كذلك تحديـد العلاقـة بـين بعض المتغيـرات الإجتماعيـة والإقتصـادية وكل مـن

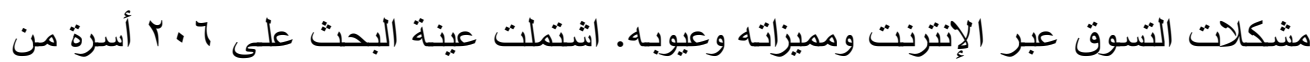
حضر المحافظتين، استخدم المنهج الوصفي التحليلي، والإستنيان كأداة لجمع البيانات. أهم النتائج أن غالبية المبحوثين يتسوقون عبر الإنترنت مرة واحدة فى الثهر ، وكان الزوج هو

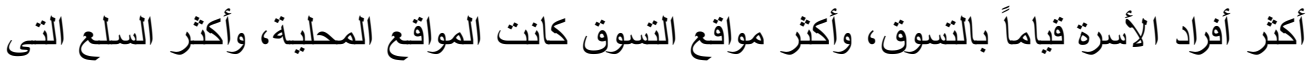

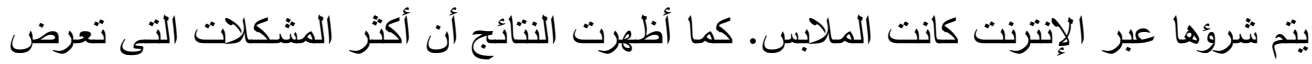

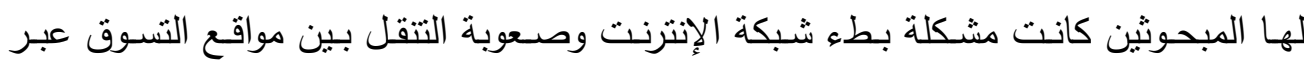
الإنترنت والتعـرض للسـرقة والنصـب مـن مواقـع وهميـة، كمـا أظهرت النتائج وجـود علاقـة إرتباطية دالة إحصائياً بين كل من المستوى التعليمى للزوج والزوجة والاخل الثـهرى للأسرة والدرجة الدالة على مميزات وعيوب التسوق عبر الإنترنت، بينما لا توجد علاقة ذات دلالـة

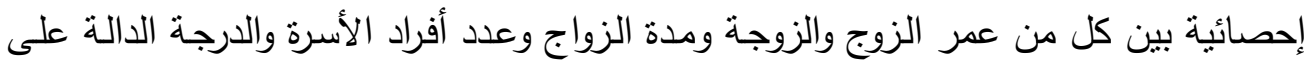

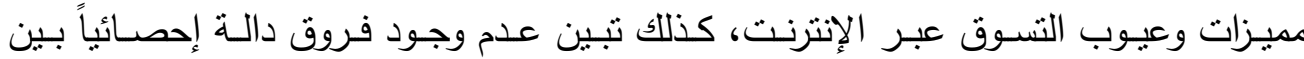
المبحوثين فى الدرجة الدالة على مميزات وعيوب التسوق عبر الإنترنت وفقا لكل من مكان

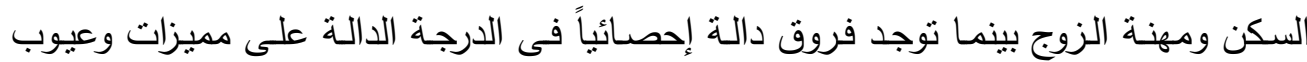

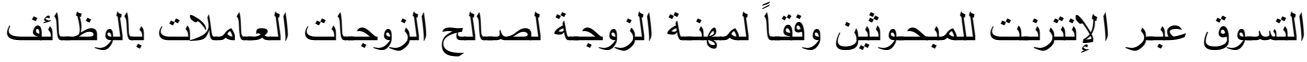

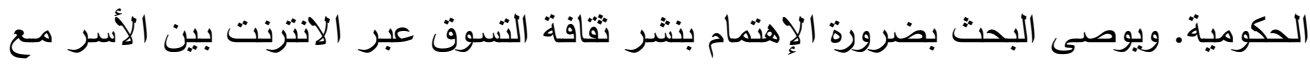
إبراز مميزاته وتوضيح عيوبه وكيفية تجنبها. كلمات دليلية:- النسوق عبر الإنترنت - المتغيرات الإجتماعية - المتغيرات الإقتصادية 
*البحث مشتق من رسـالة ماجستير غير منشـورة للباحثة / إيمان محمد إبراهيم العرجاوى

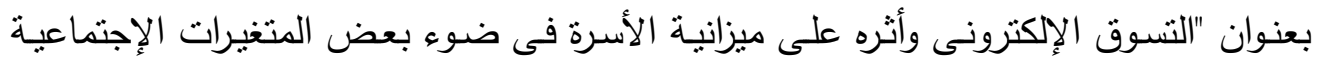

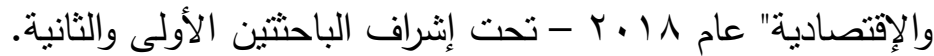

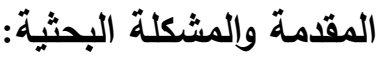

شهت دول العالم فى العقود الأخيرة تطورات سريعة ومتلاحقة أحدثت الكثير من التغيرات الكبيرة والتى أثرت بشكل أو بآخر على حباة شعوب هذه الدول، وقد أصبحت مواكبة هذه النطورات ضرورة ملحة للاستفادة منها فى النهوض بالمجتمعات وتحقيق تقدم ملموس فى جميع مجالات الحياة المختلفة وبالتالى تحقيق رفاهية هذه المجتمعات. ومن أهم هذه التطورات الثورة فى

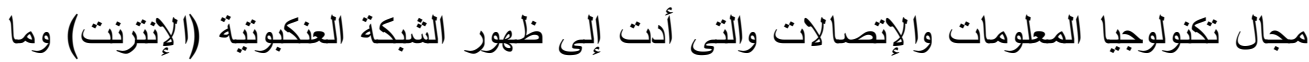
تبعها من ظهور لمواقع الويب ومحركات البحث والبريد الإكترونى والمواقع الاجتماعية التى جعلت العالم يبدو كقرية صغيرة والتى تخدم الأفراد والمجمعات بأثنكال كثيرة وعديدة (الطائى

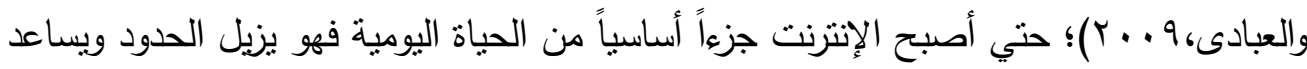

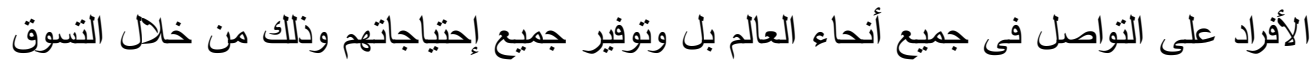
عبر الإنترنت والذى تحول إلى ظاهرة واضحة وبارزة فى حياة الأفراد حيث بدأ ينمو و ينتشر يوماً

بعد يوم ليحل محل التسوق التقليدى ( Ozkisi \& Topaloglu,2016 ). فقد تربع مفهوم التسوق عبر الإنترنت على عرش التسوق ومن دون منازع مع أن هذا

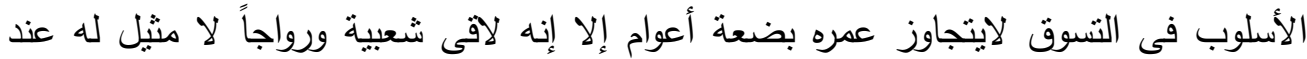

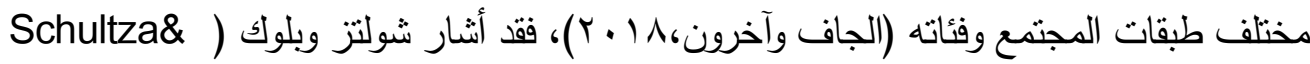

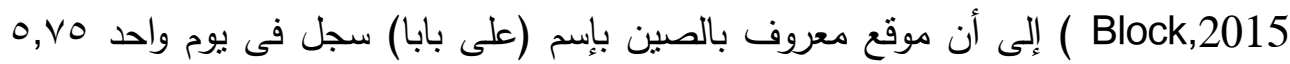

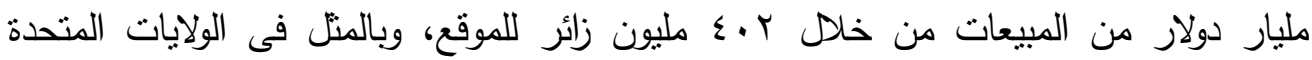
الأمريكية كانت المبيعات عبر الإنترنت خلاد الفترة التى أعقبت عيد الثنكر يوم الثامن والعشرون لئن من شهر نوفمبر عام ب ا ـ r والمعروف باسم الجمعة السوداء ( Black Friday ) مبيعات بقيمة 
r, 1, مليار دولار مما يشير إلى تحول المشترين إلى إستخدام التقنيات الجديدة فى الثراء وهى

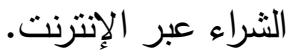

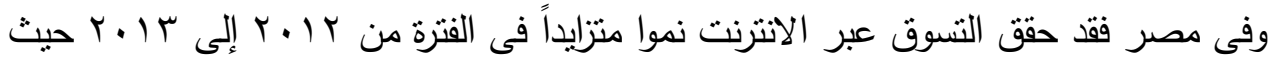

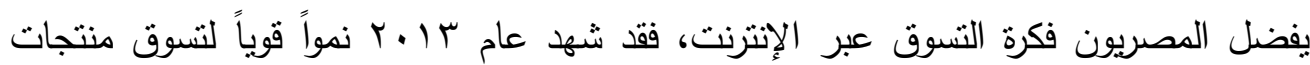

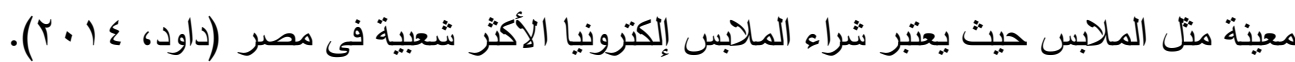

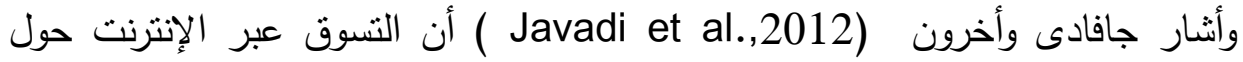
ميزان القوى لصالح المستهلك ومكنه من إجراء مقارنات قبل الثراء وتقييم البدائل دون

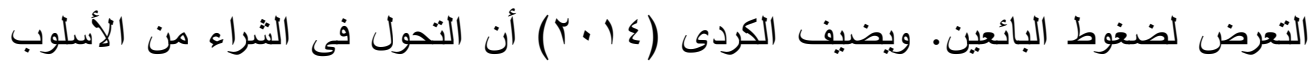
التقليدى إلى الثراء عبر الإنترنت قد أدى إلى تغير عادات وأنماط الثراء لدى المستهرئكين، وأصبح بإمكان المستهلك أن ينسوق ويتم كافة تعاملاته التجارية و المصرفية من المنزل عبر الإنس

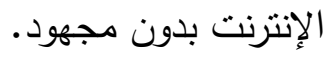

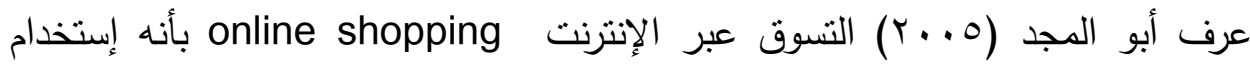
مواقع الإنترنت فى تصفح أوبحث عن أوشراء المنتجات من السلع والخدمات والمعلومات. كما الإثرنات يعرفه الوادى والوادى (1) (1) بأنه مجموعة من الجهود التى يبذلها المشترى عبر الإنترنت

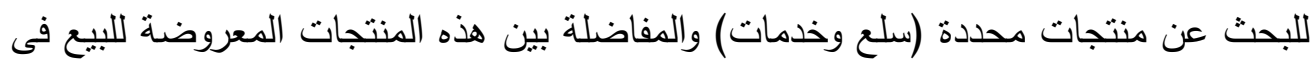

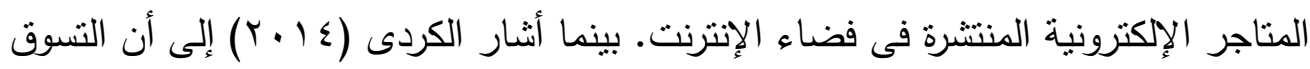

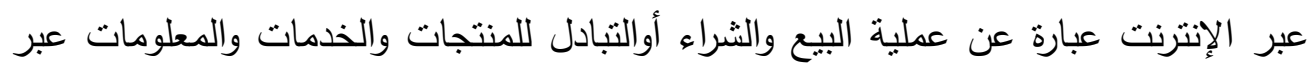

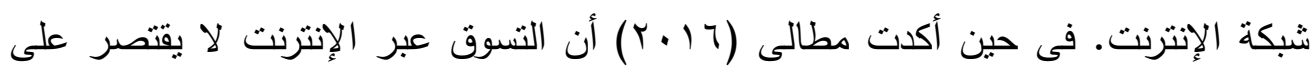

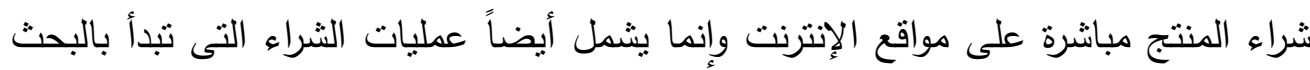
والتقصى على الإنترنت لتنتهى خارج العالم الإفتراضى أى بالثراء التقليدى.

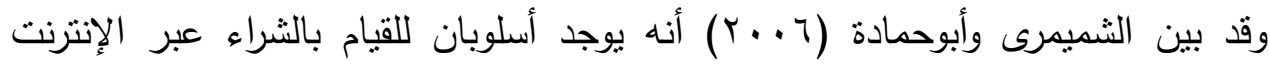

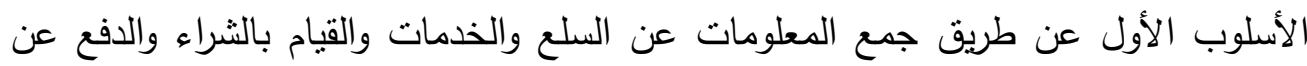


طريق الإنترنت، والثانى عن طريق جمع معلومات مختلفة عن السلع عبر الإنترنت ثم القيام

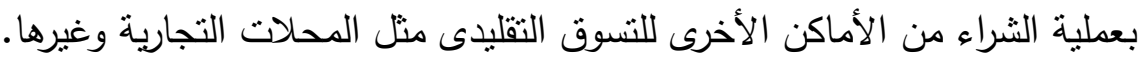
ويتمتع التسوق عبر الإنترنت بالعديد من المزايا والتى أظهرتها نتائج الدراسات التى

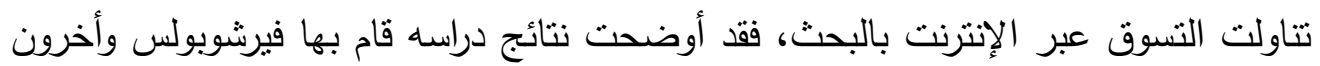
(Verchopoulos et al.,2001 ) باليونان بهدف التعرف على تأثثر الخصائص الديموغرافية والسلوكية للمستهلك اليونانى الذى هن يقوم بالتسوق عبر الإنترنت، أن من أهم المميزات التى تجعل عينة الدراسة تقبل على التسوق عبر الإنترنت أنه يوفر خدمة التسوق أربعة وعشرون ساعة، ويوفر وقت الإستر المستهلك ويؤدي لسرعة تلبية طلباته. كذلك أكدت دراسة مياتيك وأخرون ( Miyatake et al.,2015) والتني أجريت للتعرف علي تأثنير التنسوق عبر الإنترنت على تكلفة الثراء للمستهلك مقارنة بالطريقة التقليدية، والتي أوضحت أن من العوامل المهمة المؤثرة على إقبال المستهلك على التسوق عبر الإنترنت هو

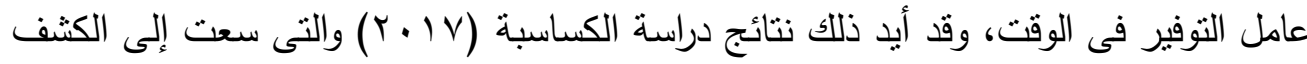
عن أثز العوامل الثقافية على تثنى قرار الثراء عبر الإنترنت من وجهة نظر عينة قوامها

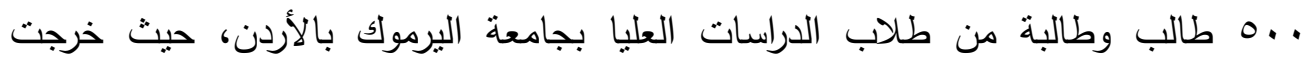
نتائجها بأن أهم هميزات التسوق عبر الإنترنت هو إمكانية التسوق فى أى وقت وأى مكان وأنه يوفر الوقت والجهر مقارنة بالثراء من الأسواق التقليدية. كما أضاف الخطيب والقتامى التهى (Y • V V) مميزات التسوق عبر الإنترنت والتى تساهم فى زيادة الإقبال عليه هو سهولة الوصول إلى

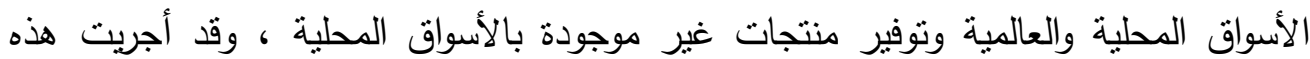

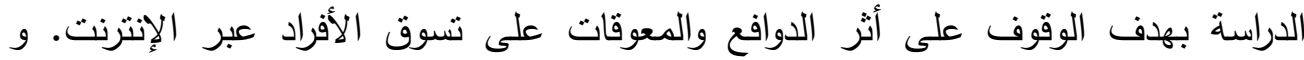

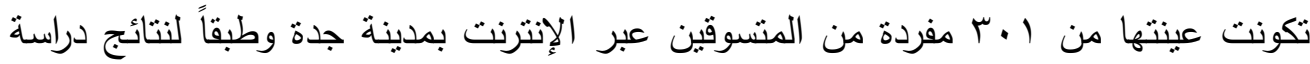
حدادين (Haddadin,2017) التى أجريت بهدف إختبار تأثثر جودة خدمات المواقع الإكترونية للتسوق على إتجاهات المستهكين فى الأردن، وطبقت على عينة من طلاب 
ثلاث جامعات بعمان قوامها r YV طالب، فقد خرجت الدراسة بأن من العوامل التى تضيف إلى مميزات التسوق عبر الإنترنت ولها تأثثر إيجابى على إقبال الأفراد عليه سهولة إستخدام الموقع الإككترونى وأمن الموقع والإلتزام بالوعود للزبائن. فى المقابل فقد رصدت العديد من الدراسات الكثير من المخاوف والعيوب التى قد تثوب

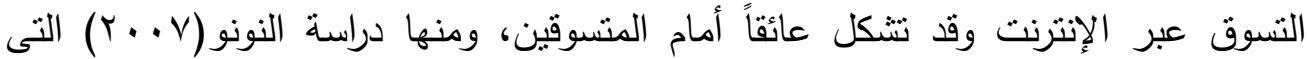

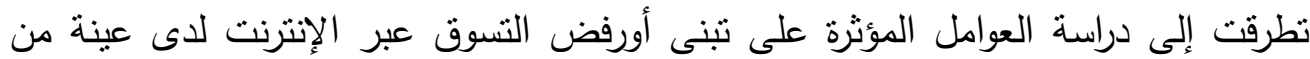
. . . متسوق وغير متسوق عبر الإنترنت بدولة الإمارات العربية المتحدة، وتبين من النتائج أن أسباب رفضهم للتسوق عبر الإنترنت هي ضعف التقة في التعاملات الإكترونية لإعتقادهم أن هذا الوسط غير آمن، بالإضافة إلى افتقارهم الخبرة لمنل هذا النوع من النسوق،

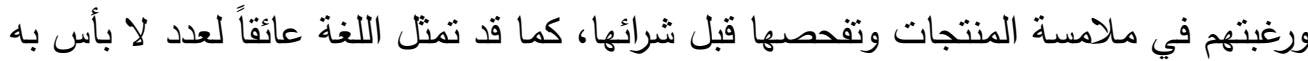

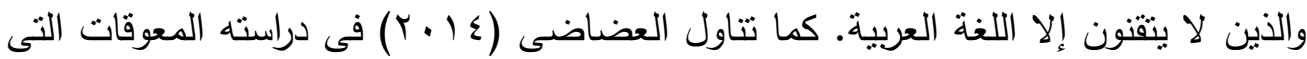
تواجه الأفراد فى المجتمع الخليجى عند إستخدامهم للتسوق الإلكترونى وتحول دون إستخدامهم

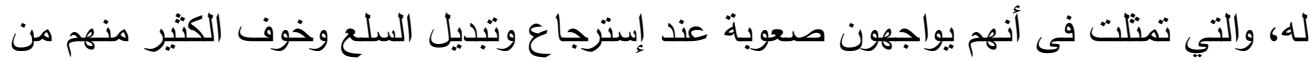
Pandey \& ) تسرب أرقام بطاقاتهم الإثتمانية. واتقفت معه نتائج دراسة باندى ونتشاونه

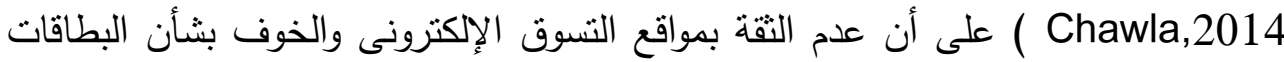

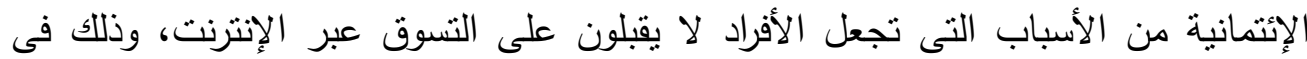

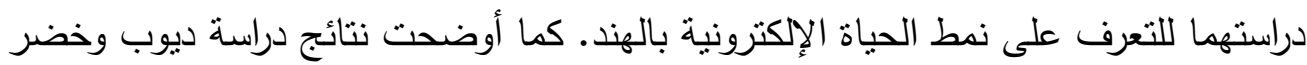

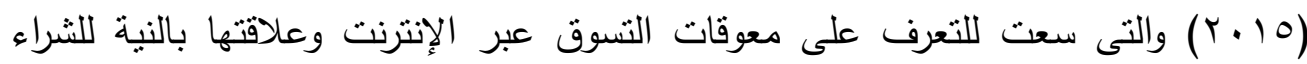
الإكترونى لدى طلاب الجامعة بطرطوس بسوريا أن المعوقات تمثلت في البنية التحتية للإنترنت، المخاطر المتوقعة للتسوق، ضعف الخبرة والوعى، عدم الثقة بالمتاجر الإلكترونية،

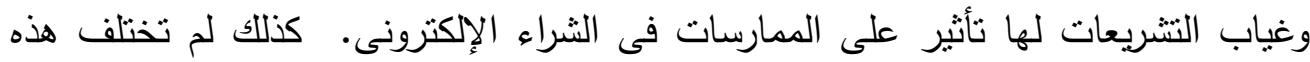

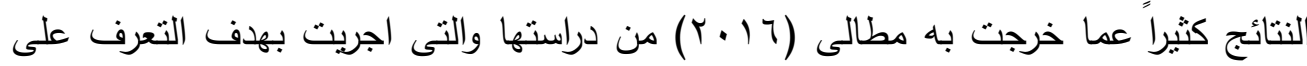

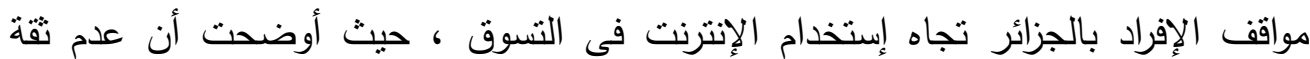


المستهلكين فى التعاملات التى تتم عبر الإنترنت كان من أسباب ضعف إقبالهم علي التسوق

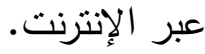

كذلك فقد تطرقت دراسة الخطيب والقثامى (Y.lV) إلى البحث عن أثر الدوافع والمعوقات على تسوق الأفراد عبر الإنترنت، من خلال عينة عشوائية مكونة من ا.ب

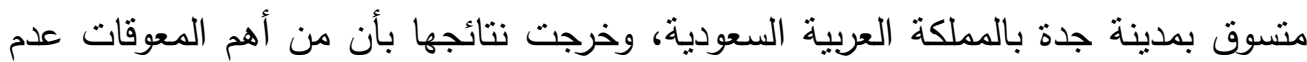

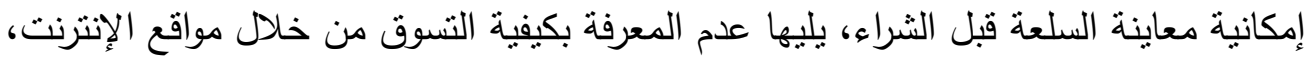

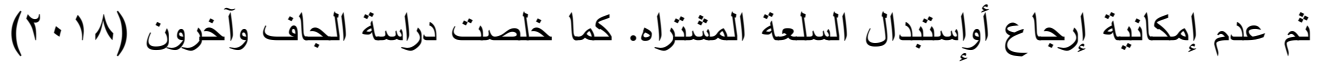
والتي طبقت بهدف التعرف على أهم المشكلات والتحديات التى تواجه المستهكين عند إستخدام الإنترنت كأداة لثراء السلع والخدمات، وشملت عينة الدراسة على الكوادر التدريسية فى الجامعات الأهلية فى محافظة أربيل بإقليم كوردستان العراق، إلى مجموعة من النتائج النى أظهرت ألى أهم

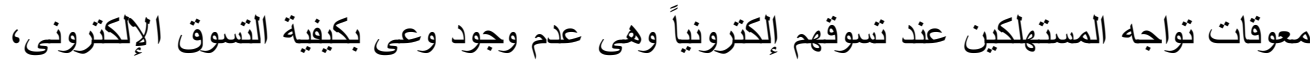
والخوف من تأخر وصول السلع المشتراه، وضعف الثقة فى التسوق عبر الانترنت، والخوف من

$$
\text { التعرض للنصب، والإفقار إلى نظام دفع إلكترونى. }
$$

يعد التسوق سلوك أساسى فى حياة الأسرة فهو الوسيلة التى من خلالهانها تحصل الأسرة

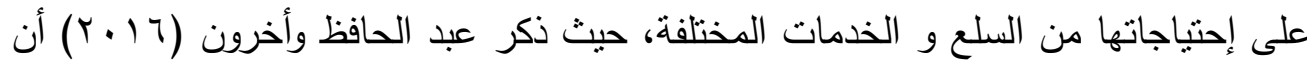

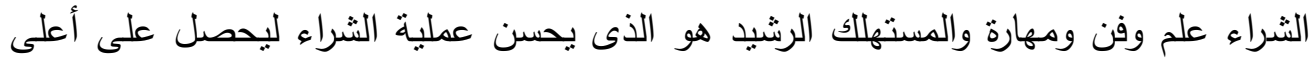
درجات المنفعة فى حدود الموارد المتاحة. وإذا كانت السياسات الإقتصادية للدولة تعنى بدراسة البدائل والحلول لتوفير مستلزمات الأسرة، فإنه لزاماً على علم إدارة المنزل معرفة ودراسة التوجهات

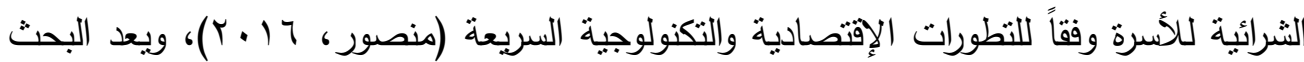
الحالى محاولة لمعرفة كيف تستقبد الأسرة في ظل المتغيرات الاجتماعية والاقتصادية من النطور التكنولوجى وخاصة مع زيادة أعداد مستخدمى الإنترنت، وذللك بتفعيل مميزات التسوق عبر التهي الإنترنت وتلافي عيوبه والذى يعد أحد التوجهات الثرائية الحديثة التى تمارسها الأسرة أو أحد أحد 
ومن هنا تبلورت المشكلة البحثية فى الإجابة على التساؤلات الأتية:

1- ما عادات التسوق عبر الإنترنت لدي الأسر بمحافظتى البحيرة والإسكندرية؟ r- ما أكثر مشكلات التسوق التي تعرضت لها الأسر عند استخدام مواقع التسوق عبر الإنس

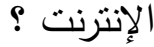

r- ما مميزات وعيوب النسوق عبر الإنترنت من وجهة نظر العينة البحثية بمحافظتى البحيرة والإسكندرية؟ معيراب وعيب

ع- ما العلاقة بين بعض المتغيرات الإجتماعية والإقتصادية (عمرالزوج والزوجةالمستوى التعليمى للزوج والزوجة- مدة الزواج- عدد أفراد الأسرة- الدخل الثهرى لئه

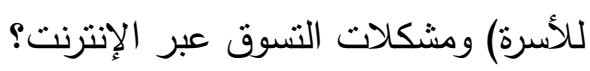

ه- ما الفروق بين الأسر بمحافظتى البحيرة والإسكندرية في مشكلات التسوق عبر الإنرات

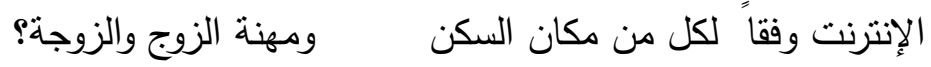

צ- ما العلاقة بين بعض المتغيرات الإجتماعية والإقتصادية (عمرالزوج والزوجة-

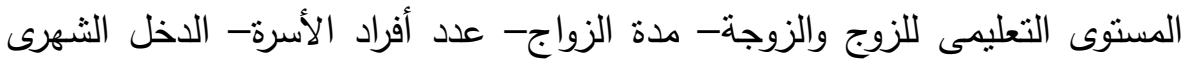

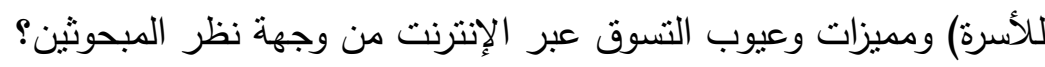
V- ما الفروق بين الأسر بمحافظتى البحيرة والإسكندرية في ادراكهم لمميزات وعيوب الإسرب وهن التسوق عبر الإنترنت وفقاً لمكان السكن ومهنة الزوج والزوجة ؟ لإني

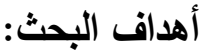

يهذف البحث بصفة رئيسية إلى دراسة مميزات وعيوب التسوق عبر الإنترنت لدي عينة من الأسر بمحافظتى البحيرة والإسكندرية فى ضوء بعض المتغيرات الإجتماعية والإقتصادية، وذللك من خلا الأهداف الفرعية التالية: 1- الكثف عن عادات التسوق عبر الإنترنت للأسر عينة البحث بمحافظتى البحيرة والإسكندرية. 
r- تحديد أكثر مشكلات التسوق التي تعرضت لها الأسر عينة البحث عند استخدام مواقع

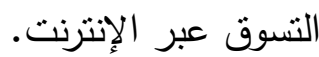

ب- تحديد مميزات وعيوب التسوق عبر الإنترنت من وجهة نظر الأسر عينة البحث بمحافظتى البحيرة والإسكندرية.

ع- تحديد العلاقة بين بعض المتغيرات الإجتماعية والإقتصادية (عمرالزوج والزوجةالمستوى التعليمى للزوج والزوجة- مدة الزواج- عدد أفراد الأسرة- الدخل الثهرى للأسرة) ومشكلات التسوق عبر الإنترنت لدي الأسر عينة البحث. ه- الكثف عن الفروق بين الأسر بمحافظتى البحيرة والإسكندرية في مشكلات التسوق عبر الإنرت الإنترنت وفقاً لكل من مكان السكن ومهنة الزوج و الزوجة. צ- تحديد العلاقة بين بعض المتغيرات الإجتماعية والإقتصادية (عمرالزوج والزوجةالمستوى التعليمى للزوج والزوجة- مدة الزواج- عدد أفراد الأسرة- الاخل الثهرى للأسرة) ومميزات وعيوب التسوق عبر الإنترنت من وجهة نظر الأسر عينة البحث. V الكثف عن الفروق بين الأسر عينة البحث بمحافظتى البحيرة والإسكندرية في ادراكهم لمميزات وعيوب التسوق عبر الإنترنت وفقاً لمكان السكن ومهنة الزوج والزوجة.

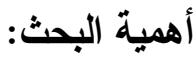

1- يستدد البحث أهميته من أهمية الموضوع الذى يتتاوله، حيث تذخل إستخدامات الإنترنت

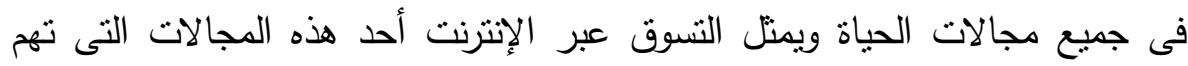
الأسرة.

r- يمكن الإستفادة من نتائج البحث فى وضع البرامج الإرشادية لتوعية الأسر بمميزات وعيوب التسوق عبر الإنترنت. 
r- قد تساهم نتائج البحث فى إعطاء صورة عن واقع النسوق عبر الإنترنت والتي يمكن أن تساعد القائمين على مواقع التسوق علي العمل على تحسين الخدمة بها، كما تساعد واضعى القوانين والتشريعات لوضع القوانين اللازمة لنتظيم التعاملات وحماية المنسوقين. ع- قد يستقيد الباحثثن فى مجال الإقتصاد المنزلى عامة ومجال إدارة المنزل خاصة من نتائج هذا البحث لتكون أساس لإجراء المزيد من الأبحاث فى هذا الموضهاد

$$
\text { الأسلوب البحثى: الأسرة والمجتمع. }
$$

أولاً: المصطلحات العلمية والتعريفات الإجرائية:

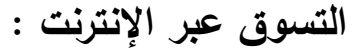

يقصد بالتسوق عبر الإنترنت Online shopping إستخدام مواقع الإنترنت فى

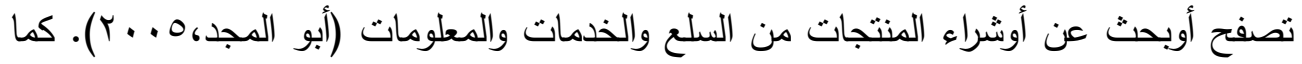
يعرف بأنه "عملية جمع المعلومات والبيانات عن السلع والخدمات التى تزود المستهلك بالمعلومات التى يحتاجها لكى يتخذ على أساسها قرار الثراء الصحيح، ويتم ذلك بواسطة زيارة

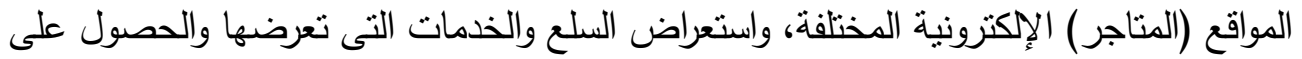

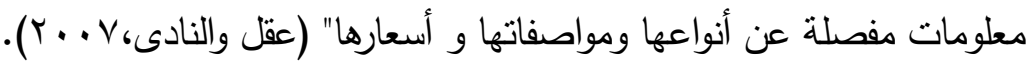

\section{التعريف الإجرائى للتسوق عبر الإنترنت:}

يقصد به فى هذا البحث عملية التسوق التى يقوم بها أفراد الأسرة عن طريق جمع المعلومات

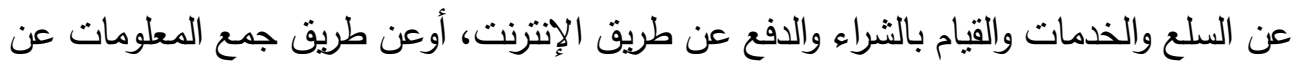
السلع والخدمات من خلال الإنترنت ثم القيام بالثراء التقليدى من المحلات التجارية. التعريف الإجرائى لمميزات وعيوب التسوق عبر الإنترنت: تقاس بالدرجة الكلية لإستجابات عينة البحث على محور مميزات وعيوب التسوق عبر الإنترنت. 


\section{المتغيرات الإجتماعية والإقتصادية:}

هى المؤثرات التى تؤثنر على سلوك المستهلك الثخصى أثثاء وجوده أوانتمائه لجماعات معينة، بحيث ينأثز هذا السلوك بعدد من العوامل الإجتماعية والإقتصادية التى تحدد اتجاهاته

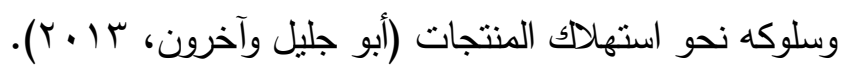
التعريف الإجرائى لبعض المتغيرات الإجتماعية والإقتصادية: يقصد بها فى هذا البحث المستوى التعليمى لكل من الزوج والزوجة، عمر الزوج والزوجة،

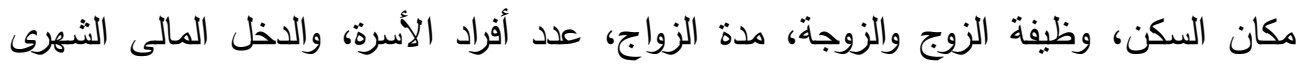
للأسرة.

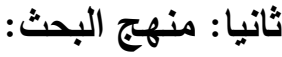

لتحقيق أهداف البحث نم إستخدام المنهج الوصفى التحليلى الذى بعتمد على دراسة الواقع أوالظاهرة كما نوجد فى الواقع، ويهنم بوصفها وصفا دقيقا، ويعبر عنها تعبيراً كيفياً أوكمياً للوصول إلى مفهوم العلاقات بين هذه الظاهرة مع غيرها من الظواهر الأخرى والقيام بجمع المعلومات المطلوبة بطريقة دقيقة ومنظمة للوصول إلى النتائج وتتظيمها وتصنيفها وتحليلها وتفسيرها، واستخلاص التعديمات والإستنتاجات منها (عبيدات وآخرون ،م . . ب).

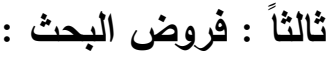

فى ضوء نتائج البحوث والدراسات السابقة وأهداف البحث صيغت الفروض على النحو التالى: 1- توجدعلاقة إرتباطية دالة إحصائياً بين بعض المتغيرات الإجتماعية والإقتصادية (عمرالزوج والزوجة- المستوى التعليمى للزوج والزوجة- مدة الزواج- عدد أفراد الأسرةالدخل الثهرى للأسرة) ومشكلات التسوق عبر الإنترنت لدي العينة البحثية.

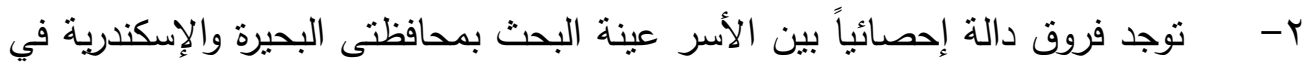
مشكلات التسوق عبر الإنترنت وفقاً لمكان السكن. r- توجد فروق دالة إحصائياً بين الأسر عينة البحث بمحافظتى البحيرة والإسكندرية في

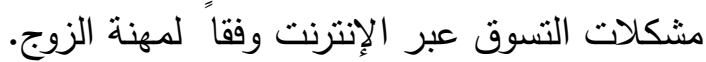


ع - توجد فروق دالة إحصائياً بين الأسر عينة البحث بمحافظتى البحيرة والإسكندرية في مشكلات التسوق عبر الإنترنت وفقاً لمهنة الزوجة.

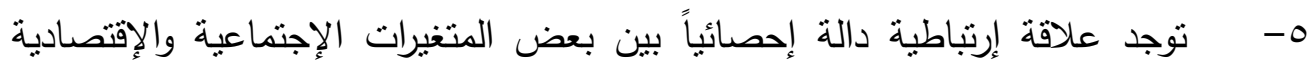
(عمرالزوج والزوجة- المستوى التعليمى للزوج والزوجة- مدة الزواج- عدد أفراد الأسرةالدخل الثهرى للأسرة) ومميزات وعيوب التسوق عبر الإنترنت من وجهة نظر الأسر عينة البحث.

צ- توجد فروق دالة إحصائياً بين الأسر عينة البحث بمحافظتى البحيرة والإسكندرية في ادراكهم لمميزات وعيوب التسوق عبر الإنترنت وفقاً لمكان السكن.

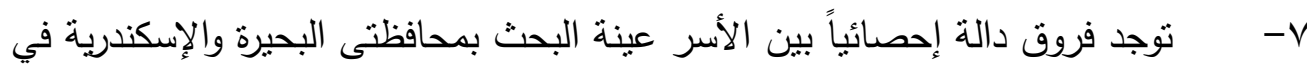

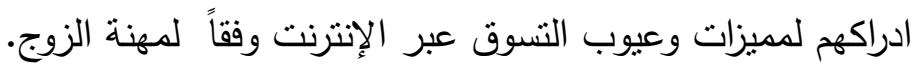
^- توجد فروق دالة إحصائياً بين الأسر بمحافظتى البحيرة والإسكندرية في ادراكهم لمميزات وعيوب التسوق عبر الإنترنت وفقاً لمهنة الزوجة.

$$
\text { الحداً: حدود البحث: البشرية: وتثثمل: }
$$

شاملة البحث: تضم جميع الأسر فى حضر محافظتى البحيرة والإسكندرية.

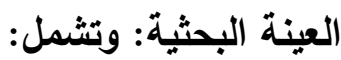
العينة الإستطلاعية: تكونت من (•r) أسرة تتطبق عليهم شروط العينة الأساسية تم اختيارهم بطريقة قصدية من محافظتى البحيرة والإسكندرية، طبقت عليهم أدوات البحث (استمارة الإسنتيان) لحساب الصدق والثنات، وكذللك للتأكد من وضوح عبارات الإسنتيان، وبعد إجراء الدراسة الإسنطلاعية ومراجعة الإستجابات تنين وضوح العبارات وسلامة صياغتها.

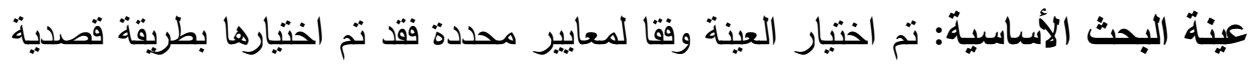
حيث يثترط فيها أنها تقوم بالتسوق عبر الإنترنت، وبلغ عددها (. r. أسرة من محافظتى البحيرة

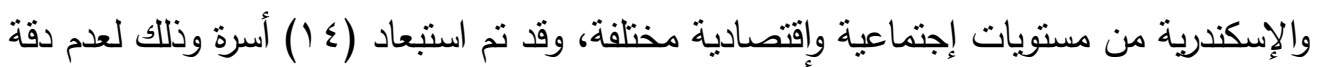




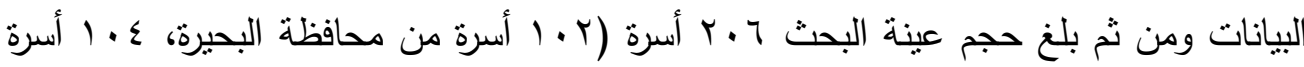
من محافظة الأسكندرية)، نم التعامل مع الأزواج أوالزوجات لجمع البن البيانات.

الحدود الزمنية: تم إجراء البحث فى الفترة من شهر إبريل وحتى نهاية شهر سبتمبر V ا ـ Y. الحدود الجغرافية: أجرى البحث في حضر محافظة البحيرة وشمل أربعة مراكز هى "مركز شبراخيت، مركز الرحمانية، مركز دمنهور، مركز كفر الدوار"، وحضر محافظة الأسكندرية وشمل عدة أحياء هي "حي المنتزة، حي العامرية، حي شرق، حي وسط، حي العجمى".

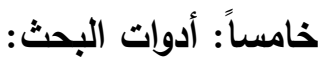

تكونت أداوات البحث من إستمارة إسنيان نم استنفاء بياناتها عن طريق المقابلة الثخصية

$$
\text { وقد انتملت على ثنلاث محاور وهى: }
$$

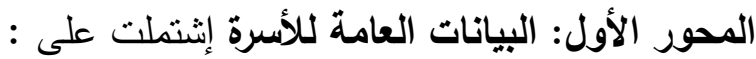

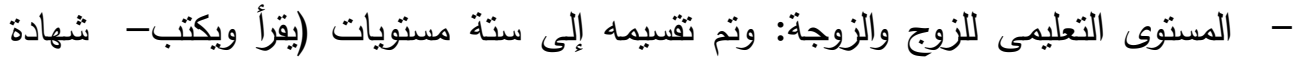
ابتدائية- شهادة إعدادية- دبلوم وثانوى عام- شهادة جامعية- شهادة فوق جامعية)

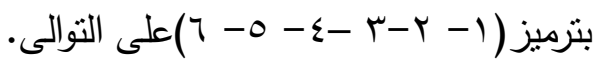

- مهنة الزوج : تم تقسيمها إلى ست فئات (وظيفة حكومية- قطاع خاص- أعمال حرة-

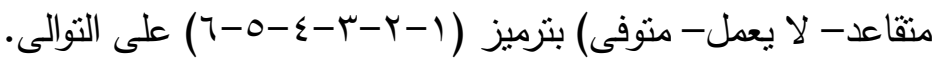

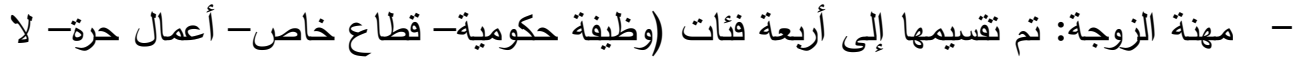

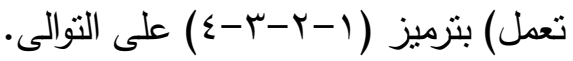

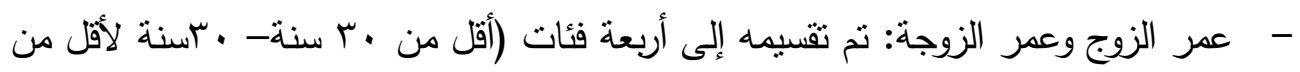

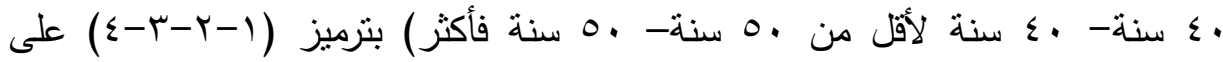

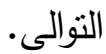
- - مدة الزواج بالأعوام: قسمت إلى أربعة فئات (أقل من ه أعوام- من ه لأقل من • ـ أعوام-

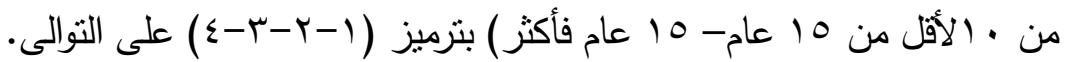


- الدخل المالى الثهري للأسرة: تم تصنيفه إلى أربعة فئات (أقل من . . . اجنيه- من

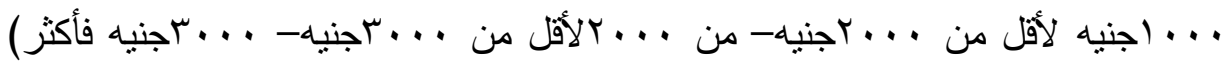

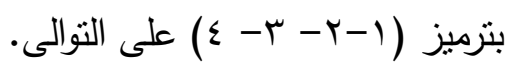

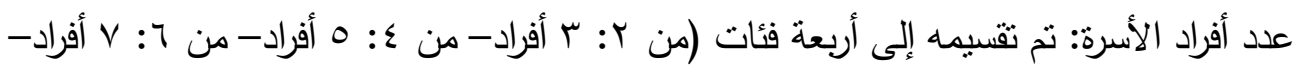

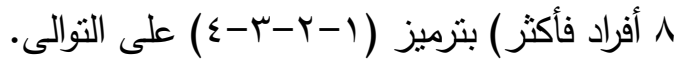
المحور الثانى: عادات التسوق عبر الإنترنت: ويشمتل على على الثئ:

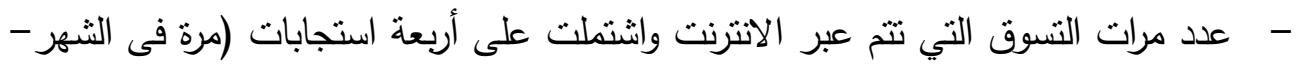

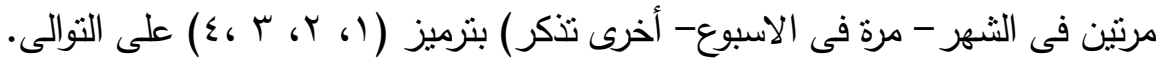

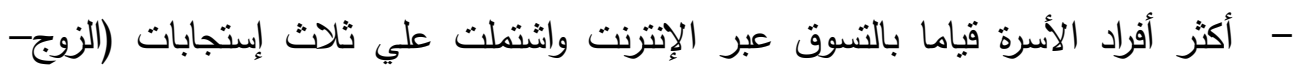

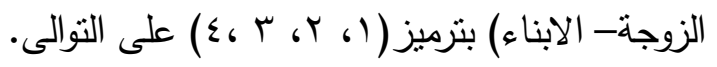

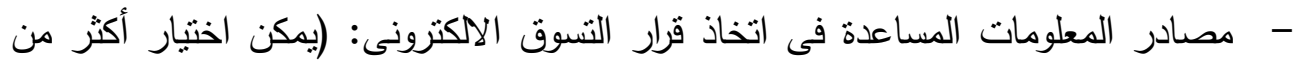
إجابة) واثتنملت على (الأصدقاء والمعارف والجيران - اعلانات الثركات عبر الانترنتاعلانات الثشركات فى الصحف والمجلات- الثركة المقدمة لخدمة الانترنت- اعلانات الثركات فى الراديو والتلفزيون- شركات ومعارض الكمبيوتر - التجربة الثخصية-

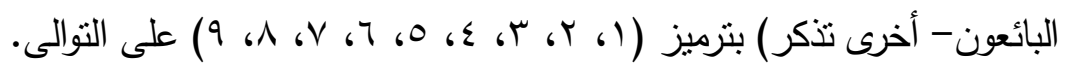
- - أكثر الخدمات التي يمكن استخدامها عن طريق الإنترنت (يمكن اختيار أكثر من خدمة) (خدمات صحية- خدمات تعليمية- خدمات السياحة والسفر - شراء منتجات- أخرى تذكر )

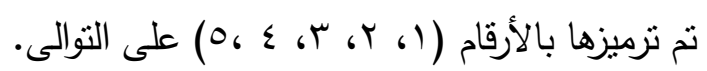

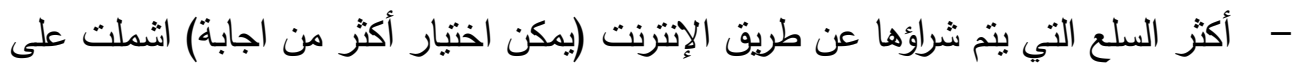
(مواد غذائية- ملابس- أدوات منزلية- أجزة كهربائية- التجميل والعطور - سياراتاكسسوارات- أثناث ومفروشات- أجهزة الكمبيوتز والموبايل- الكتب والمراجع- عقارات-

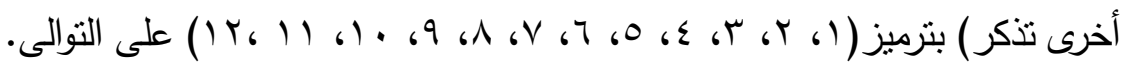


- - أكثر المواقع التي تتسوق منها عبر الانترنت وشملت (المواقع المحلية- المواقع العربية-

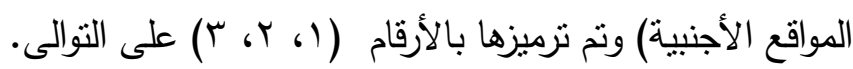

- أفضل طريقة للافع عند الثراء عبر الإنترنت واشتملت على (بطاقة "فيزا- ماستر كارد"-

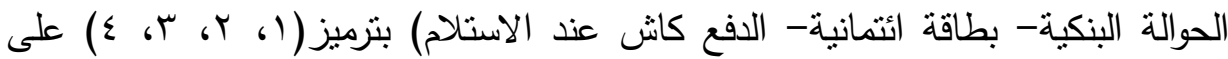

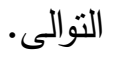

- المحور الثالث: أكثر مشكلات التسوق التي تعرضت لها الأسر عند استخدام مواقع

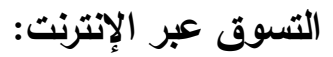

اشتمل المحور على تسع عبارات تم وضعها بعد الإطلاع على الأبحاث والدراسات

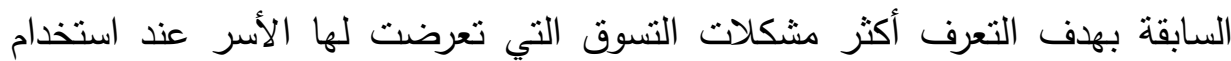
مواقع التسوق عبر الإنترنت وتتحدد الإستجابة وفقا لإختبارين (نعم واجهتى- لا لم لم تواجهني) بترميز (1، r ب) على التوالى، وفي حالة وجود مشكلة واجهت المبحوثين تم التعرف على عدد مرات التعرض لهذه المشكلة، ثم التصرف الذى قام به المبحوث عند التعرض لهذه المشكلة وقد قسم إلى ثلاث استجابات (عدم التعامل مع الموقع مرة أخرى- نصحت أصدقائى بعدم التعامل مع الموقع- أرفض استلام السلعة بدون معاينة)

$$
\text { بترميز (l، Y، r) على التوالى. }
$$

المحور الرايع: مميزات وعيوب التسوق الإكترونى:

تم وضع مجموعة من العبارات بلغ عددها ؟Y عبارة، تهذف إلى التعرف على مميزات

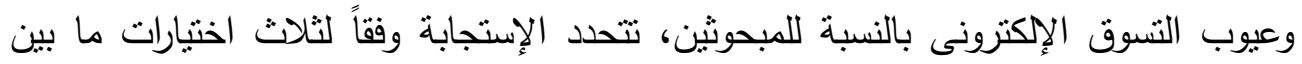

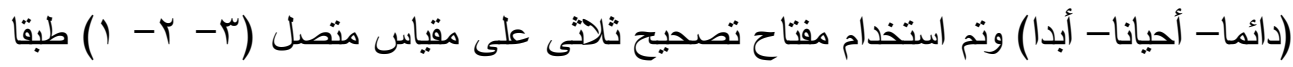

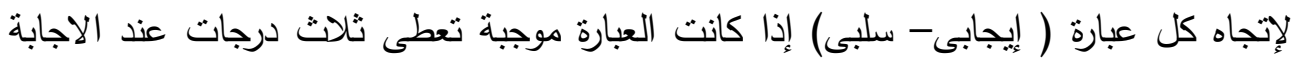

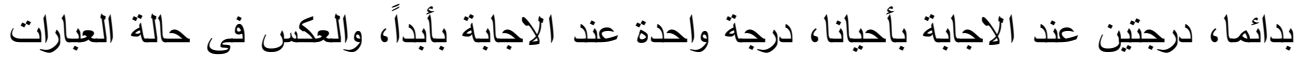




\section{ضبط الإستبيان وتقنينه:}

أولا: صدق الإستبيان: نم التحقق من صدق الإستبيان عن طريق : صدق المحكمين: للتحقق من الصدق الظاهري لمحتوى الإستيان نم عرضه على مجموعة

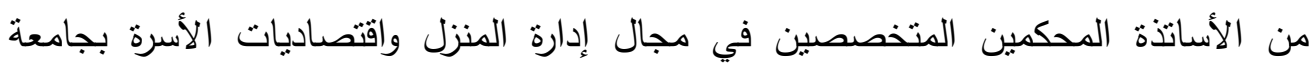
الأسكندرية وجامعة المنوفية، وذلك للحكم على الإستيان من حيث مناسبة كل عبارة من عبارات الإستبيان للجانب الذي تقيسه، وكذلك تحديد مدى صحة صباغة العبارات. وقد أثنار السادة المحكمون إلى إجراء بعض التعديلات على بعض العبارات وتم إجراء التعديلات

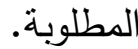

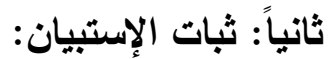

لتحديد معامل الثبات للإستبيان، نم حساب معامل ألفا كرونباخ وقد بلغت قيمة معامل

$$
\text { الثبات ( 90V . . . ) وهي قيمة عالية ومقبولة. }
$$
سادساً: أسلوب جمع البيانات: تم إستيفاء البيانات البحثية عن طريق المقانه البابلة الثخصية مع

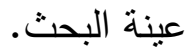
سابعاً: إجراء المعاملات الإحصائية: تم تحليل البيانات وإجراء المعالجات الإحصائية باستخدام برنامج الحزم الإحصائية للعلوم الاجتماعية S.P.S.S.) Statistical Package of social science) الإصدار رقم بعد إخخال البيانات ومراجعتها لضمان صحة النتائج ودقتها، وقد نم استخدام بعض (Y. ) الأساليب الإحصائية لكثف العلاقة بين متغيرات البحث واختبار صحة الفروض وهى معامل ألفا كرونباخ، التكرارات والنسب المئوية، المتوسط الحسابى والإنحراف المعيارى، تحليل التباين الاحادى (One Way ANOVA) "ف" ، اختبار "ت" ، اختبار نوكي (Tukey HSD) لل لمقارنات المتعددة ومعامل ارتباط "سبيرمان". 
عدد خاص من مجلة "بحوث في العلوم والقنون النوعيه" العزيه

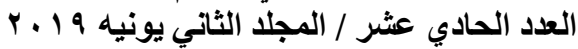

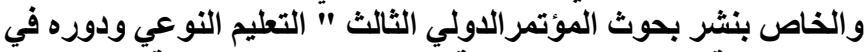

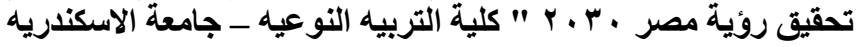

\%

ALEXANDRIA

U N I VER S I T Y

AlexU Press

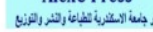

النتائج ومناقشتها:

أولاً : وصف عينة البحث :

فيما يلى وصف لبعض المت غيرات الإجتماعية و الإقتصادية للمبحوثين بمحافظتي

البحيرة والإسكندرية

1 - المستوى التعليمى للزوج و الزوجة :

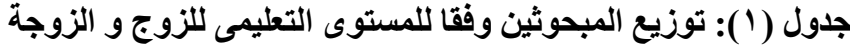

\begin{tabular}{|c|c|c|c|c|c|c|c|}
\hline \multicolumn{2}{|c|}{ الإجمالى (ن=r · r r ) } & \multicolumn{2}{|c|}{ الإسكندرية (ن=\& + 1) } & \multicolumn{2}{|c|}{ البحيرة (ن = r l) } & \multirow{2}{*}{ فئات المتغير } & \multirow{2}{*}{ المتغير } \\
\hline$\%$ & ن & $\%$ & ن & $\%$ & ن ن & & \\
\hline$\leqslant . \wedge 0$ & 1. & .99 & 1 & $\Lambda . \wedge Y$ & 9 & يقز اويكتب & \\
\hline. $.9 \mathrm{~V}$ & r & .99 & 1 &. .91 & 1 & شهاد إبتدائية & \\
\hline$\cdot .9 \mathrm{~V}$ & $r$ &. .97 & 1 & $\cdot .91$ & 1 & شهادة اعدادية & \\
\hline Yr.Vq & $\leq 9$ & 10.97 & YV & YI.0V & YY & دبلوم وثانوي عام & ل ل لروج \\
\hline $0 \wedge . \vee \leq$ & $|r|$ & 71.05 & $7 \leq$ & $00 . \wedge \Lambda$ & ov & شهادة جامعية & \\
\hline $1 \cdot .71$ & YY & 9.74 & $1 \cdot$ & 11.87 & Ir & شهادة فوق جامعية & \\
\hline $0 . \Gamma \leq$ & 11 & .99 & 1 & $9 . \wedge$. & 1. & تقراويكتب & \\
\hline $1.9 \varepsilon$ & $\varepsilon$ & $1.9 r$ & $r$ & 1.97 & $r$ & شهاد إبتدائية & \\
\hline$\cdot .59$ & 1 & $\because \cdots$ & $\cdot$ & .911 & 1 & شهادة اعدادية & المستوى التعليمى \\
\hline rV.TV & OV & $r \leq . . \leq$ & ro & rI.rv & $r r$ & دبلوم وثانوي عام & للزوجة \\
\hline $00 . r \leqslant$ & $11 \leq$ & $7 . .01$ & $8 \pi$ & $0 \cdot . \cdots$ & 01 & شهادة جامعية & \\
\hline Q.YY & 19 & $1 Y .0$. & $1 T$ & $\bullet . \wedge \wedge$ & 7 & شهادة فوق جامعية & \\
\hline
\end{tabular}

يظهر جدول (1) أن أكثر من نصف المبحوثين من الأزواج حاصلون على شهادة

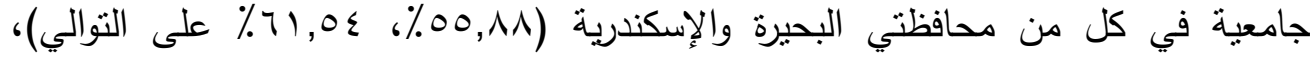

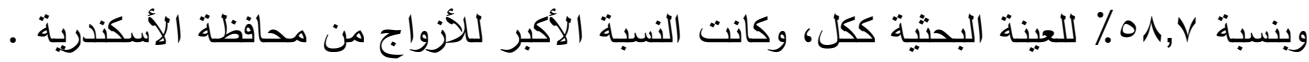
مما يشير إلى إرتفاع المستوى التعليمى للأزواج عينة البحث، كما نتير البيانات إلى إرتفاع

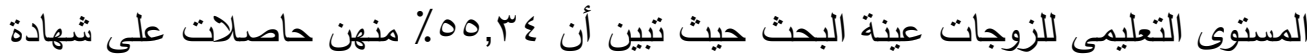

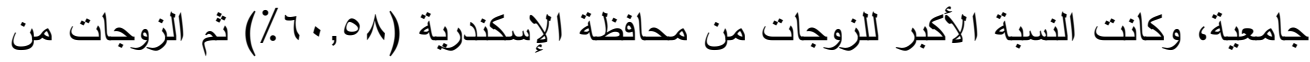

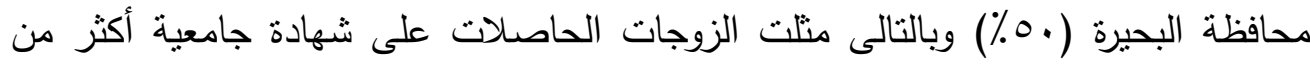

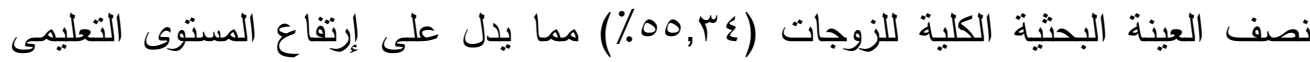
للزوجات عينة البحث

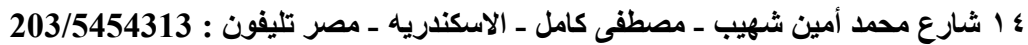
Alexandria - Egypt, Tel. : 203/5454313 - 203/5442776 Fax :203/5442776 E-mail : journal.edusp@alexu.edu.eg Web site: RSSA.edusp@lexu.edu.eg 
عدد خاص من مجلة "بحوث في العلوم والقنون النوعيه" المجيه

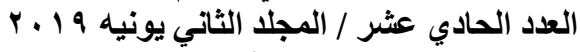

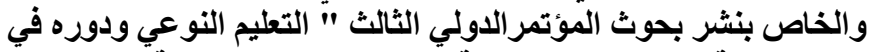

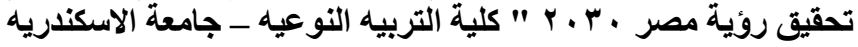

\%

ALEXANDRIA

U N I V ER S I T Y

Alexu Press

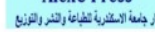

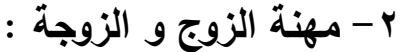

جدول (r): توزيع المبحوثين وفقا للمهنة الزوج و الزوجة الزوجة

\begin{tabular}{|c|c|c|c|c|c|c|c|}
\hline \multicolumn{2}{|c|}{ الإجمالى (ن= † • ץ ) } & \multicolumn{2}{|c|}{ (ن) الإسكندرية } & \multicolumn{2}{|c|}{ البحيرة (ن=r r · l) } & \multirow{2}{*}{ فئات المتغير } & \multirow{2}{*}{ المتغير } \\
\hline$\%$ & ن & $\%$ & ن & $\%$ & ن & & \\
\hline $0 . . \cdots$ & $1 \cdot r$ & or.10 & 07 & $\leqslant 7.1$ & $\sum V$ & وظيفة حكومية & \multirow{6}{*}{ مهنة الزوج } \\
\hline ro. $r \leq$ & or & ro. & rY & ro. $\leqslant 9$ & ry & قطاع خاص & \\
\hline 19.9. & 纟1 & $1 \leqslant . \leqslant r$ & 10 & ro. $\leqslant 9$ & ry & أعمال حرة & \\
\hline$r . \varepsilon r$ & 0 & r.10 & $\varepsilon$ & $\cdot .9 \lambda$ & 1 & متقاعد & \\
\hline $1 . \leqslant 7$ & $r$ & $\cdot .97$ & 1 & 1.97 & r & لايعمل & \\
\hline$\cdot .9 \mathrm{~V}$ & r & 1.94 & r & $\because \cdot$ & - & 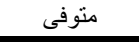 & \\
\hline 纟0.7T & $9 \varepsilon$ & $0 \leqslant .11$ & or & r. rV & rv & وظيفة حكومية & \multirow{4}{*}{ مهنة الزوجة } \\
\hline$\varepsilon . r v$ & 9 & Y.AN & $r$ & $0 . \wedge \Lambda$ & 7 & قطاع خاص & \\
\hline $0 . \Gamma \leq$ & 11 & $0 . V V$ & 7 & $\varepsilon .9$. & 0 & أعمال حرة & \\
\hline$\varepsilon \varepsilon .77$ & 94 & r. & rA & or. $9 \leq$ & $0 \leqslant$ & لاتعمل & \\
\hline
\end{tabular}

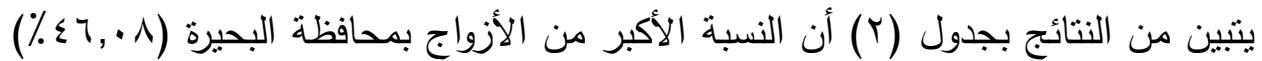
يعلمون بوظائف حكومية، كذلك بالنسبة للأزواج بمحافظة الإسكندرية فقط شكل الأزواج العاملون بالوظائف الحكومية أعلى نسبة بين المبحوثين (10,rه\%)، كما تبين أن النسبة

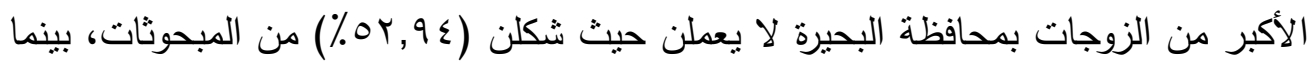

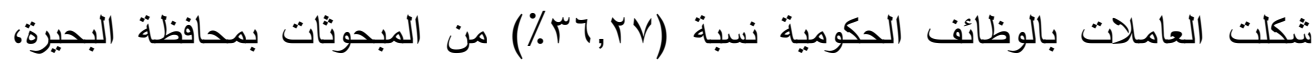
وعلى العكس بالنسبة للمبحوثات بمحافظة الإسكندرية فكانت النسبة الأكبر من الزوجات

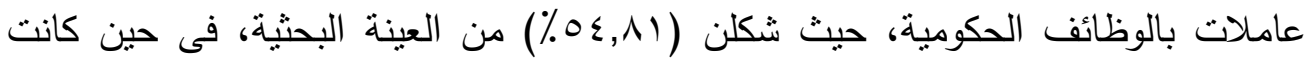
نسبة الزوجات غير العاملات (ع ب, بـ\%). 
عدد خاص من مجلة "بحوث في العلوم والقنون النوعيه" التوبه

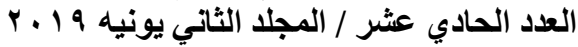

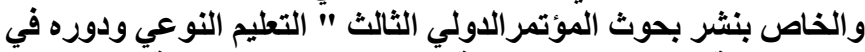

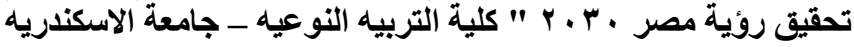

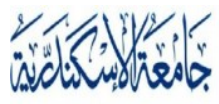

ALEXANDRIA

U N I VER S I T Y

AlexUPress

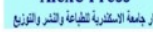

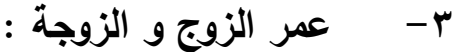

جدول (ب): توزيع المبحوثين وفقا لعمركل من الزوج و الزوجة

\begin{tabular}{|c|c|c|c|c|c|c|c|}
\hline \multicolumn{2}{|c|}{ 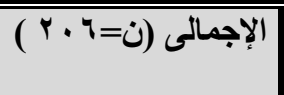 } & \multicolumn{2}{|c|}{ (ن= الإسكندرية } & \multicolumn{2}{|c|}{ 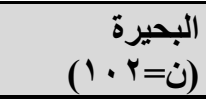 } & \multirow{2}{*}{ فئات المتغير } & \multirow{2}{*}{ المتغير } \\
\hline$\%$ & ن & $\%$ & ن ن & $\%$ & ن & & \\
\hline 10.04 & Mr & 7.V $\mathrm{Vr}$ & v & $r \leqslant .01$ & ro & اقل من · ب سنة & \multirow{4}{*}{ عمر الزوج } \\
\hline ґ..یr & $\wedge$. & rT.70 & ro & 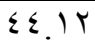 & $\leqslant 0$ & من.ب لأقل من .ـ سنة & \\
\hline YА. 17 & 01 & ro.01 & rV & $r . .09$ & r) & من •؛ لإقل من • مسنة & \\
\hline $\mid V . \varepsilon A$ & ד & $r \varepsilon . \cdot \varepsilon$ & ro & $1 . . \mathrm{VA}$ & 11 & • م فأكثر & \\
\hline$r \leqslant . \leqslant V$ & vi & $10 . r 1$ & 17 & or.9r & 00 & اقل من • ب سنة & \multirow{4}{*}{ عمر الزوجة } \\
\hline$\varepsilon \cdot . \vee \wedge$ & $\Lambda \varepsilon$ & $0 . .$. & or & $r . r v$ & r & من ·r لأقل من • • س سنة & \\
\hline 17.99 & ro & YY.IT & r & 11.17 & IT & من •؛ لإقل من • مسنة & \\
\hline$V . V V$ & 17 & 1r.o. & $\pi$ & r. $9 \varepsilon$ & $r$ & . • ف فأكثر & \\
\hline
\end{tabular}

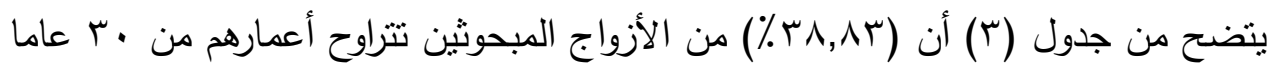
إلى أقل من •ـ عاماً، حيث منلت هذه الفئة أعلى فئة عمرية بين الأزواج فى محافظة

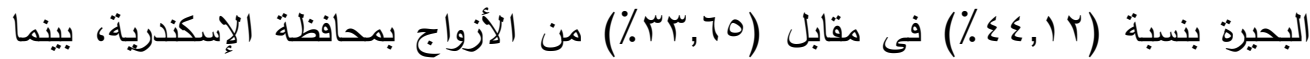

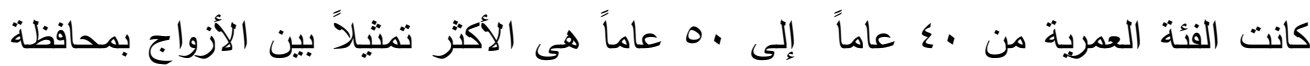

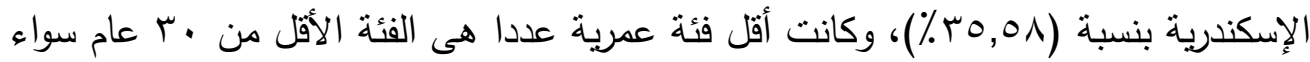

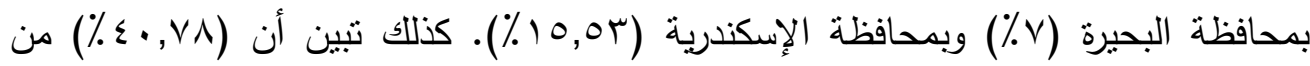

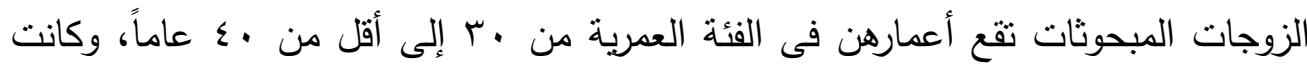

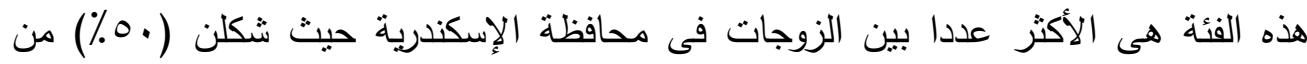

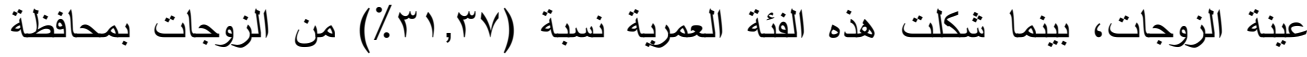
البحيرة، بينما دلت النتائج بجدول (r) على صغر أعمار الزوجات المبحوثات بمحافظة

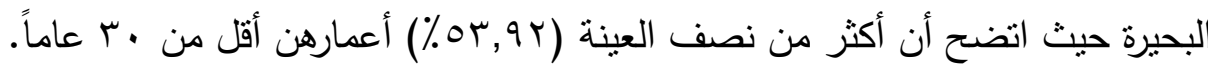


عدد خاص من مجلة "بحوث في العلوم والقنون النوعيه" التوديه

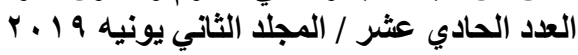

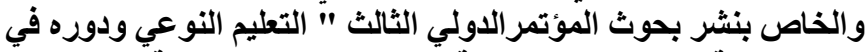

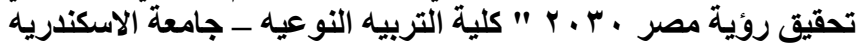

\%

ALEXANDRIA

U N I V E R S I T Y

AlexUPress

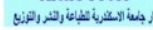

ع - مدة الزواج بالأعوام :

جدول (؛ ): توزيع المبحوثين وفقا لمدة الزواج

\begin{tabular}{|c|c|c|c|c|c|c|c|}
\hline \multicolumn{2}{|c|}{ الإجمالى (ن= † · r ) } & \multicolumn{2}{|c|}{ الإسكندرية (ن=ء 1) } & \multicolumn{2}{|c|}{ البحيرة (ن=r r م ا ) } & \multirow[b]{2}{*}{ فئات المتغير } & \multirow{2}{*}{ المتغير } \\
\hline$\%$ & $\dot{~ ن}$ & $\%$ & ن & $\%$ & $\dot{0}$ & & \\
\hline$Y \leqslant . V T$ & 01 & 17.40 & IV & מד.ז" & TE & أقل من 0 سنو ات & \\
\hline rq.1T & 7. & $Y V . \wedge \Lambda$ & rq & $r \cdot r q$ & Tा & من هلأقل من · 1 & مدة الزواج \\
\hline 18.97 & TV & $10 . \mathrm{H}$ & 17 & 4.09 & YI & من · الأقل من 10 & بالأعوام \\
\hline Y^.1T & 01 & $\varepsilon \cdot . \mu \wedge$ & $\varepsilon r$ & 10.79 & 17 & 10 انة فأكثر & \\
\hline
\end{tabular}

تظهر النتائج بجدول (ع) أن أعلي نسبة من عينة المبحوثين بمحافظة البحيرة

(r (Tr, ) مدة زواجهم أقل من خمس سنوات ، بينما كانت أعلى نسبة لمدة الزواج بمحافظة

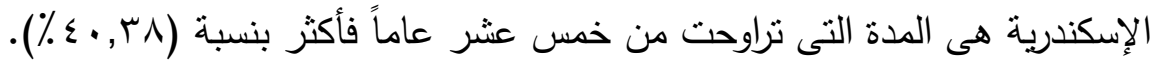

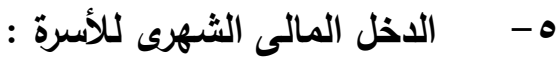

جدول (•) : توزيع المبحوثين وفقا للاخل المالى الثهرى للأسرة

\begin{tabular}{|c|c|c|c|c|c|c|c|}
\hline$(r \cdot\urcorner=$ & الإجم & \multicolumn{4}{|c|}{ الإسكندرية(ن=؛ - 1 ) } & \multirow[b]{2}{*}{ فئات المتغير } & \multirow{2}{*}{ المتغير } \\
\hline$\%$ & ن ن & $\%$ & ن & $\%$ & ن & & \\
\hline 11.70 & $\overline{r \varepsilon}$ & $0 . \mathrm{VV}$ & 7 & 18.70 & $\overline{11}$ & أقل من ..... & \\
\hline rA.Tई & 09 & $r \wedge . \wedge 0^{\prime}$ & $r$. & YA.हT & 19 & من ... ا_ لأقل من ... & المالي \\
\hline $1 \wedge \leqslant 0$ & rᄉ & $r \varepsilon \cdot \varepsilon$ & ro & Irvo & IT & مز........... & 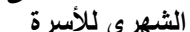 \\
\hline$\xi 1, Y \uparrow$ & 10 & $\varepsilon 1 . \% 0$ & $\varepsilon r$ & $\varepsilon 1.1 \wedge$ & $\varepsilon r$ & 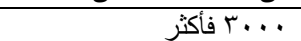 & \\
\hline
\end{tabular}

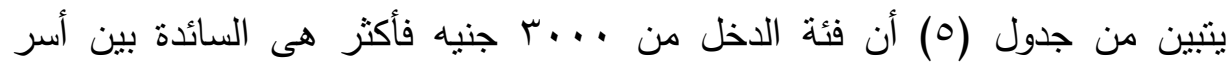

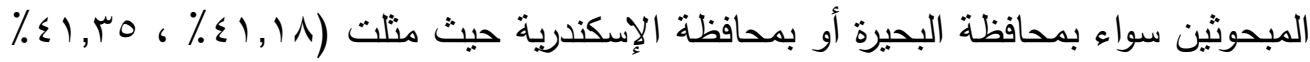
علي التوالي)، مما يثير إلى إرتفاع الدخل نسبياً للمبحوثين عينة الدراسة بالمحافظتين.

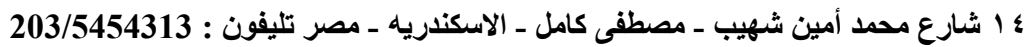

Alexandria - Egypt, Tel. : 203/5454313 - 203/5442776 Fax :203/5442776

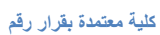

E-mail : journal.edusp@alexu.edu.eg Web site: RSSA.edusp@lexu.edu.eg 
عدد خاص من مجلة "بحوث في العلوم والقنون النوعيه" المجيه

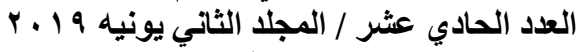

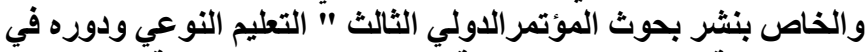

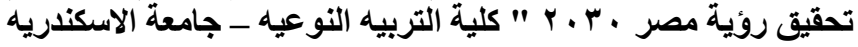

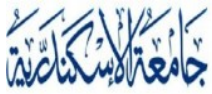

ALEXANDRIA

U N I VER S I T Y

AlexUPress

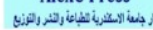

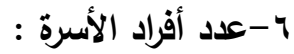

جدول (૫): توزيع المبحوثين وفقا لعدد أفراد الأسرة

\begin{tabular}{|c|c|c|c|c|c|c|c|}
\hline \multicolumn{2}{|c|}{ 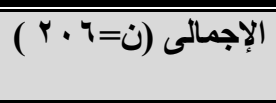 } & \multicolumn{2}{|c|}{ (الإسكندرية 1 (1) } & \multicolumn{2}{|c|}{ 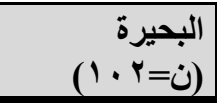 } & \multirow{2}{*}{ فئات المتغير } & \multirow{2}{*}{ المتغير } \\
\hline$\%$ & ن & $\%$ & ن & $\%$ & ن & & \\
\hline$\overline{r V . r \Lambda}$ & VV & $Y 1.10$ & $\overline{Y Y}$ & Or.9Y & 00 & من ك إلى س أفر اد & \\
\hline OY.YA & 111 & $V T \cdot \cdot \Lambda$ & $\sqrt{17}$ & $\sum 1.11$ & $\varepsilon r$ & من ع إلى 0 & أفراد \\
\hline$\leqslant .10$ & 1. & $0 . V V$ & 7 & $r .94$ & $\varepsilon$ & من 7إلى V V & الأسرة \\
\hline$\cdot . \leqslant 9$ & 1 & $\because \cdots$ & . & .91 & 1 & ^ أفراد فأكثر & \\
\hline
\end{tabular}

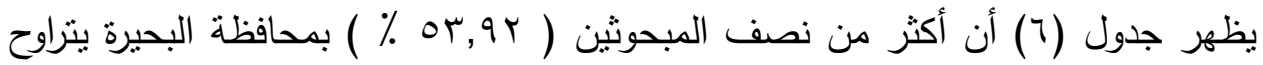

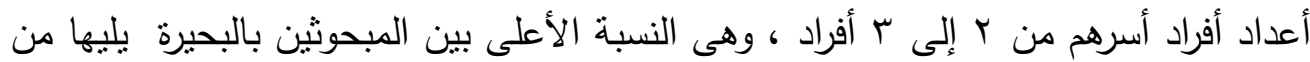

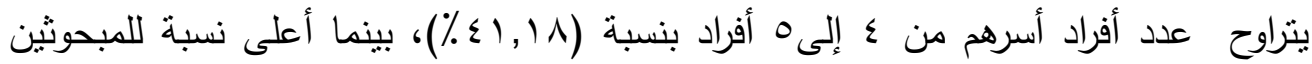

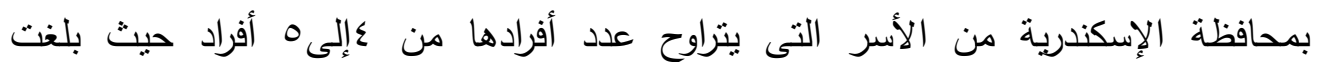

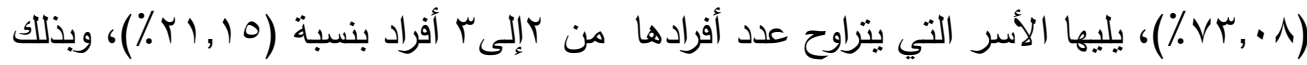
تكون الأسر التى يتراوح عدد أفرادها من ؛ إلى هـ أفراد هي الأعلى نسبة في على عينة البحث

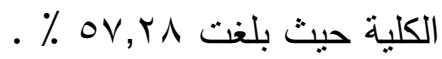




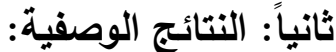

أ- عادات التسوق عبر الإنترنت للأسر عينة البحث بمحافظتى البحيرة والإسكندرية:

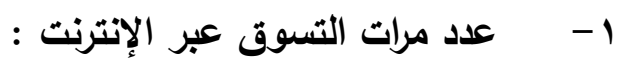

جدول (V): توزيع المبحوثين وفقاً لعدد مرات التسوق عبر الإنترنت

\begin{tabular}{|c|c|c|c|c|c|c|c|c|}
\hline$(r \cdot \gamma$ & |الإجما & \multicolumn{2}{|c|}{ (الإسكندارية } & \multicolumn{2}{|c|}{ 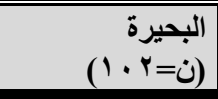 } & \multirow[t]{2}{*}{ فئات المتغير } & & \multirow[t]{2}{*}{ المتغير } \\
\hline$\%$ & ن & $\%$ & ن & $\%$ & ن ن & & & \\
\hline $1 \pi, 11$ & rv & $1 \cdot, 01$ & 11 & 10,79 & 17 & مرة فى الاسبوع & & \\
\hline Or,. & 11. & 0. & or & 07,14 & $0 \wedge$ & مرة فى الشهر & & عدد \\
\hline $1 \cdot, 7 \Lambda$ & rr & 1,70 & 9 & Ir,Vo & $\pi$ & مرتين فى الثهر & عبر & التسوق \\
\hline rr,Ar & $\leqslant v$ & $r \cdot, v v$ & rr & $1 \varepsilon, V \mid$ & 10 & أخرى الإحتاج) (حسب & & \\
\hline
\end{tabular}

يبين جدول (V) أن حوالي نصف المبحوثين (•ـ,ror\%) لا نزيد عدد مرات تسوقهم

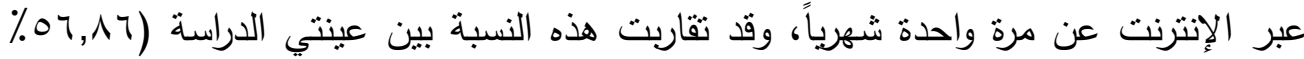
من المبحوثين بمحافظة البحيرة، ـ من المبحوثين بمحافظة الإسكندرية).

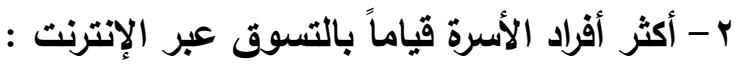

جدول (^): توزيع المبحوثين وفقاً لأكثر أفراد الأسرة قياماً بالتسوق عبر الإنبر الإنترنت

\begin{tabular}{|c|c|c|c|c|c|c|c|}
\hline \multicolumn{2}{|c|}{ 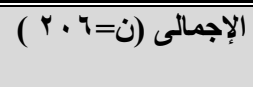 } & \multicolumn{2}{|c|}{ 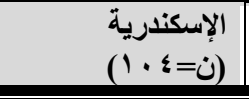 } & \multicolumn{2}{|c|}{ 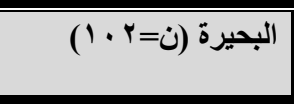 } & \multirow{2}{*}{ المتغير } & \multirow{2}{*}{ المتغير } \\
\hline$\%$ & ن & $\%$ & $\dot{u}$ & $\%$ & ن & & \\
\hline$\{0.7 \pi$ & $\overline{9 \varepsilon}$ & Tr.70 & ro & $\overline{O V . \wedge \varepsilon}$ & 09 & الزوج & أكثر أفراد الأسرة \\
\hline$\varepsilon \cdot . \varphi^{\prime}$ & $\Delta r$ & $\varepsilon 9 . \cdot \varepsilon$ & 01 & $\mu I . r v$ & rY & الزوجة & " \\
\hline $1 \leqslant . \cdot 1$ & rq & $|V . r|$ & 11 & $1 \cdot . \mathrm{vA}$ & 11 & الابناء & عبرالإنترنت \\
\hline
\end{tabular}

يلاحظ من جدول (^) الإختلاف بين العينة البحثية بمحافظة البحيرة والعينة البحثية بمحافظة الإسكندرية من حيث أكثر أفراد الأسرة قباماً بالتسوق عبر الأنترنت فقد كان الزوج 


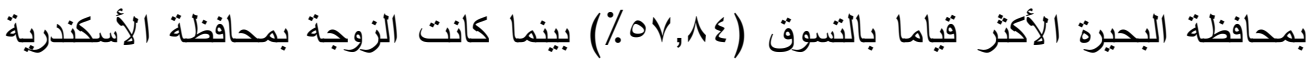

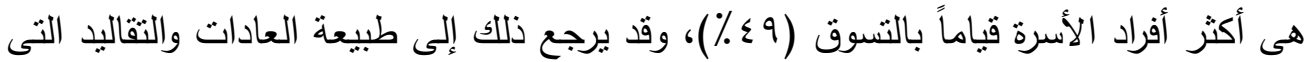

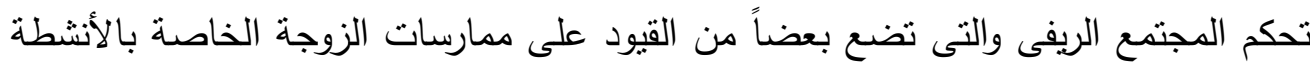

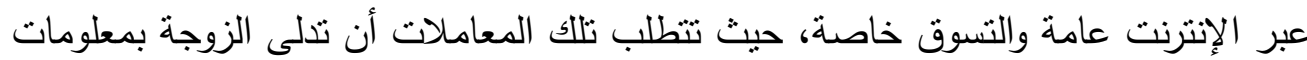
عنها وعن عنوانها وهذا ما قد يرفضه الكثبرون من أهل الريف، وعامة فقد تبين أن إندان

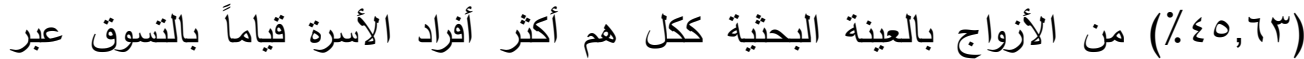

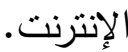

r- مصادر المعلومات عن التسوق عبر الإنترنت

جدول (9): توزيع المبحوثين وفقاً لمصادر المعلومات عن التسوق عبر الإنترنت

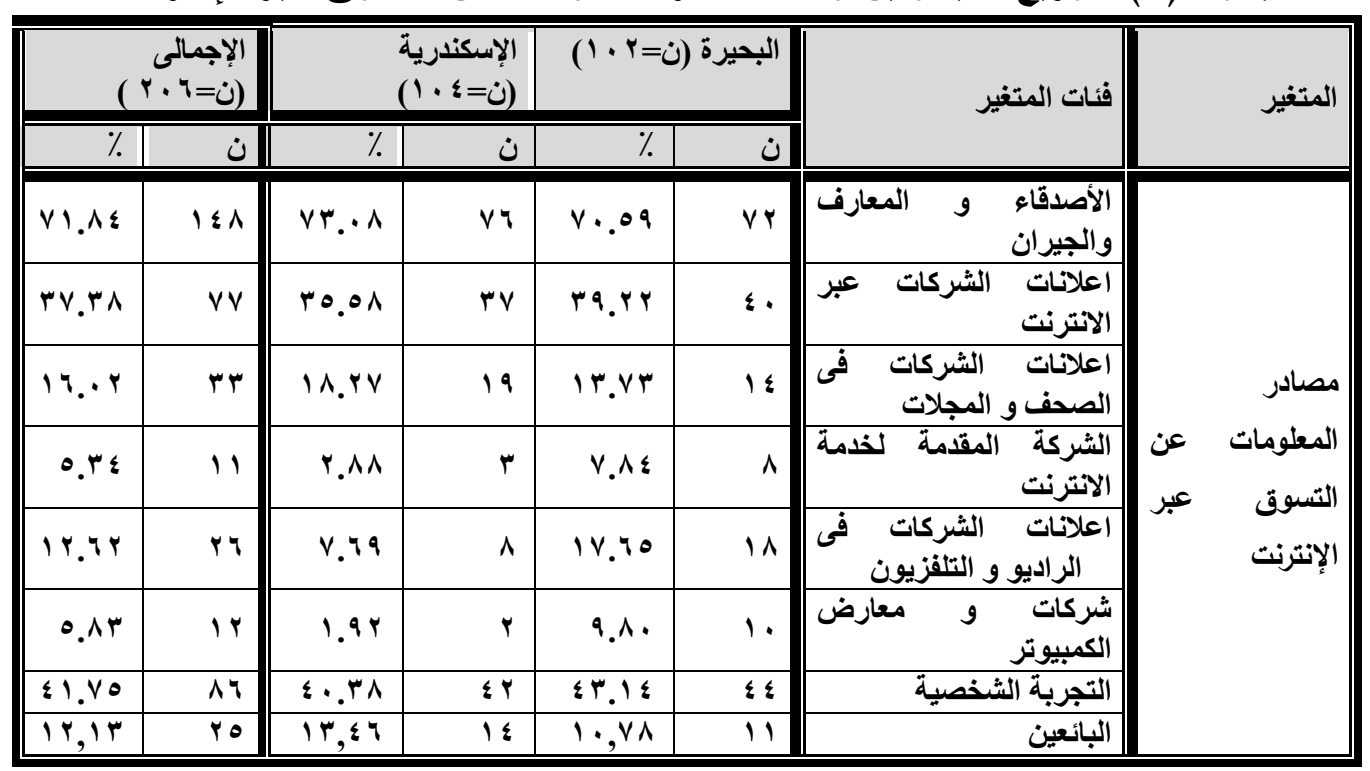

يتضح من جدول (9) أن الأصدقاء والمعارف والجيران هم أكثر مصدر يحصل منه

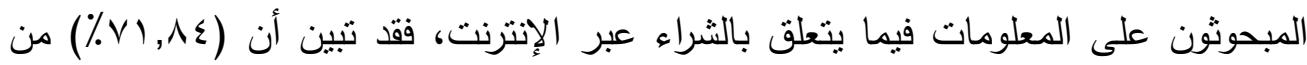
المبحوثين يعتمدون عليهم كمصدر لمعلوماتهم، وقد تثابه فى ذلك نسب المبحوثين بمحافظة

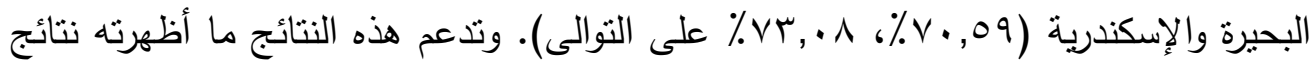


دراسة الزغيمى (Y V P والتى هدفت إلى التعرف على تأثثر الجماعات المرجعية (الأهل والأصدقاء) على مراحل قرار الثراء للمستهلك لمختلف السلع والخدمات، والتي توصلت إلى الى

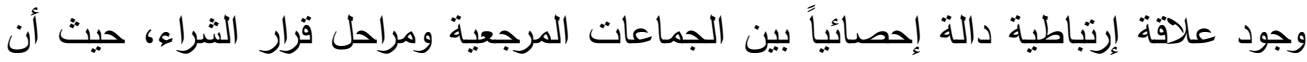

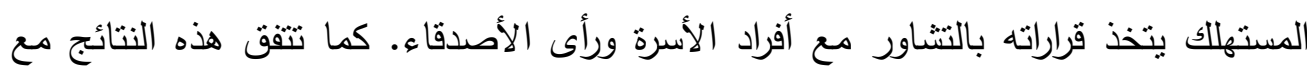

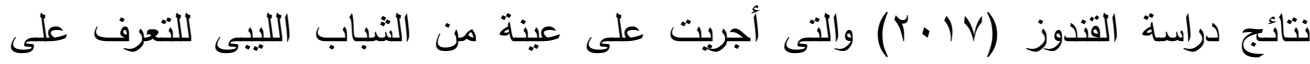

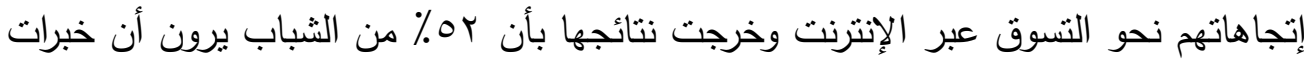
تجارب الأصدقاء تدفعهم إلى إتخاذ قرار الثراء من مواقع الإنترنت.

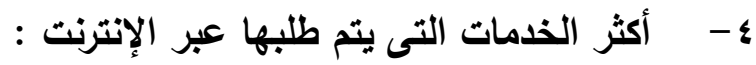

جدول ( • 1): توزيع المبحوثين وفقاً لأكثر الخدمات التى يتم طلبها عبر الإنترنت

\begin{tabular}{|c|c|c|c|c|c|c|c|}
\hline \multicolumn{2}{|c|}{ 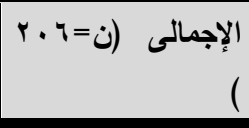 } & \multicolumn{2}{|c|}{ 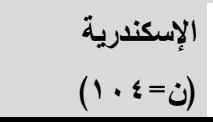 } & \multicolumn{2}{|c|}{ 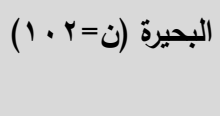 } & \multirow[t]{2}{*}{ فئات المتغير } & \multirow[t]{2}{*}{ المتغير } \\
\hline$\%$ & $\dot{u}$ & $\%$ & $\dot{ن}$ & $\%$ & ن & & \\
\hline \&1.Yq & 10 & $\varepsilon \cdot . \mu \Lambda$ & $\varepsilon r$ & \&Y.17 & $\varepsilon r$ & خلمات صحية & \\
\hline $0.9 \mathrm{VV}$ & 1.0 & $\leqslant 9 . \cdot \varepsilon$ & 01 & or.q & $0 \leq$ & خذمات تعليمية & \\
\hline rr.r. & $\varepsilon \wedge$ & 19.r & $r$. & $r V . \leqslant 0$ & rA & خدمات السياحة و & 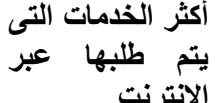 \\
\hline$\varepsilon \cdot . r^{q}$ & AT & $\varepsilon \wedge . \cdot \wedge$ & o. & ס ש.ru & r & شراء منتجات & \\
\hline $.9 \mathrm{~V}$ & $r$ & 1.94 & $r$ & $\because \cdots$ & . & أخرى & \\
\hline
\end{tabular}

تثنير النتائج بجدول (• (1) أن الخدمات التعليمية هى أكثر الخدمات طلباً عبر الإنترنت

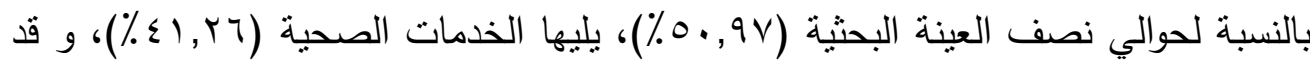

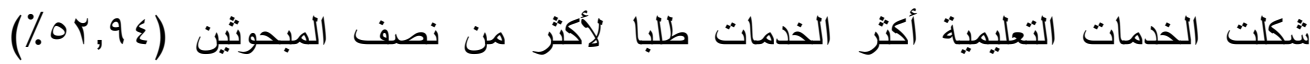
بمحافظة البحيرة، (ع .,9ء \%) للمبحوثين بمحافظة الإسكندرية، بينما كانت خدمات السياحة

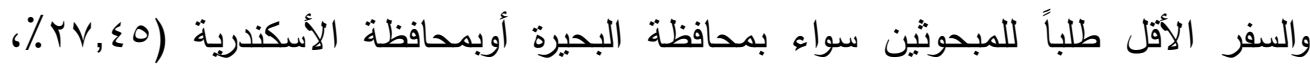

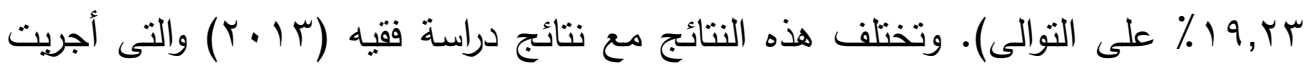


على عينة من الأسر بالسعودية بهدف إيجاد العلاقة بين قيام تلك الأسر بالتسوق الإكترونى

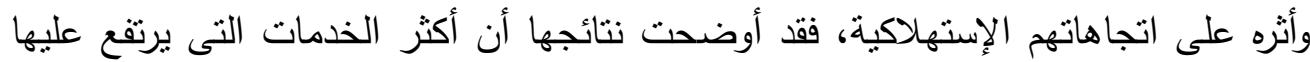
الطلب عبر مواقع الإنترنت كانت السياحة والسفر (حجوزات الطيران والفنادق) وذلك بنسبة

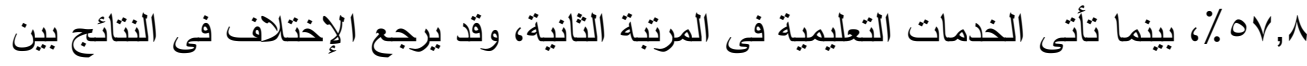
البحث الحالى ونتائج تلك الدراسة إلى إختلاف المستوى المعيثى بين البلدين فكلما ارتفع

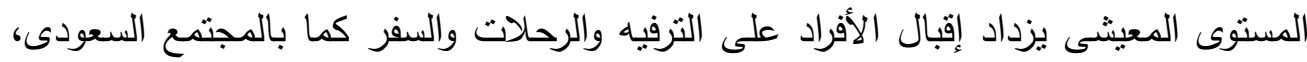

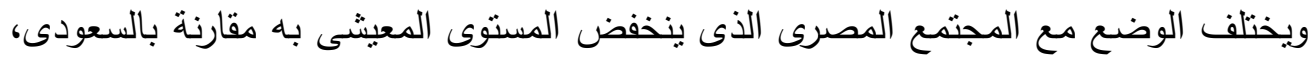
فنجد أن الإهتمام يكون بضروريات الحياة كالتعليم والصحة وغيرها. ه- أكثر السلع التى يتم شرائها عبر الإنترنت جدول (11) : 11 توزيع المبحوثين وفقاً لأكثر الخدمات التى يتم طلبها عبر الإنترنت

\begin{tabular}{|c|c|c|c|c|c|c|c|}
\hline \multicolumn{2}{|c|}{ الإجمالى (ن= · • ) ) } & \multicolumn{2}{|c|}{ الإسكندرية } & \multicolumn{2}{|c|}{ البحيرة (ن= r · l ) } & \multirow[t]{2}{*}{ فئات المتغير } & \multirow[t]{2}{*}{ المتغير } \\
\hline$\%$ & $\dot{ن}$ & $\%$ & $\dot{ن}$ & $\%$ & $\dot{ن}$ & & \\
\hline 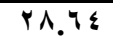 & 09 & ro... & rq & rr.ro & $r r$ & مواد غذائية & \multirow{12}{*}{ 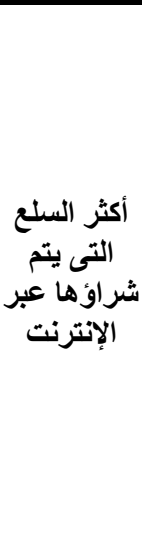 } \\
\hline \&Y.YT & $\Lambda V$ & $\varepsilon \cdot . \mu \wedge$ & $\varepsilon Y$ & $\varepsilon \varepsilon .1 Y$ & $\varepsilon 0$ & ملابس & \\
\hline$r . .1$. & $7 r$ & $r \vee . \wedge \Lambda$ & rq & rr.ro & $\mu$ & أدوات منزلية & \\
\hline MY.OY & $7 V$ & ro... & $r q$ & $\varepsilon . . Y$. & \&1 & أجهزة كهربائية & \\
\hline 15.09 & $r \wedge$ & IY.O. & 14 & $\mid \varepsilon . V 1$ & 10 & التجميل و العطور & \\
\hline $1 \leqslant .07$ & $r$. & $|V . M|$ & 11 & 11.87 & Ir & سبارات & \\
\hline 10.0 & M & 11.05 & Ir & 11.74 & 19 & اكسسوارات & \\
\hline 17.0. & $r \varepsilon$ & $1 \leqslant . \leqslant Y$ & 10 & $11.7 \%$ & 19 & أثثاث و مفروشات & \\
\hline rr.e & 77 & $19 . \mathrm{Yr}$ & r. & $\leq 0.1$. & $\leq 7$ & أجهزة الكمبيوتر و & \\
\hline q.YY & 19 & $\varepsilon . \wedge 1$ & 0 & IT.VT & $1 \varepsilon$ & الكتب و المراجع & \\
\hline $1 \leqslant .07$ & r. & 11.10 & $r r$ & $\vee . \wedge \varepsilon$ & $\Lambda$ & عقارات & \\
\hline 7.91 & 7 & .99 & 1 & $\varepsilon .9$. & 0 & أخرى & \\
\hline
\end{tabular}

كثفت النتائج بجدول (1) أن أكثر السلع التى حازت على أعلى نسبة شراء عبر

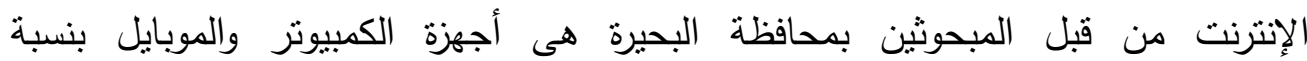

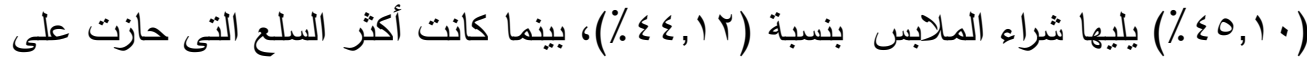


أعلى نسبة شراء عبر الإنترنت من قبل المبحوثين بمحافظة الأسكندرية هى الملابس بنسبة

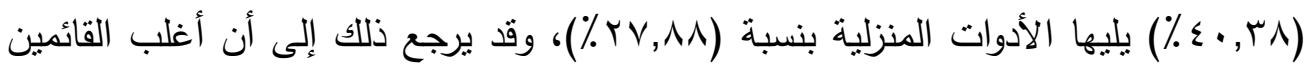

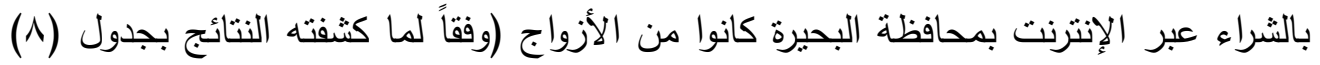

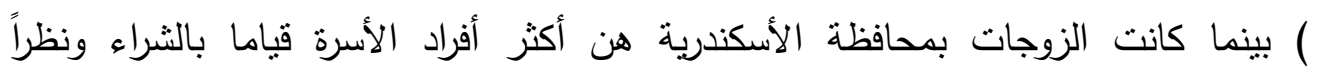

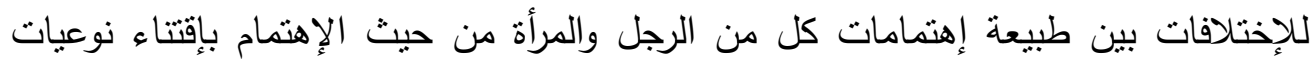

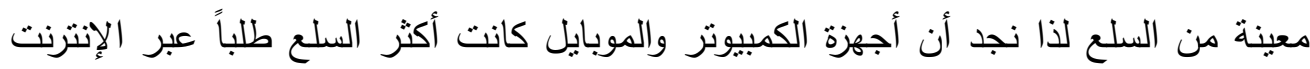
بالنسبة للمبحوثين من محافظة البحيرة والذين أغلبهم من الرجال، بينما كانت الملابس ثمبرهي

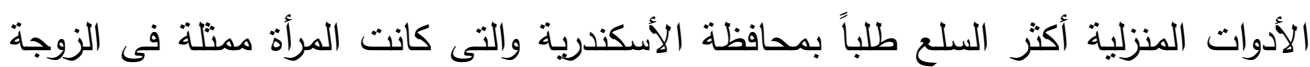

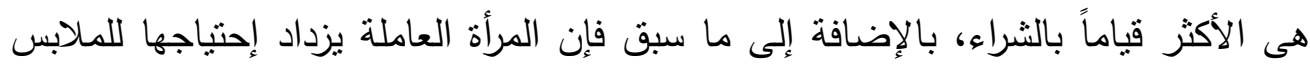

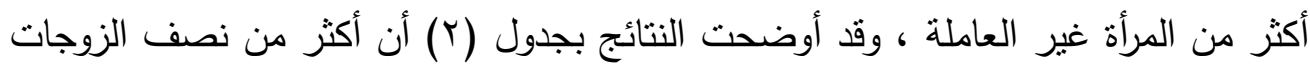

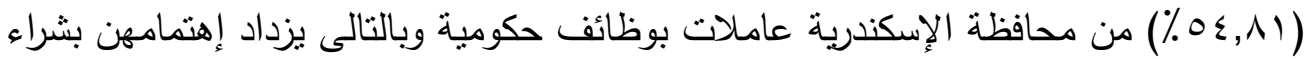
الملابس، كما تهتم بإقتتاء الأدوات المنزلية التى تعينها على أداء الأعمال المنزلية.

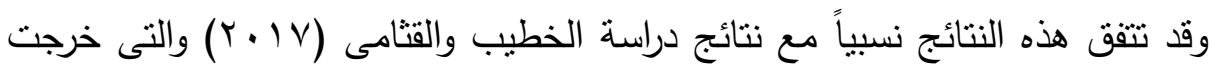
بأن الملابس والإكسسورات كانت أكثر السلع طلباً عبر الإنترنت من عينة الدراسة. بينما

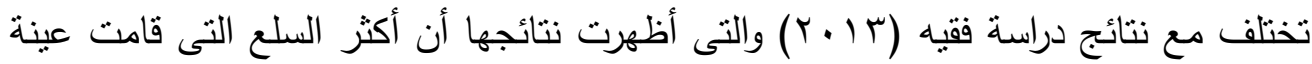
دراستها بشرائها عن طريق التسوق الإلكترونى هى مواد التجميل فى المرتبة الأولى تليها الأحذية والحقائب ثم الإكسسوارات. 


$$
\text { ד - أكثر مواقع التسوق عبر الانترنت : }
$$

جدول (r l ): توزيع المبحوثين وفقاً لأكثر مواقع التسوق عبر الانترنت

\begin{tabular}{|c|c|c|c|c|c|c|c|}
\hline \multicolumn{2}{|c|}{ 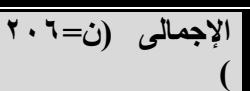 } & \multicolumn{2}{|c|}{ الإسكندرية } & \multicolumn{2}{|c|}{ البحيرة (ن= r r 1) } & \multirow{2}{*}{ فئات المتغير } & \multirow[t]{2}{*}{ المتغير } \\
\hline$\%$ & ن & $\%$ & ن & $\%$ & ن & & \\
\hline$\overline{V I . \wedge \varepsilon}$ & $1 \leqslant 1$ & $V 0.97$ & $\sqrt{19}$ & $7 v, 70$ & 79 & المواقع المحلية & مواقع \\
\hline rr.t. & « & rY.IY & rr & $r \leqslant .01$ & ro & المواقع العربية & التسوة \\
\hline $19 . \leqslant r$ & $\varepsilon$. & IV.r. & 11 & r $1.0 V$ & rY & المواقع الأجنبية & إختيار أكثر من إنتاجة) \\
\hline
\end{tabular}

يتبين من جدول (r) أن أكثر المواقع التى يقوم المبحوثين بالنسوق من خلالها هى المواقع المحلية فقد حازت المرتبة الأولى سواء للمبحوثين بمحافظتي البحيرة والإسكندرية (7V,70٪)

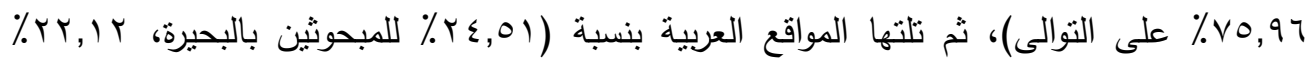

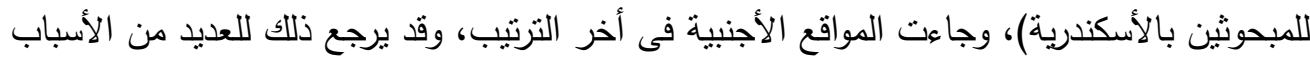

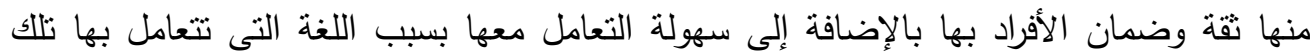
المواقع والتى غالباً ما تكون اللغة العربية بالإضافة إلى إنخفاض تكلفة الثحن والتوصيل. وتختلف

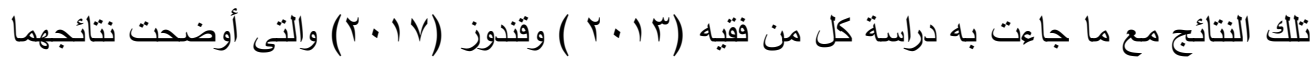
تفضيل المبحوثين لديهما النسوق من المواقع الأجنبية.

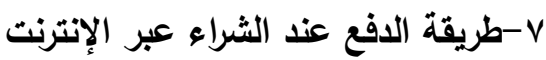

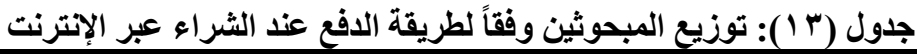

\begin{tabular}{|c|c|c|c|c|c|c|c|}
\hline \multicolumn{2}{|c|}{ 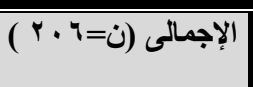 } & \multicolumn{2}{|c|}{ 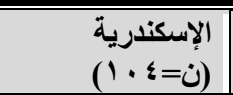 } & \multicolumn{2}{|c|}{ 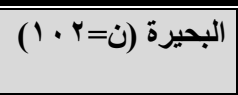 } & \multirow[t]{2}{*}{ فئات المتغير } & \multirow[t]{2}{*}{ المتغير } \\
\hline$\%$ & ن & $\%$ & ن & $\%$ & ن & & \\
\hline $0 . \wedge \mu$ & $\overline{T H}$ & r.^o & $\varepsilon$ & $\overline{V . \wedge \varepsilon}$ & $\Lambda$ & بطاقة(فيز ا-ماستر كارد) & 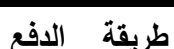 \\
\hline$r . \wedge \wedge$ & $\Lambda$ & $r . \wedge \wedge$ & $r$ & ๕.9. & 0 & الحو الةُة(البنكيةــ البريدية ) & \\
\hline 10.0 & $r 1$ & $1 \mathrm{T. \mu 1}$ & 11 & IY.VO & 14 & بطاقة انتمانية & عند الثشراء \\
\hline VV.TV & 17. & V५. 94 & ^. & $v \wedge . \leqslant \mu$ & A. & الدفع كاش عند الاستلام & عبر الإنترنت \\
\hline
\end{tabular}

203/5454313 : أشارع محمد أمين شهيب ـ مصطفى كامل - الاسكندريه ـ مصر تليفون Alexandria - Egypt, Tel. : 203/5454313 - 203/5442776 Fax :203/5442776

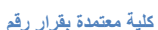
E-mail : journal.edusp@alexu.edu.eg Web site: RSSA.edusp@lexu.edu.eg 
كما تبين من جدول (r ا (أن أكثر طريقة يستخدمها المبحوثون لدفع ثمن السلع المشتراه عبر الإنترنت سواء من محافظة البحيرة أوالإسكندرية كانت الدفع كاش عند الإستلام

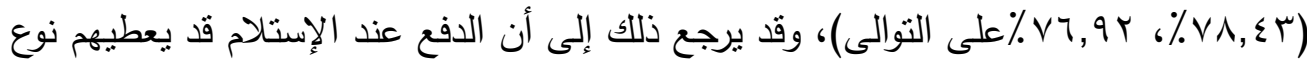

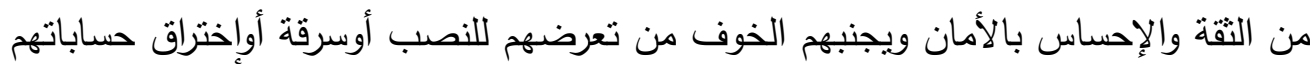

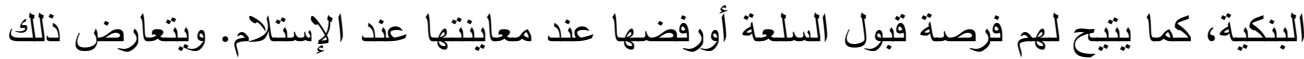

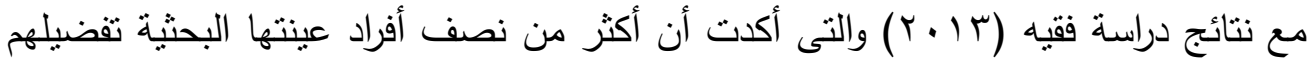
لأساليب الدفع الإلكترونى عن الدفع كاش عند إستالام المشتريات. ب-أكثر مشكلات التسوق التي تعرضت لها الأسر عند استخدام مواقع التسوق عبر الإن

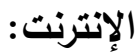

تم التعرف على بعض المشكلات التي قد تتعرض لها الأسر عند التسوق عبر

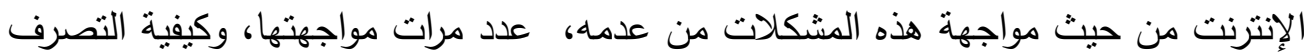

عند التعرض لهذه المشكلات. جدول (؛ ()): توزيع المبحوثين وفقا للمشكلات التي يتعرضون لها عند التسوق عبر الإنترنت

\begin{tabular}{|c|c|c|c|c|c|c|}
\hline \multirow{2}{*}{\multicolumn{2}{|c|}{ 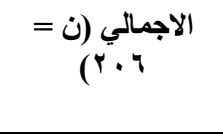 }} & \multicolumn{4}{|c|}{ نعم واجهتي } & \multirow{3}{*}{ المشكلات التي يتعرض لها المبحوثين عند الإنترنت } \\
\hline & & \multicolumn{2}{|c|}{ الاسكندرية (ن } & \multicolumn{2}{|c|}{ 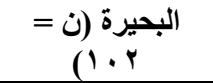 } & \\
\hline$\%$ & 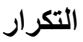 & $\%$ & 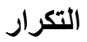 & $\%$ & 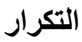 & \\
\hline$\{9.01$ & $1 \cdot r$ & $\varepsilon Y . r$ & $\varepsilon \varepsilon$ & $07 . \wedge 7$ & $\Delta \wedge$ & التعرض لعروض وتخفيضات غير حقيقة \\
\hline$\varepsilon 7.1$ & 90 & $\varepsilon r . r$ & $\varepsilon \varepsilon$ & $\bullet \cdot \cdot$ & 01 & 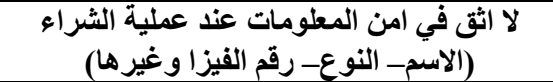 \\
\hline$r \cdot .9$ & $\varepsilon r$ & $1 \varepsilon . \varepsilon$ & 10 & YV.0 & rᄉ & اخذوا مني مبالغ مالية اكبر من قيمة السلعة \\
\hline V.r & 10 & 0.1 & 7 & $\wedge . \wedge$ & 9 & تعرضت لاختراق بطاقتي الائتماتية وسحب اموال \\
\hline$\varepsilon r . V$ & $\wedge \wedge$ & $\varepsilon 1 . r$ & $\varepsilon r$ & $\varepsilon \varepsilon .1$ & $\varepsilon 0$ & بطء شبكة الانترنت وصعوبة التنقل عبر المواقع \\
\hline$r \cdot .1$ & $7 r$ & YI. Y & rr & rq. & $\varepsilon$ & عدم وصول السلعة المطلوبة في الموعد المحدد \\
\hline IV.. & ro & $1 \cdot .7$ & 11 & YT.O & Y & تعرضت للسرقة والنصب عن طريق مواقع وهمية \\
\hline$\varepsilon r . V$ & 9. & rV.o & rq & $0 .$. & 01 & عدم السماح بمعاينة المنتج قبل دفع المال \\
\hline $0 \cdot$. & $1 \cdot r$ & 01.9 & $0 \leq$ & $\varepsilon \wedge$. & $\varepsilon 9$ & السلعة تكون غير مطابقة للمواصفات المعروضة \\
\hline
\end{tabular}

203/5454313 : شارع محمد أمين شهيب ـ مصطفى كامل ـ الاسكندريه ـ مصر تليفون 203/5442 Alexandria - Egypt, Tel. : 203/5454313 - 203/5442776 Fax :203/5442776

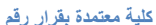
E-mail : journal.edusp@alexu.edu.eg Web site: RSSA.edusp@lexu.edu.eg 
يتضح من جدول (ع () أن حوالي نصف العينة البحثية قد تعرضوا لعدة مشاكل حيث نجد أن السلعة كانت غير مطابقة للمواصفات المعروضة أوتعرضوا لعروض وتخفيضات غير

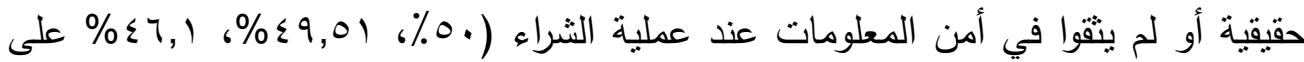

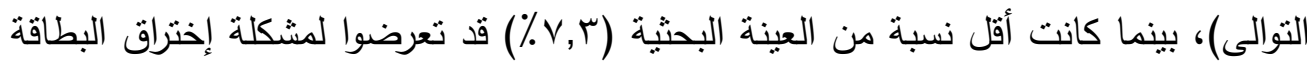

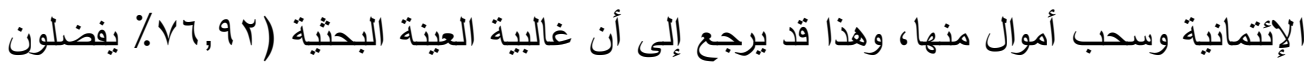

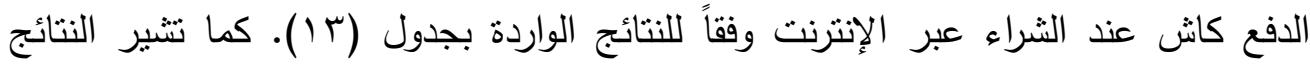

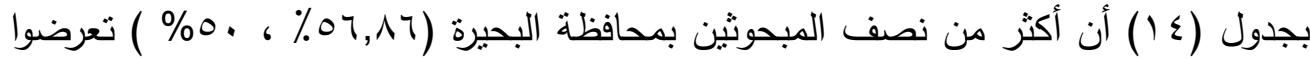
إما لمشكلة العروض والتخفيضات غير الحقيقية أو عدم تقتهم في أمن المعلومات عند عملية الثراء أوعدم السماح بمعاينة المنتج قبل دفع المال، بينما أعلى نسبة من المبحوثين بمحافظة

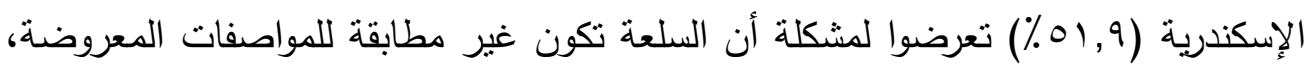

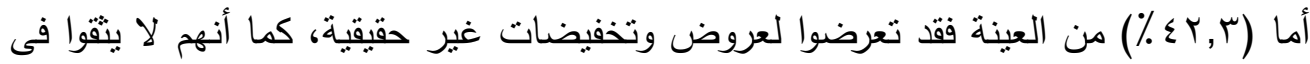

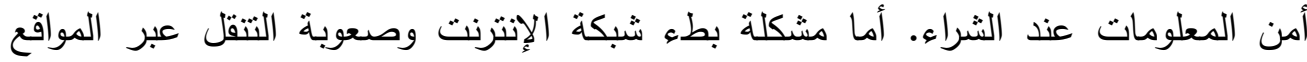
الإككترونية فكانت من المشكلات التى وافق عليها نسب متقاربة من المبحوثين سواء بمحافظة

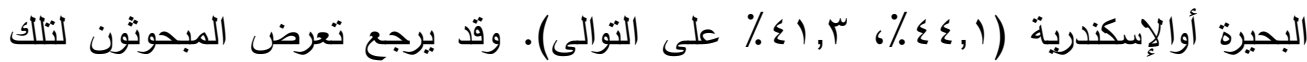

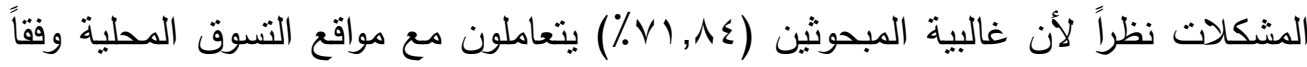
لجدول (r) والتى قد تكون سبياً فى تعرضهم لتلك المشكلات نظراً لأن أغلبها قد يكون مواقع صغيرة يديرها أفراد لا يهمه سوى بيع منتجاتهم بأى طريقة وليست شركات كبيرة مثل المواقع العالمية ذات الثهرة الواسعة والتى تسعى للحفاظ على سعتها وكسب المزيد من العملاء ويكون لها سياسات واضحة فى التعامل مع مشكلات المتسوقين والإهتمام بجودة

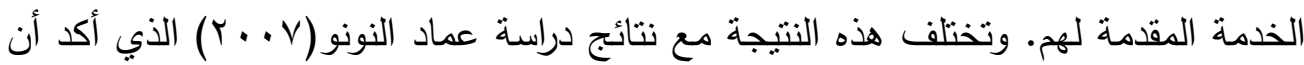
المشكلات التي تواجه المستهلكين خلال التسوق الإكتروني هي قلة المعرفة بكيفية إجراء التعاملات على الإنترنت، وتورط البعض بالإندفاع نحو شراء سلع قد لا يحتاج إليها الفرد 
نتيجة جاذبية الإعلان وسهولة الثراء ببطاقات الإتنمان، وبالتالي تراكم الديون الثخصية

والعائلية.

- متوسط عدد مرات تعرض المبحوثين للمشكلات عند التسوق عبر الإنترنت: جدول (10): توزيع المبحوثين وفقا لمتوسط عدد مرات مواجهة المشكلات عند التسوق عبر الإنترنت

\begin{tabular}{|c|c|c|c|}
\hline \multirow{3}{*}{ 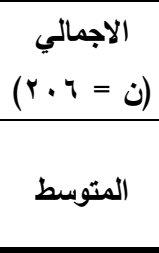 } & \multicolumn{2}{|c|}{ متوسط عدد مرات مواجهة المشكلات } & \multirow{3}{*}{ لمشكلات التي يتعرض لها المبحوثون } \\
\hline & الاسكندرية (ن = \& + 1) & البحيرة (ن = r • (1) & \\
\hline & المتوسطـ الانحراف & المتوسط 土الانحراف & \\
\hline$\varepsilon, 99$ & $r 0,7 T \pm 9, r r$ & $r, r \cdot \pm 1, r 1$ & التعرض لعروض وتخفيضات غيرحقيقة \\
\hline 7, YV & $r \mid, \varepsilon \varepsilon \pm 1 r, r$. & $\cdot, 0 \cdot \pm 1,17$ & 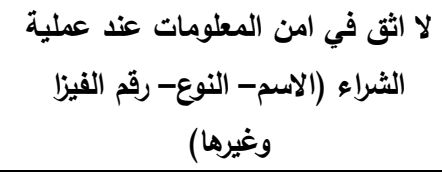 \\
\hline r,0 & $r 0, r r \pm \lambda, r$. & $\cdot, r \wedge \pm 1, \cdot v$ & اخذوا مني مبالغ مالية اكبر من قيمة \\
\hline 1 & $\cdots \pm 1$ & $\cdots \pm 1$ & تعرضت لاختراق بطاقتي الانتمانية \\
\hline$\wedge, \cdot$ & $10, .7 \pm 0, r r$ & $r v, q 9 \pm 1 \cdot, \varepsilon$ & بطء شبكة الانترنت وصعوبة التنقل \\
\hline 1,11 & $\cdot, \varepsilon \vee \pm 1,1 \leqslant$ & $\cdot, r \wedge \pm 1,1$. & عدم وصول السلعة المطلوية في \\
\hline 7,7 & $\cdots \pm 1$ & $r v, 7 r \pm 9, r)$ & تعرضت للسرقة والنصب عن طريق \\
\hline $0, \Sigma 9$ & $r \curlyvee, \varepsilon r \pm \lambda, 79$ & $M, V Y \pm r, \cdot \varepsilon$ & عدم السماح بمعاينة المنتج قبل دفع \\
\hline$\varepsilon, 1$. & $r Y, T r \pm T, V \varepsilon$ & $\cdot$, or $\pm 1,11$ & السلعة تكون غير مطابقة للمواصفات \\
\hline$r$ & $\cdots \pm r$ & - & اخري \\
\hline
\end{tabular}

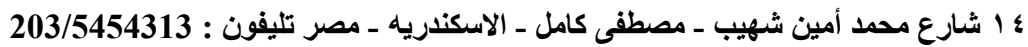
Alexandria - Egypt, Tel. : 203/5454313 - 203/5442776 Fax :203/5442776 E-mail : journal.edusp@alexu.edu.eg Web site: RSSA.edusp@lexu.edu.eg 
يوضح جدول (10) المتوسط الحسابي والإنحراف المعياري لكل مشكلة من المشاكل التي تعرض لها المبحوثون عند التسوق عبر الإنترنت في محافظتي البحيرة والإسكندرية، حيث اتضح أن مشكلة "بطء شبكة الإنترنت وصعوبة التنقل عبر المواقع الإلكترونية" حققت

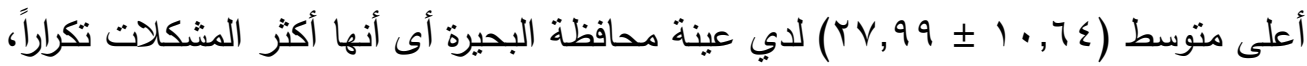

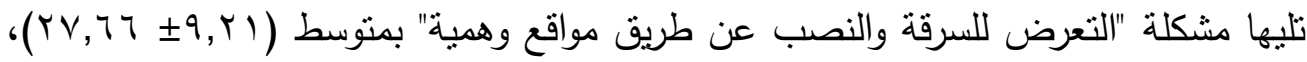

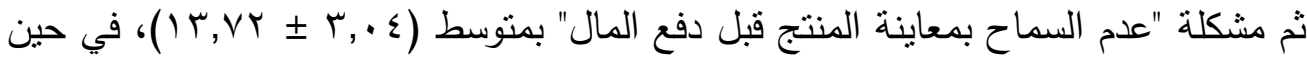

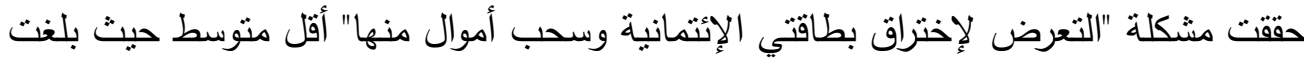

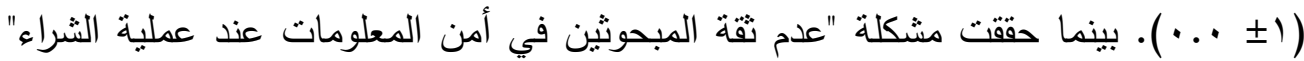

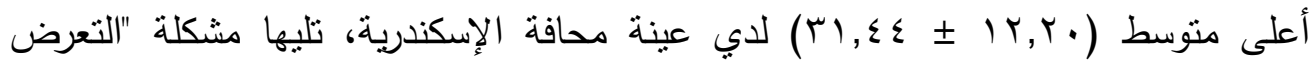

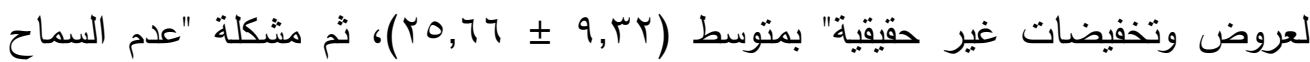
بمعاينة المنتج قبل دفع المال" ومشكلة " أخذ مبالغ مالية أكبر من قيمة السلعة أوالسعر

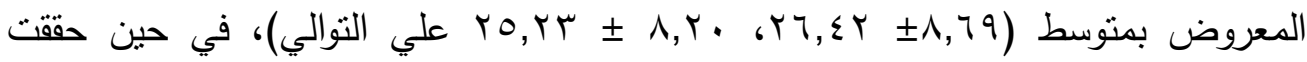

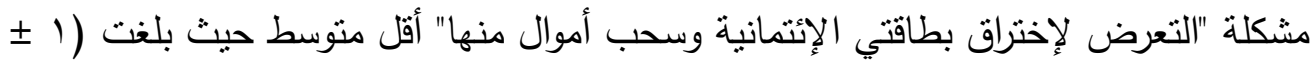
•. ·. .). وبالتالي حققت مشكلة "بطء شبكة الإنترنت وصعوبة التنقل عبر المواقع الإكترونية" أعلى متوسط في العينة الكلية للمبحوثين بمتوسط (•,^)، وقد يرجع ذللك إلى الزيادة الكبيرة

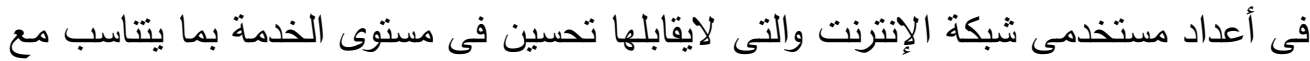

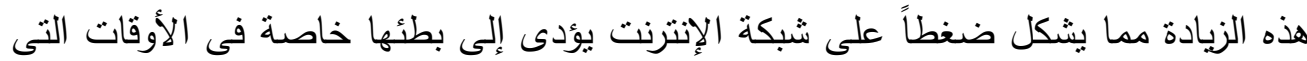

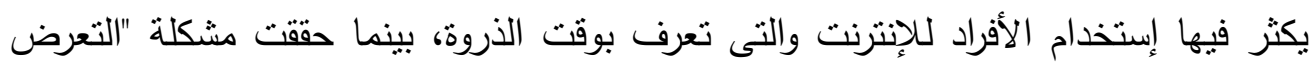
لإختراق بطاقتي الإتنمانية وسحب أموال منها" أقل متوسط في العينة الكلية للمبحوثين بمتوسط (1)، هذا يرجع إلى أن غالبية المبحوثين يفضلون الدفع كاش عند إستلام السلعة وبالتالى لا يتعاملون مع المواقع التى يتم الدفع بها عند طريق البطاقات الإثتمانية. 


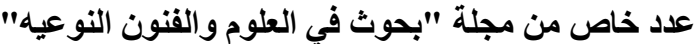

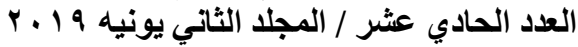

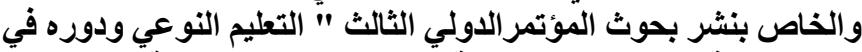

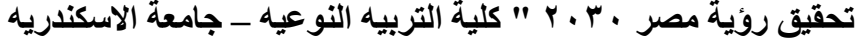

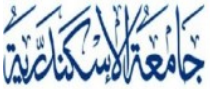

ALEXANDRIA

U N I VER S I T Y

AlexUPress

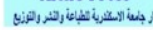

-تصرف المبحوثين عند التعرض لمشكلات عند التسوق عبر الإنترنت:

جدول (1 1 ): توزيع المبحوثين وفقا للتصرف مع المشكلات التي تواجههم خلال التسوق

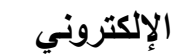

\begin{tabular}{|c|c|c|c|c|c|c|}
\hline \multirow{2}{*}{\multicolumn{2}{|c|}{ 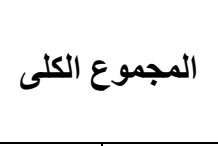 }} & \multicolumn{4}{|c|}{ مكان السكن } & \multirow{3}{*}{ نوعية التصرف مع المشكلات } \\
\hline & & \multicolumn{2}{|c|}{ 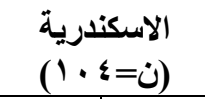 } & \multicolumn{2}{|c|}{ 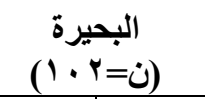 } & \\
\hline$\%$ & التكرار & $\%$ & التكرار & $\%$ & التكرار & \\
\hline & & & & & & التعرض لعروض وتخفيضات غير حقيقة \\
\hline Ar. $\varepsilon$ & $\Lambda \varepsilon$ & vo. & חז & NV. 9 & 01 & عدم التعامل مع الموقع مرة اخري \\
\hline 11.7 & 19 & $11 . r$ & $\wedge$ & 19. & 11 & نصحت اصدقائي بعدم التعامل مع الموقع \\
\hline 9.1 & 1. & $r \cdot .0$ & 9 & 1.v & 1 & ارفض استلام السلعة بدون معاينة \\
\hline$\vee \wedge .9$ & vo & $\vee 9.0$ & ro & $\vee \wedge . \varepsilon$ & $\varepsilon$. & 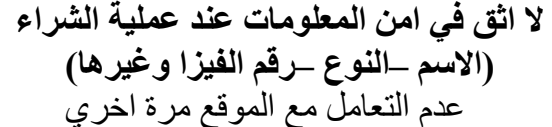 \\
\hline rV. $\varepsilon$ & ץ & T..$\wedge$ & $1 \varepsilon$ & rT.O & Ir & نصدت اصدقائي بعدم التعامل مع الموقع \\
\hline 7. & 7 & 7.1 & r & 0.9 & r & ارفض استلام السلعة بدون معاينة \\
\hline 79.1 & r. & r.. & 9 & Vo. & r) & اخذوا مني مبالغ مالية اكبر من قيمة السلعة او \\
\hline rV.Y & 17 & $\leqslant 7 . \vee$ & $\mathrm{v}$ & T. I & 9 & نصحت اصدقائي بعدم التعامل معا لمُوقع \\
\hline 纟. $\mathrm{V}$ & r & 7. $\mathrm{V}$ & 1 & r. .7 & 1 & ارفض استلام السلعة بدون معاينة \\
\hline $7 .$. & 9 & $0 .$. & r & 77. $\mathrm{V}$ & 7 & 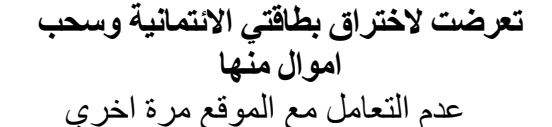 \\
\hline หч. . & $\varepsilon$ & 17.8 & 1 & ח.ז" & r & نصحت اصدقائي بعدم التعامل مع الموقع \\
\hline$r .$. & r & ז. ז"ז & r & 11.1 & 1 & ارفض استلام السلعة بدون معاينة \\
\hline & & & & & & بطء شبكة الاترنت وصعوبة التتقل عبر المواقع \\
\hline $00 . \mathrm{V}$ & $\leqslant 9$ & 70.1 & rA & $\leqslant 7 . \vee$ & r) & عدم التعامل مع الموقع مرة اخري \\
\hline$\varepsilon \wedge .9$ & $\varepsilon r$ & 00.1 & $r \varepsilon$ & $\varepsilon r . r$ & 19 & نصحت اصدقائي بعدم التعامل مع الموقع \\
\hline 0.1 & 0 & $9 . r$ & $\varepsilon$ & r.r & 1 & ارفض استلام السلعة بدون معاينة \\
\hline
\end{tabular}

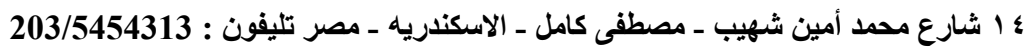

Alexandria - Egypt, Tel. : 203/5454313 - 203/5442776 Fax :203/5442776

E-mail : journal.edusp@alexu.edu.eg Web site: RSSA.edusp@lexu.edu.eg

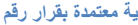

$r \cdot \mid 1 / v / r \cdot-(1 \Lambda \cdot)$

$7 \leqslant \varepsilon$ 
تابع جدول (7 1 ): توزيع المبحوثين وفقا للتصرف مع المشكلات التي تواجههم خلال التسوق الإلكتروني

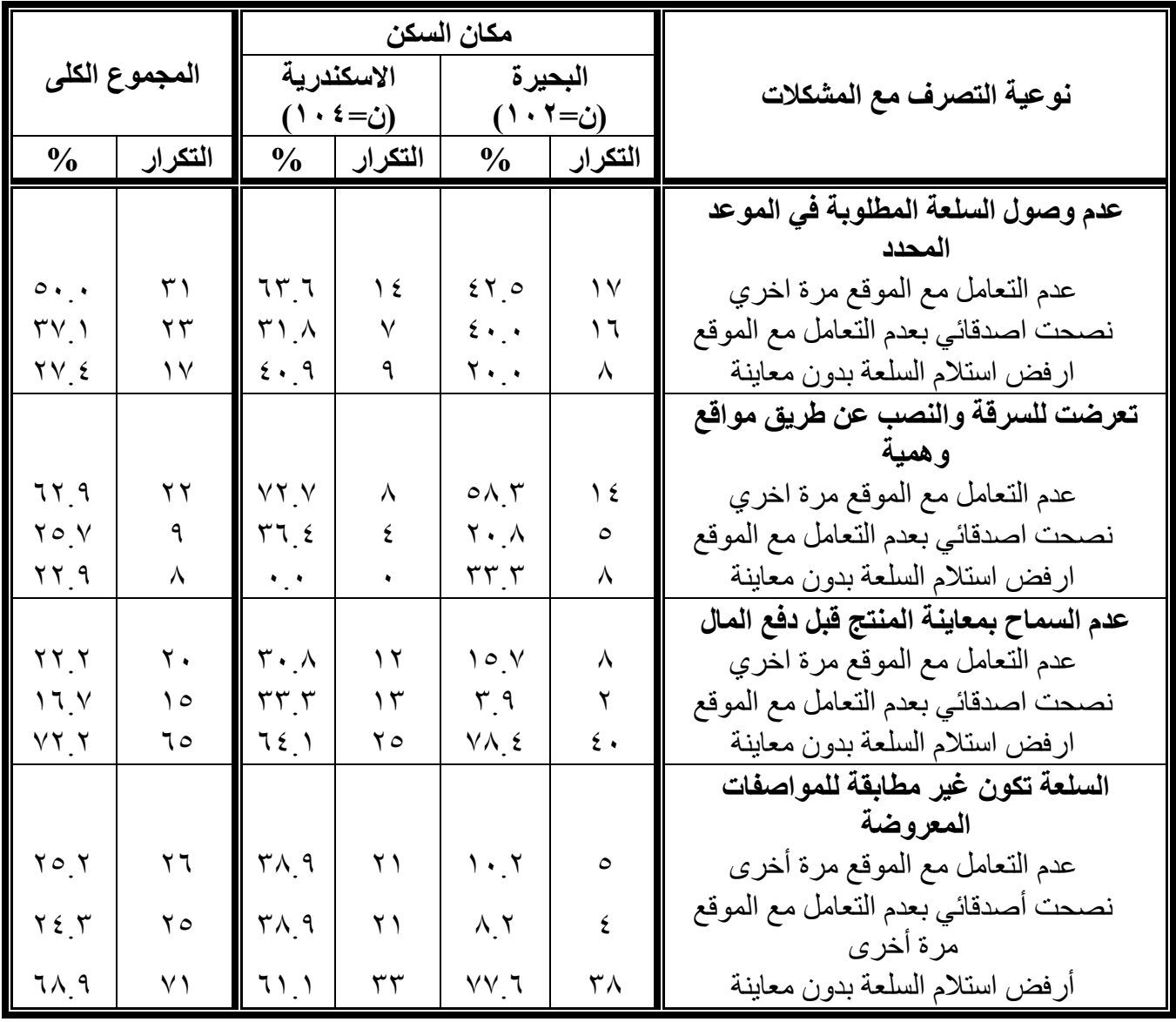

يتبين من النتائج الواردة بجدول (16) أن أكثر تصرف يقوم به المبحوثون بمحافظتى البحيرة والإسكندرية عندما يتعرضون للمشكلات التي تم عرضها بذات الجدول هو عدم

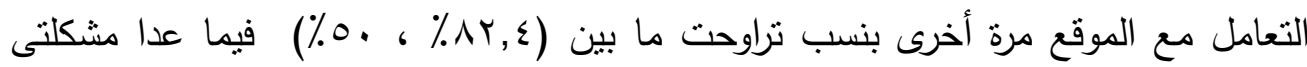

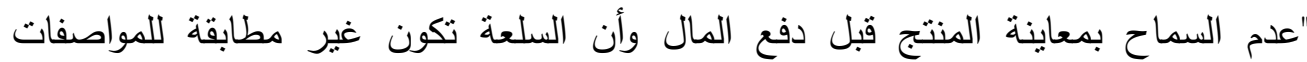

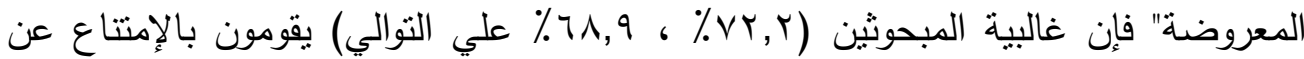
إستلام السلعة بدون معاينة. ولم يختلف المبحوثون بمحافظة البحيرة عن المبحوثين من 
محافظة الأسكندرية فى ذلك كثيرا حيث تقاربت النسب بينهم سواء فى عدم تعاملهم مع الموقع مرة أخرى أو المتتاع عن إستلام السلع ، وهذا يثير إلى عدم وعى المبحوثين بحقوقهم عند التسوق عبر الإنترنت، كذلك عدم وجود خبرة كافية للتعامل مع المشكلات التى قد يتعرضون إليها. وتختلف هذه النتائج مع ما توصلت إليه نتائج دراسة آل عامر ( • • (Y) والتى أجريت بهدف إستطلاع أراء وإتجاهات عينة من مستخدمى الإنترنت فى المملكة العربية السعودية نحو التجارة الإلكترونية، والتعرف على أهم المعوقات التى تحد من إستخدامهم لها كوسيلة تسوق حديثة، حيث أظهرت أن 00\% من المنسوقين ممن خالفت مشترياتهم توقعاتهم أووصلت بخلاف ما توقعوه عاودوا الإتصال بمن باع لهم تللك المنتجات.

$$
\text { ج- مميزات وعيوب التسوق عبر الإنترنت: }
$$

مميزات التسوق عبر الإنترنت:

\begin{tabular}{|c|c|c|c|c|c|c|c|c|c|c|c|c|c|c|c|c|c|c|}
\hline \multirow{2}{*}{\multicolumn{6}{|c|}{ المجموع الكلى ن= † r r }} & \multicolumn{12}{|c|}{ الإستجابات } & \multirow{4}{*}{ 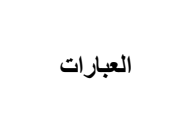 } \\
\hline & & & & & & \multicolumn{6}{|c|}{ الأسكندرية } & \multicolumn{6}{|c|}{ البحيرة } & \\
\hline \multicolumn{2}{|c|}{ أبدا } & \multicolumn{2}{|c|}{ |أحيانا } & \multicolumn{2}{|c|}{ دائما } & \multicolumn{2}{|c|}{ أبدا } & \multicolumn{2}{|c|}{ أحياتا } & \multicolumn{2}{|c|}{ دائما } & \multicolumn{2}{|c|}{ || أبدا || || } & \multicolumn{2}{|c|}{ أحيانا } & \multicolumn{2}{|c|}{ دائما } & \\
\hline$\%$ & S & $\%$ & s & $\%$ & s & $\%$ & s & $\%$ & S & $\%$ & S & $\%$ & S & $\%$ & S & $\%$ & S & \\
\hline$r .9$ & $\Lambda_{.} \cdot$ & 10.0 & $r r_{.}$ & $\wedge \cdot .7$ & 174. & $r . \wedge$ & ๕.• & $1 \leq . \leq$ & 10. & $\wedge 1 . \vee$ & $\wedge \bullet$. & $r .9$ & ๕. & 17.8 & $1 v_{0}$ & $\vee \vee . \leqslant$ & $\wedge 1$. & عبر الإنترنت التسوق \\
\hline $0 . \wedge$ & Ir. & 11.9 & rq. & $v \theta . r$ & 100. & V.V & ^. $\cdot$ & 19.4 & $r \cdot \cdot$ & $v r .1$ & $\vee{ }^{\circ}$. & 4.9 & \&. & 11.7 & 19. & $\vee \vee .0$ & $\vee q^{\circ} \cdot$ & اكثر الإنترنت المنت تنو عات التسوق \\
\hline$r 7 . V$ & 00.0 & $r 9 . \wedge$ & $\wedge r_{.} \cdot$ & rr.o & 79.0 & r. 7.9 & $r \wedge . \cdot$ & $\leqslant 9$. & 01. & $r \varepsilon . \cdot$ & ro. & r 7.0 & $r v . \cdot$ & $r \cdot . \varepsilon$ & ri.. & $\leqslant r .1$ & $\leqslant \varepsilon . \cdot$ & منتجات الأنترنت ألتسوق \\
\hline$\Lambda . r$ & IV. & $r \cdot .7$ & Tr.". & $71 . Y$ & $1 \times 4$. & ^. $\vee$ & 9. & ri.v & rr. & 09.7 & 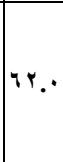 & $v . \wedge$ & ^.• & Y $9 . \varepsilon$ & $r \cdot \cdot$ & Tr.V & $7 \leqslant .0$ & 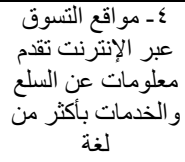 \\
\hline$r v . v$ & $0 v_{.} \cdot$ & rr. & $7 \wedge$. & $r q . r$ & A1.. & rq. & $r v . \cdot$ & ro. 7 & $r v$. & $r \wedge .0$ & $\leqslant \cdot \cdot$ & rq. & $r \cdot . \cdot$ & $r \cdot . \varepsilon$ & r. & $\varepsilon \cdot . Y$ & $\leqslant 1.0$ & هـ الإنترنت منتجات التسوق عبرت \\
\hline$r .9$ & ^.. & ro.r & or. & $v \cdot .9$ & $1 \leq 4$. & $\varepsilon .1$ & $0 . \cdot$ & rr. & $r \leqslant$. & VY. & vo.. & r.q & r.. & $r v .0$ & Y^. & 79.7 & $\vee 1 . \cdot$ & 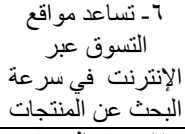 \\
\hline 17.1 & $r v . \cdot$ & r. $r$ & $0 \leqslant$. & $r \cdot . V$ & iro. & 11.0 & $1 r_{.} \cdot$ & $r \leqslant .$. & ro. & $7 \leq . \leq$ & TV. & $1 \leq . v$ & 10.0 & $Y \wedge . \xi$ & rq. & 07.9 & $\bullet \wedge . \cdot$ & 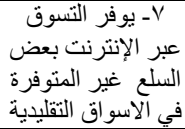 \\
\hline
\end{tabular}

203/5454313 : شارع محمد أمين شهيب ـ مصطفى كامل ـ الاسكندريه ـ مصر تليفون

Alexandria - Egypt, Tel. : 203/5454313 - 203/5442776 Fax :203/5442776

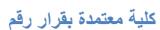

E-mail : journal.edusp@alexu.edu.eg Web site: RSSA.edusp@lexu.edu.eg 
عدد خاص من مجلة "بحوث في العلوم والقنون النوعيه" التوبه

العدد الحادي عشر / المجلد الثاني يونيه 9 /

\begin{tabular}{|c|c|c|c|c|c|c|c|c|c|c|c|c|c|c|c|c|c|c|}
\hline \multirow{2}{*}{\multicolumn{6}{|c|}{ المجموع الكلى ن= † r r }} & \multicolumn{12}{|c|}{ الإستجابات } & \multirow{4}{*}{ العبارات } \\
\hline & & & & & & \multicolumn{6}{|c|}{ الأسكندرية } & \multicolumn{6}{|c|}{ البحيرة } & \\
\hline \multicolumn{2}{|c|}{ أبدا } & \multicolumn{2}{|c|}{ أحيانا } & \multicolumn{2}{|c|}{ دائما } & \multicolumn{2}{|c|}{ أبدا } & \multicolumn{2}{|c|}{ أحيانا } & \multicolumn{2}{|c|}{ دائما } & \multicolumn{2}{|c|}{ أبدا } & \multicolumn{2}{|c|}{ أحيانا } & \multicolumn{2}{|c|}{ دائما } & \\
\hline$\%$ & S & $\%$ & S & $\%$ & S & $\%$ & S & $\%$ & S & $\%$ & S & $\%$ & S & $\%$ & S & $\%$ & S & \\
\hline $1 \% .1$ & $r v$. & $r \cdot .1$ & Tr. & $|\circ . . \wedge|$ & $11 v_{0}$ & $11 . r$ & 19. & $r v . q$ & rq. & or.A & 07. & $\vee . \wedge$ & ^. & rr.s & rr. & $\bullet ৭ . \wedge$ & 71. & 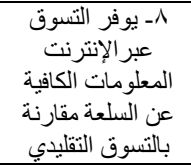 \\
\hline rr.. & 41. & $\varepsilon \cdot . \wedge$ & $\wedge \varepsilon$. & $r 4 . r$ & $0 \leqslant$. & r.. & $r v .{ }^{\circ}$ & $\leqslant 9$. & 01. & ro. & $Y \%$. & $\leqslant \cdot Y$ & $\leqslant 1$. & rr.s & rr. & $r v .0$ & $r \wedge$. & 9 ـ مبر الإنتر التسوقت \\
\hline$\wedge . \vee$ & 11. & $r \cdot . \varepsilon$ & $\varepsilon r$. & $v \cdot .9$ & $1 \leq 7$. & $v . v$ & $\Lambda_{.} \cdot$ & $1 \Lambda . \%$ & 19.0 & $V \leq$. & Vv. & $9 . \wedge$ & $1 \cdot \cdot$ & rr.o & rr. & $7 V .7$ & 79. & 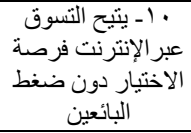 \\
\hline$\wedge . \vee$ & 1^. & rr.A & $\leqslant 9$. & 7v. 0 & $1+9$. & ^. $\vee$ & 9. & $r \cdot . r$ & r. & Vi.r & $V \leq$. & $\wedge . \wedge$ & १. & $r v .0$ & Y^. & Tr.V & 70. & 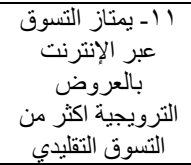 \\
\hline$\wedge . \vee$ & 1^. & 11. & $r v .$. & vr.r. & 101. & 0.1 & 7. & $1 \Lambda . r$ & 19. & V५. & $\vee q$. & $11 . \wedge$ & ir.• & 18.7 & 11. & $v \cdot .7$ & $V_{\text {r. }} \cdot$ & أي عبر الانترنت التين في التسوق \\
\hline
\end{tabular}

جدول(V) توزيع المبحوثين وفقاً لأرائهم حول مميزات النسوق عبر الإنترنت

$$
(r \cdot T=\dot{ })
$$

يتضح من النتائج الواردة بجدول (IV) تعدد مميزات النسوق عبر الإنترنت بالنسبة للمبحوثين من محافظة البحيرة إلا أن أكثر هذه المميزات والتى أتفق عليها أكبر عدد من الإنرات

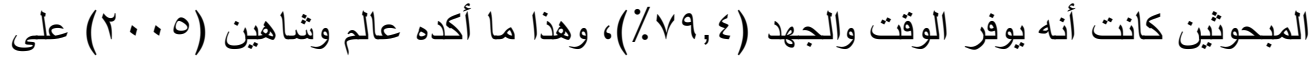

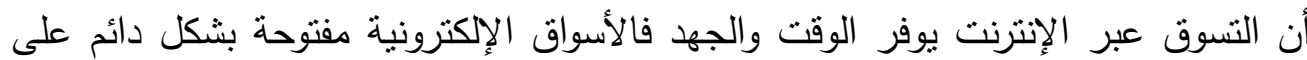

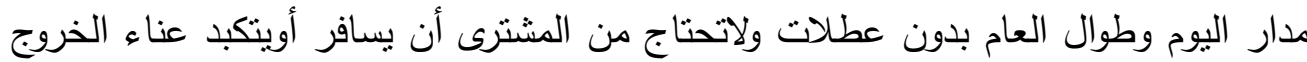
من البيت أوالإنتظار لشراء منتج معين ولا تتطلب سواء النقر على المنتج. وهذا قد يمثل أهمية كبيرة للأفراد الذى يعيشون فى مناطق يغلب عليها الطابع الريفى حيث لا تتوفر المحلات الكافية لسد إحتباجاتهم من السلع فيسعون إلى البحث عنها بالمدن الكبيرة مما

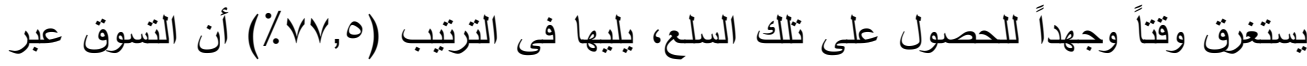

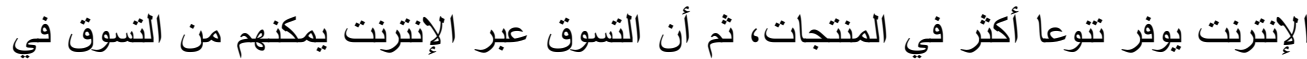


أي وقت خلال اليوم (ך, ••٪)، وهذه النتائج تتفق نسبياً مع ما توصلت إليه نتائج دراسة الخطيب والقتامى (Y. V V) والتى أظهرت أن إمكانية التسوق عبرالإنترنت فى أى وقت تليها توفير الوقت والجهد من المميزات التى حازت على درجة عالية من الأهمية لدى عينة دراستهما. ثم جاء بعد ذلك فى الترتيب أن مواقع التسوق عبر الإنترنت تساعد المبحوثين في

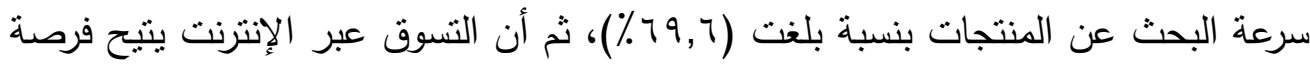

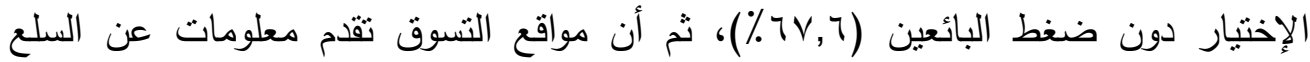

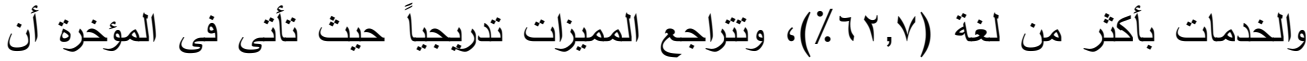

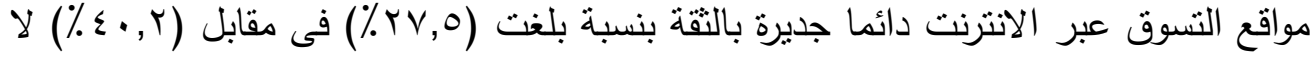
يوافقون على ذلك.

وفيما يتعلق بأراء المبحوثين بمحافظة الإسكندرية عن مميزات التسوق عبر الإنترنت فلم تختلف كثيراً عن ما سبق فقد شكلت مبزة توفير الوقت والجهد المرتبة الأولى بنسبة

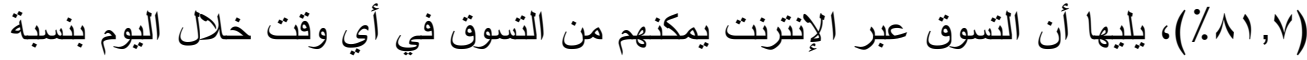

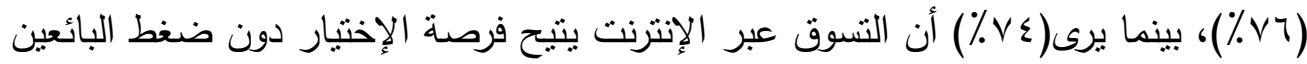

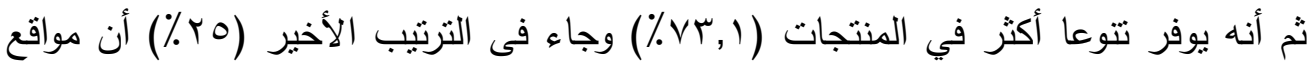
التسوق عبر الإنترنت دائما تكون جديرة بالثقة. وتختلف هذه النتائج مع ما توصلت إليه نتائج

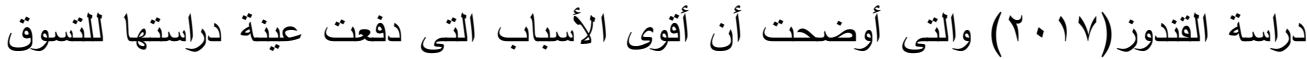
عبر الإنترنت كانت تعدد الخيارات وتوفر سلع غير موجودة فى السوق المحلى. 
عدد خاص من مجلة "بحوث في العلوم والقنون النوعيه" العدد الحادي عشر / المجلد الثاني يونيه 9 /

• عيوب التسوق عبر الإنترنت

\begin{tabular}{|c|c|c|c|c|c|c|c|c|c|c|c|c|c|c|c|c|c|}
\hline \multirow{2}{*}{\multicolumn{6}{|c|}{ المجموع الكلى ن= † · r }} & \multicolumn{11}{|c|}{ الإستجابات } & \multirow{4}{*}{ العبارات } \\
\hline & & & & & & \multicolumn{5}{|c|}{ الأسكندرية } & \multicolumn{6}{|c|}{ البحيرة } & \\
\hline \multicolumn{2}{|c|}{ أبدا } & \multicolumn{2}{|c|}{ أحيانا } & \multicolumn{2}{|c|}{ دائما } & \multicolumn{2}{|c|}{ أبدا } & أحيانا & \multicolumn{2}{|c|}{ دائما بائما } & \multicolumn{2}{|c|}{ أبدا } & \multicolumn{2}{|c|}{ أحيانا } & \multicolumn{2}{|c|}{ دائما } & \\
\hline$\%$ & 5 & $\%$ & st & $\%$ & 5 & $\%$ & 5 & \begin{tabular}{l|l|}
$\%$ & $s$ \\
\end{tabular} & $\%$ & ك & $\%$ & ك & $\%$ & ك & $\%$ & st & \\
\hline$\vee . \wedge$ & 17. & A. & $v$. & 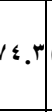 & or. & ४.. & $v_{.} \cdot$ & & 1 \&. & v. & $\wedge . \wedge$ & $\cdot$ & ४.. & v. & & Vฯ. & الثراء حسبا او شخصنيا النسلعة قبل \\
\hline 9 & & & & ..$\varepsilon$ & $\leqslant 0$. & $\leqslant . \wedge$ & ๑. & & $\cdot$. & r. & $\wedge . \wedge$ & $\therefore$ & & &. .4 & Vr.. & درجة من المخاطرة في عملية الإنترنت \\
\hline & & $T_{\text {. }}$ & & & & & 4. & & & & & & & & & $r r_{.}$ & 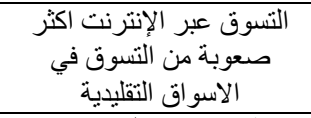 \\
\hline & & & & & & & & & & & & & & & & $r \leq$. & خطوات عمبة الثر اء عبر \\
\hline & & & & $\mathrm{v} . \wedge$ & 19. & & 1. & & & & & & & & & 09. & 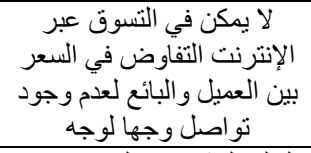 \\
\hline & & & & & 94. & r. & 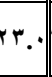 & & & & & & & & $v_{0} 1$ & $\leqslant \Lambda_{.}$. & الإلنتر المشتر ليس لها بالتسوق عبر . \\
\hline & & & & & $\wedge \leq$. & & & & & & & & & & & $\leq \cdot$. & اثنثاء التسوق عبر متعة الإنترنت \\
\hline & & & & & .9. & $\bullet$ & v. & & & & & & & & & or. & 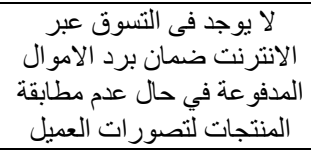 \\
\hline & & & & & & & & & & & & & & & & or. & الإنترنت عيور عدم التلاغوق العملاء \\
\hline & & & & $\wedge . \vee$ & r. & $0 . \wedge$ & $\because$. & & & & & & & & & $0 \Lambda_{.}$. & 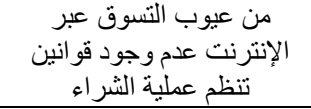 \\
\hline & & & & $\cdot$ & $r \leqslant$. & A.v & १.• & & & & & & & & & $\because .0$ & 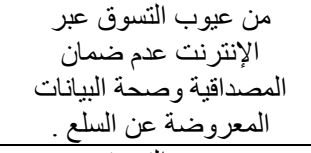 \\
\hline & & & & & & & & & & & & & & & & $\varepsilon 9$. & الإنترنت تئَخر وصول التسول السبلعة \\
\hline
\end{tabular}

ع ا شارع محمد أمين شهيب ـ مصطفى كامل ـ الاسكندريه ـ مصر تليفون : 203/5454313 : 203/5442

Alexandria - Egypt, Tel. : 203/5454313 - 203/5442776 Fax :203/5442776 E-mail : journal.edusp@alexu.edu.eg Web site: RSSA.edusp@lexu.edu.eg

كلمية معتمدة بقرار رقمر

$r \cdot \mid \Lambda / V / T \cdot-(1 \Lambda \cdot)$ 
يتضح من جدول (1) أن أكثر عيوب النسوق عبر الإنترنت من وجهة نظر المبحوثين في محافظة البحيرة أنه يصعب معاينة السلعة قبل الشراء حسيا أوشخصيا وذلك وفقاً لأراء

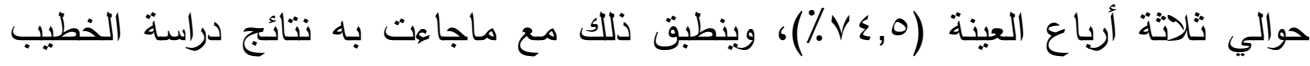

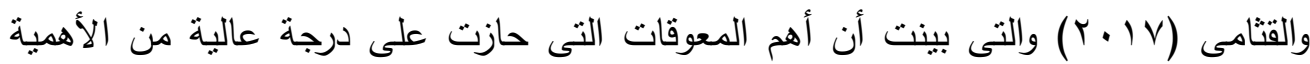

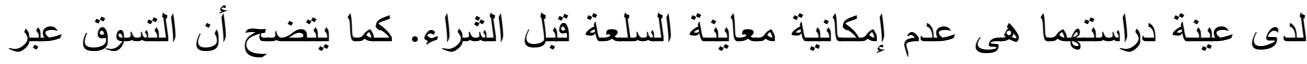

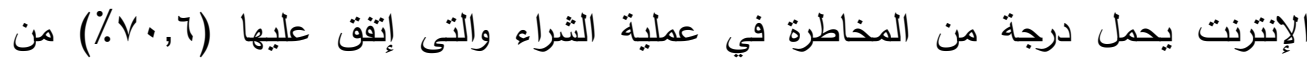
المبحوثين، ثم عدم ضمان المصداقية وصحة البيانات المعروضة عن السلع، يليها أنه لاهن لاهن يمكن معه التفاوض في السعر بين العميل والبائع لعدم وجود تواصل وجها لوجه، ثم أنه لا لا توجد قوانين تتظم عملية الثراء من خلال الإنترنت، وأخيرا عدم ابلاغ العملاء بالتطورات

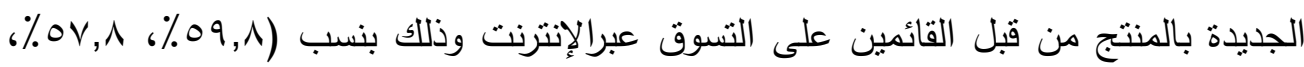

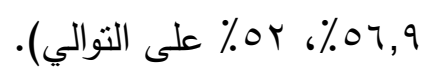

كذلك يمكن أن نستتتج من جدول(1/1 (1) عدم إختلاف أراء المبحوثين بمحافظة الإسكندرية

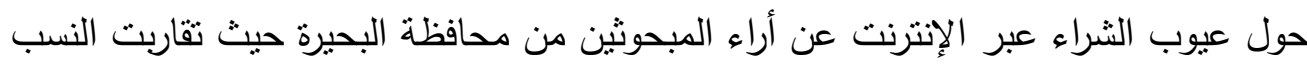
وكادت تتطبق مع بعضها البعض فقد تبين أن أكثر عيوب التسوق عبر الإنترنت وفقا لإتفاق العدد الأكبر من المبحوثون في محافظة الإسكندرية هو أنه يصعب فيه معاينة السلعة قبل فيل

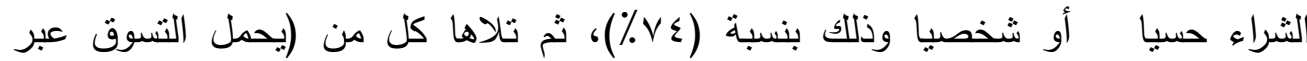
الإنترنت درجة من المخاطرة في عملية الثراء، عدم ضمان المصداقية وصحة البيانات

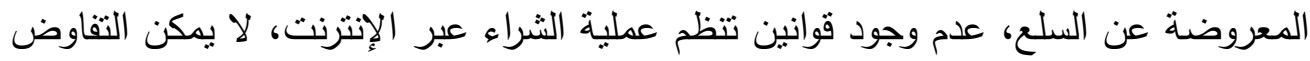

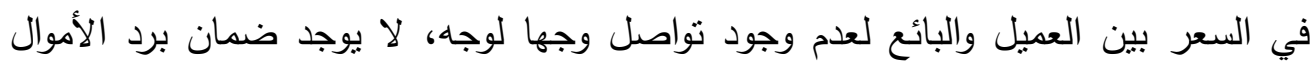
المدفوعة في حال عدم مطابقة المنتجات لتصورات العميل، وأخيرا أن التسوق عبرالإنترنت

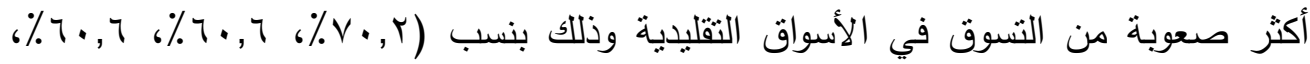

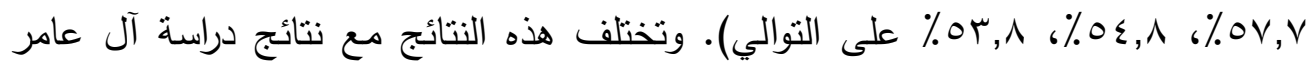

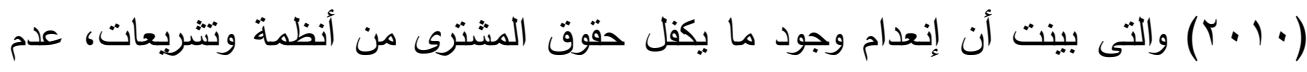


إنتشار وسائل دفع مقبولة عن طريق الإنترنت، ثم عدم لمس المنتجات التى يرغب المشترى

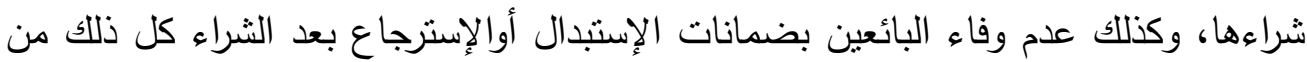
العيوب التى تؤدى إلى الإمتتاع عن الثراء عبر الإنترنت.

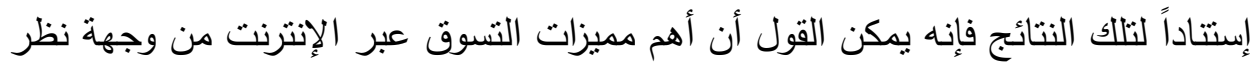

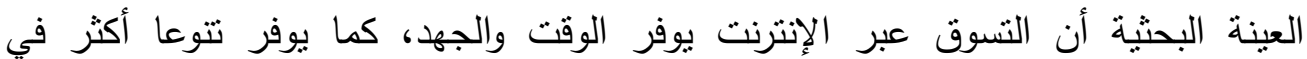

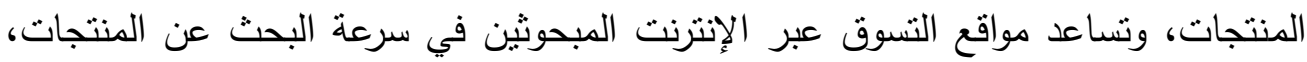

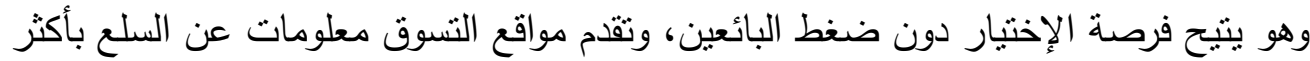
من لغة. بينما تمنلت أكثر عيوب التسوق عبر الإنترنت فى صعوبة معاينة السلعة قبل الشراء

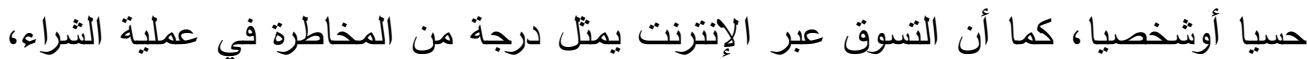
وعدم ضمان المصداقية وصحة البيانات المعروضة عن السلع، أيضا عدم وجود قوانين تنظم عملية الثراء، كما أنه لا يوجد ضمان برد الأموال المدفوعة في حال عدم مطابقة المنتجات لتصورات العميل وأخيرا فإن التسوق عبر الإنترنت أكثر صعوبة من التسوق في الأسواق التقليدية.

ثالثاً: النتائج في ضوء الفروض البحثية: ا - النتائج فى ضوء الفرض لمي الأول:

نص الفرض الأول على أنه "توجد علاقة إرتباطية دالة إحصائياً بين بعض المتغيرات الإجتماعية والإقتصادية (عمر الزوج والزوجة- المستوى التعليمي للزوج و الزوجة- مدة

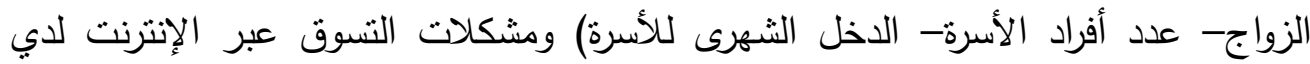
العينة البحثية". وللتحقق من صحة الفرض تم استخدام معامل إرتباط سبيرمان لتحديد العلاقة بين بعض المتغيرات الإجتماعية والإقتصادية ومشكلات التسوق عبر الإنترنت. 
عدد خاص من مجلة "بحوث في العلوم والقنون النوعيه" المجيه

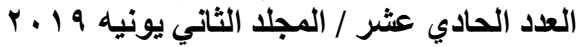

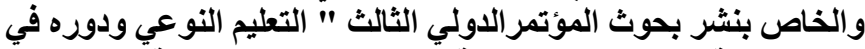

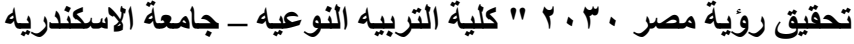

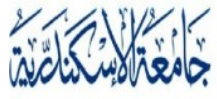
ALEXANDRIA

U N I V E R S I T Y AlexUPress

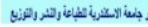

جدول(19): قيم معامل الإرتباط لتحديد العلاقة بين بعض المتغيرات الإجتماعية والإقتصادية ومشكلات التسوق عبر الإنترنت (ن = Y • r )

\begin{tabular}{|c|c|c|c|c|c|c|c|c|}
\hline 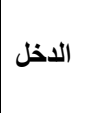 & | علاسد افراد & بالأعواج & اللزعليميتي & اللتزعيتوى & 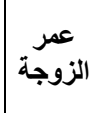 & 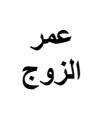 & $\dot{~}$ & مشكلات التسوق عبر الإتترنت \\
\hline$* \begin{array}{l}- \\
.\end{array}$ & $.17^{1}$ & * $\cdot$ TYt & $.11 \times 9-$ & ${ }^{*} \cdot r_{\text {. }}$ & .110 & .177 & $1 \cdot r$ & التعرض لعروض وتخفيضات غير حقيقية \\
\hline (t) & ${ }^{* *} \cdot$ Y Y人 & $\cdot 1 \cdots$ & $\because 1 \vee \leqslant-$ & $* \cdot r \cdot \Lambda_{-}$ & $.1 \cdot 9$ & $.1 \vee 9$ & 90 & 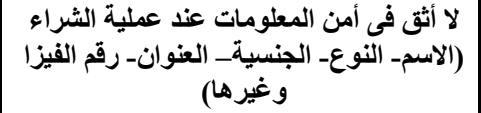 \\
\hline$\cdot .199-$ & $\cdot$. & $.194-$ & .194 & ת & $\cdot 11 \cdot$ & $\cdot Y r \cdot$ & $\varepsilon r$ & أخذوا منى مبالغ مالية أكبر من قيمة السلعة \\
\hline- & - & - & - & - & - & - & 10 & تعرضت لاختراق بطاقتى الائتمانية وسحب \\
\hline$\because \cdot 7 V-$ & $* * \cdot r \leq r$ & .117 & *. & *. & .170 & $.17 \varepsilon$ & $\wedge \Lambda$ & بطء شبكة الاتترنت وصعوبة التنقل عبر المواقع \\
\hline$\because \cdot r V^{-}$ & 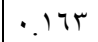 & $\because 7 \varepsilon$ & $* . r 01-$ & *.rTr- & $\because$ ro & $.11 \mathrm{r}$ & 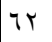 & عدم وصول السلعة المطلوبة في الموعد المحدد \\
\hline$\because \cdot T-$ & * & $\cdot r \cdot 1$ & **..$\leq \leqslant r_{-}$ & $\because \leqslant 0 \Lambda_{-}$ & $\because r)$ & .109 & ro & تعرضت للسرقة والنصب عن طريق مواقع \\
\hline$\cdot .111-$ & .194 & $\because 11$ & $\cdot .11 \leq-$ & $\cdot .1 \leq 7-$ & $\because \varepsilon \wedge$ & $\because r$ & 9. & عدم السماح بمعاينة المنتج قبل دفع المـال \\
\hline. $.1 V V_{-}$ & $.11 \mathrm{r}$ & $.17 \varepsilon-$ & $\because \cdots$ & $\because \cdots$ & $.1 \cdot 9-$ & . & $1 \cdot 4$ & لسلعة تكون غير مطابقة للمواصفات المعروضة \\
\hline$\because \wedge 1-$ & $\because r \leq$ & $* * \cdot r \cdot q$ & $\because \cdot V T$ & $\because$ Vo & $* * .19$ & $* * \cdot r^{*} \cdot$ & & الاجمالي \\
\hline
\end{tabular}

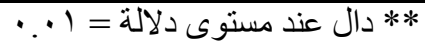

* دال عند مستوى دلالة = • •.

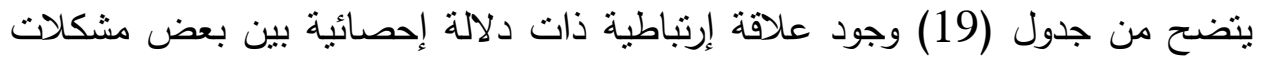
التسوق عبر الإنترنت وبعض المتغيرات الإجتماعية والإقتصادية، حيث كانت النتيجة الإجمالية تدل علي وجود علاقة ارتباطية قوية بين (عر الزوج وعمر الزوجة، مدة الزواج

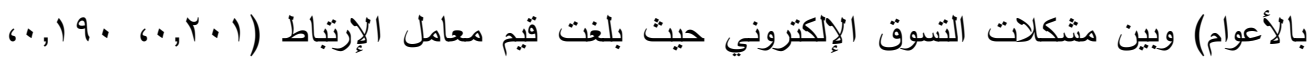

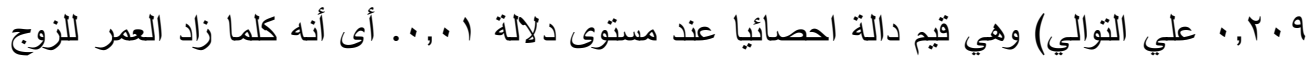
والزوجة وزادت مدة الزواج كلما زاد التعرض لبعض المشكلات عند التنسوق عبر الإنترنت، وقد يرجع

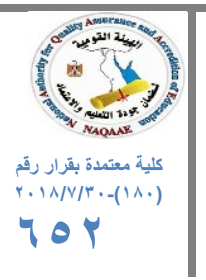

203/5454313 : شارع محمد أمين شهيب ـ مصطفى كامل ـ الاسكندريه ـ مصر تليفون 203/5442 Alexandria - Egypt, Tel. : 203/5454313 - 203/5442776 Fax :203/5442776 E-mail : journal.edusp@alexu.edu.eg Web site: RSSA.edusp@lexu.edu.eg 


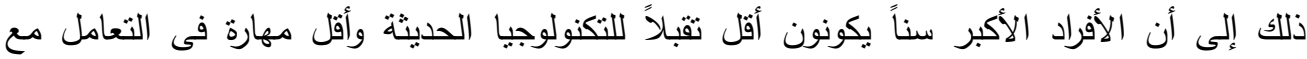
تطبيقاتها المختلفة وبالتالى أكثر عرضة للوقوع فى المشكلات المرتبطة بها. وتختلف هذه النتائج ما نتائج دراسة الخطيب والقنامى (Y. V V والتى أظهرت عدم وجود فروق دالة إحصائياً فى معوقات

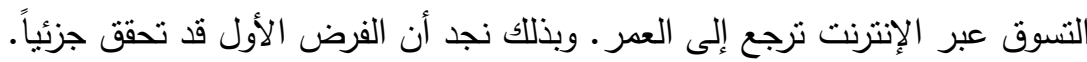

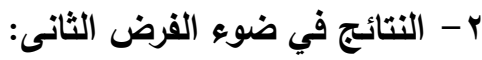

نص الفرض على أنه " توجد فروق دالة إحصائياً بين الأسر عينة البحث بمحافظتى البحيرة والإسكندرية في مشكلات النسوق عبر الإنترنت وفقاً لمكان السكن ". وللتحقق من صحة الفرض تم الته

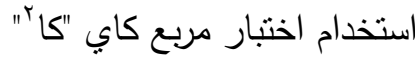
جدول (20): قيم "كا ץ" لبيان دلالة الفروق بين المبحوثين فى مشكلات التسوق عبر الإنترنت وفقا لمكان

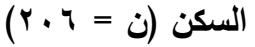

\begin{tabular}{|c|c|c|c|c|c|c|}
\hline \multirow{3}{*}{ 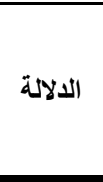 } & \multirow{3}{*}{ Si } & \multicolumn{4}{|c|}{ مكان السكن } & \multirow{3}{*}{ مشكلات التسوق عبر الإنترنت } \\
\hline & & \multicolumn{2}{|c|}{ 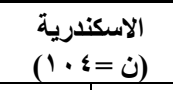 } & \multicolumn{2}{|c|}{$\begin{array}{c}\text { البحيرة } \\
(1 \cdot r=0 \\
\end{array}$} & \\
\hline & & $\%$ & ن & $\%$ & ن & \\
\hline دال & 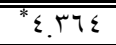 & $\sum r . r$ & $\varepsilon \varepsilon$ & 07.9 & 01 & التعرض لعروض وتخفيضات غير حقيقية \\
\hline غير دال & 1.rY & $\varepsilon r . r$ & $\varepsilon \varepsilon$ & $0 . \cdot$ & 01 & 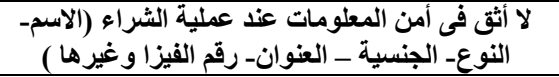 \\
\hline دال & *0.09r & $1 \leqslant . \varepsilon$ & 10 & rV.O & ru & أخذوا منى مبالغ مالية أكبر من قيمة السلعة أو السعر \\
\hline غير دال &. $\mathrm{VIY}$ & 0.1 & 7 & $\wedge . \wedge$ & 9 & تعرضت لاختراق بطاقتى الانتمانية وسحب أموال منها \\
\hline 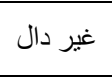 &. .174 & $\varepsilon 1 . r$ & $\leqslant \pi$ & «.1 & «o & بطء شبكة الانترنت وصعوبة التنقل عبر المواقع \\
\hline دال & ${ }^{* *} \vee .910$ & rI.r & rT & r9.r & $\varepsilon$. & عدم وصول السلعة المطلوبة في الموعد المحدد \\
\hline دال & ${ }^{*} 7.117$ & $1 . .7$ & 11 & rT.O & $T \xi$ & تعرضت للسرقة والنصب عن طريق مواقع وهمية \\
\hline غير دال & r.TVI & rv. o & rq & $0 \cdot . \cdot$ & 01 & عدم السماح بمعاينة المنتج قبل دفع المال \\
\hline غير دال & $\cdot .11$ & 01.9 & $0 \varepsilon$ & $\varepsilon \Lambda_{.}$. & $\leq 9$ & السلعة تكون غير مطابقة للمواصفات المعروضة \\
\hline & & & & & & 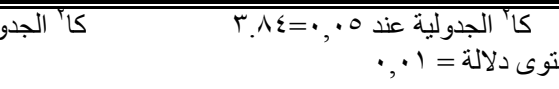 \\
\hline
\end{tabular}

تظهر النتائج الواردة بجدول ( 20 ) وجود فروق ذات دلالة إحصائية بين الأسر بمحافظتى البحيرة والإسكندرية فى بعض مشكلات النسوق عبر الإنترنت تبعاً لمكان السكن

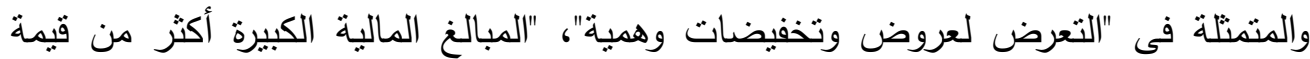


السلعة أوالسعر المعروض"، " التعرض للسرقة والنصب عن طريق مواقع وهمية"، حيث كانت

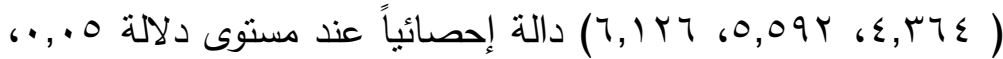
قيم "كاب"

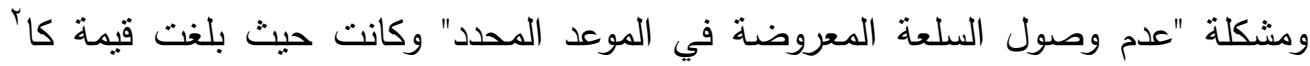

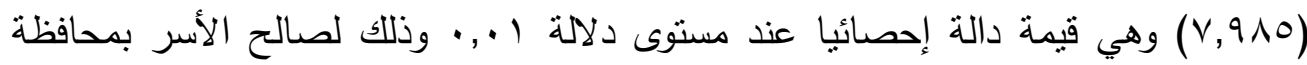

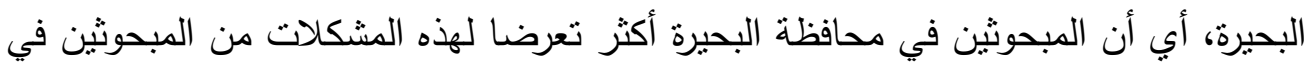
محافظة الإسكندرية، بينما لم توجد فروق دالة إحصائيا بين العينتين فى باقى المشكلات وفقاً لمكان السكن. ويمكن تفسير هذه النتيجة بملاحظة نوعية المشكلات النى تواجه المبحوثين بمحافظة البحيرة والتى قد ترجع إلى طبيعة مكان سكنه فالتعرض لعروض وتخفيضات وهمية أو دفع مبالغ مالية أعلى من قيمة السلعة قد يرجع إلى عدم معرفتهم للسعر الحقيقي للسلعة، وقد يرجع ذلك إلى قلة عدد المحلات والمراكز التجارية الكبيرة والتى تتوفر بها تللك السلع

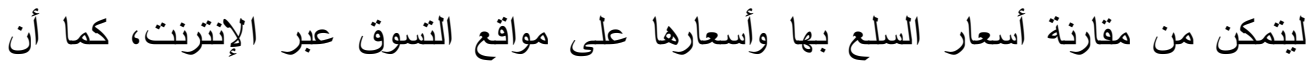
مشكلة عدم وصول السلعة المطلوبة فى الموعد المحدد قد برجع أيضا إلي طبيعة مكان مهان السكن فعملية الثحن والتوصيل للمدن الكبرى منل الإسكندرية أسهل بكثير من الثحن والتوصيل لمحافظة مثل محافظة البحيرة التى تتميز بكبر مساحتها وتعدد مدنها ومراكزها. وبذلك نجد أن الفرض الثانى قد تحقق جزئياً. النتائج فى ضوء الفرض الثالث:

نص الفرض على أنه " توجد فروق دالة إحصائياً بين الأسر عينة البحث بمحافظتى فئى فئل

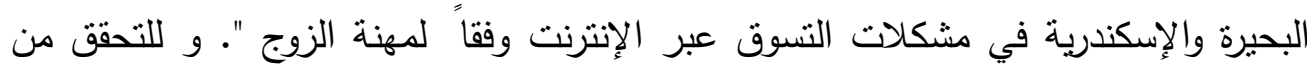
صحة الفرض نم استخدام اختبار مربع كاي "كا؟ّ". 
عدد خاص من مجلة "بحوث في العلوم والقنون النوعيه" التوبه العدد الحادي عشر / المجلد الثاني يونيه 9 /

جدول (21) قيم "كاץ " لبيان دلالة الفروق بين مشكلات التسوق عبر الإنترنت لاي المبحوثين وفقا

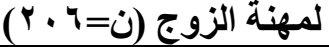

\begin{tabular}{|c|c|c|c|c|c|c|c|c|c|c|c|c|c|c|}
\hline \multirow{3}{*}{ 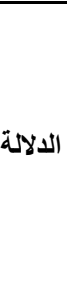 } & \multirow{3}{*}{ كاץ } & \multicolumn{12}{|c|}{ مهنة الزوج } & \multirow{3}{*}{ مشكلات التسوق عبر الإنترنت } \\
\hline & & \multicolumn{2}{|c|}{$\begin{array}{l}\text { متوفى }) \\
(Y=0\end{array}$} & \multicolumn{2}{|c|}{ 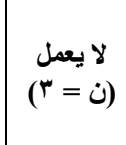 } & \multicolumn{2}{|c|}{$\begin{array}{c}\text { منقاعد } \\
(0=0)\end{array}$} & \multicolumn{2}{|c|}{ 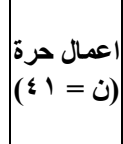 } & \multicolumn{2}{|c|}{$\mid \begin{array}{c}\text { قطاص } \\
\text { خاص } \\
\text { (ن })\end{array}$} & \multicolumn{2}{|c|}{ وكوميفه } & \\
\hline & & $\%$ & ن & $\%$ & ن & $\%$ & $\dot{~ ن}$ & $\%$ & $\dot{~ ن}$ & $\%$ & $\dot{0}$ & $\%$ & ن & \\
\hline غير & 7.vro & $\cdots \cdot$ & $r$ & 79.8 & r & $\wedge \cdot . \cdot$ & $\varepsilon$ & 07.1 & $r r$ & $\varepsilon \cdot . \varepsilon$ & $r_{1}$ & $\leqslant \wedge .0$ & 0. & التعرض لعروض وتخفيضات غير \\
\hline غير & $1 \cdot .9 \leq 9$ & $\cdots \cdot$ & $r$ & $\because \cdot$ & - & $\varepsilon \cdot$. & r & $\leqslant 7 . \%$ & 19 & rr.v| & iv & or.s & 00 & 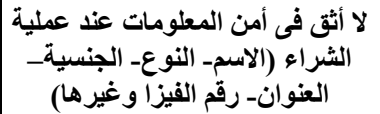 \\
\hline 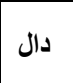 & $* 11.74$ & $\bullet \cdot$. & 1 & (r.r & 1 & $\because \cdot$ & - & r. & 10 & 11.0 & 7 & $19 . \varepsilon$ & $r$. & 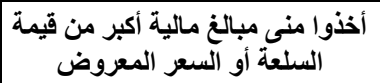 \\
\hline 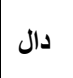 & *Ir.va & $\bullet \cdot . \cdot$ & 1 & ( & 1 & $\because \cdot$ & - & $v . r$ & $r$ & $\because \cdot$ & - & $9 . \vee$ & 1. & تعرضت لاختراق بطاقتى الائتمانية \\
\hline غال & $1.9 \mathrm{~V} \cdot$ & $\bullet \cdot . \cdot$ & 1 & rr.r & 1 & $r \cdot . \cdot$ & 1 & $\leq ५ . \%$ & 19 & $r \wedge .0$ & $r \cdot$ & $\leqslant \varepsilon . V$ & $\leqslant 7$ & بطء شبكة الانترنت وصعوبة التنقل \\
\hline غال & ^ ז. & $\cdots \cdot$ & $r$ & $\because \cdot$ & • & $r \cdot . \cdot$ & 1 & r $1 . v$ & $1 T$ & $r \wedge . \wedge$ & 10 & $r \cdot .1$ & I & عدم وصول السلعة المطلوبة فى المحد \\
\hline 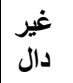 & $9.19 \mathrm{~V}$ & ๑... & 1 & r.r & 1 & $7 .$. & $r$ & $1 v .1$ & V & 10.5 & $\Lambda$ & $1<.7$ & 10 & تعرضت للسرقة والنصب عن طريق \\
\hline 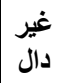 & $\Lambda .90 r$ & $0 . . \cdot$ & 1 & $1 \cdots$ & $r$ & $7 .$. & $r$ & $01 . Y$ & ri & $r \cdot . \wedge \mid$ & 17 & $\leqslant \leqslant . V$ & $\leqslant 7$ & عدم السماح بمعاينة المنتج قبل دفع \\
\hline دال & * & $\cdots \cdot$ & $r$ & $\because \cdot$ & • & $1 \cdots \cdot$ & 0 & $\leq r .9$ & 11 & $\leqslant Y . r$ & $r r$ & $0 \leqslant . \leqslant$ & 07 & السلعة تكون غير مطابةة للمواصفات \\
\hline
\end{tabular}

يتضح من جدول (21) عدم وجود فروق ذات دلالة إحصائية بين المبحوثين بمحافظتى دله البحيرة والإسكندرية في بعض مشكلات التسوق عبر الإنترنت وفقا لمهنة الزوج فيما عدا مشكلات "أخذ مبالغ مالية أكبر من قيمة السلعة أوالسعر المعروض"، "التعرض لإختراق

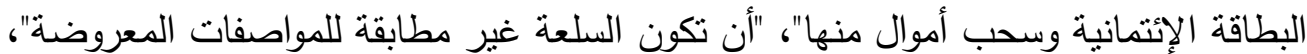

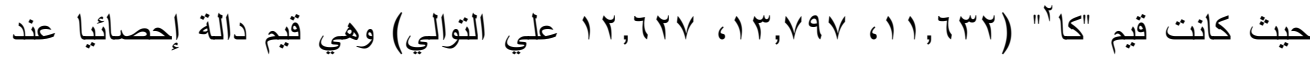


مستوى دلالة ه.,.،، لصالح الوظيفة الحكومية. و قد يرجع السبب في ذلك إلى أن نصف عينة

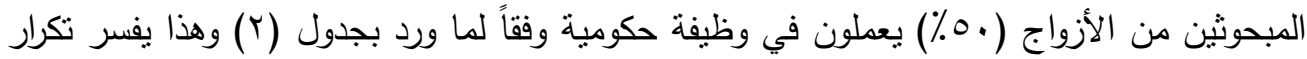
حدوث المشكلات وذللك لأنهم يشكلون النسبة الأكبر بين المبحوثين. وفقاً لما سبق يمكن القول أن الفرض الثالث تحقق جزئياً.

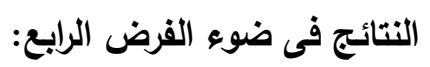
نص الفرض على أنه " توجد فروف دالة إحصائياً بين الأسر عينة البحث بمحافظتى البحيرة

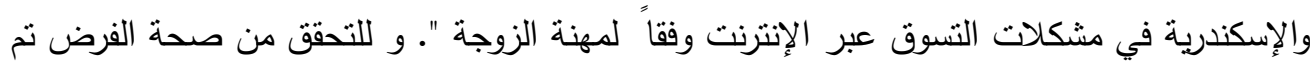

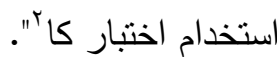

جدول(Y Y) قيم"كاب" لبيان دلالة الفروق بين الأسر مشكلات التسوق عبرالإنترنت لاي المبحوثين وفقا

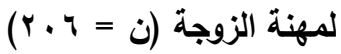

\begin{tabular}{|c|c|c|c|c|c|c|c|c|c|c|}
\hline \multirow{3}{*}{ 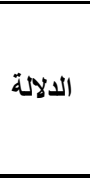 } & \multirow{3}{*}{ كاr } & \multicolumn{8}{|c|}{ مهنه الزوجة } & \multirow{3}{*}{ مشكلات التسوق عبر الإتترنت } \\
\hline & & \multicolumn{2}{|c|}{$\begin{array}{l}\text { لا يعمل } \\
(q Y=0)\end{array}$} & \multicolumn{2}{|c|}{ اعمال حرة } & \multicolumn{2}{|c|}{ 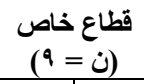 } & \multicolumn{2}{|c|}{ وظيفه حكوميه } & \\
\hline & & $\%$ & ن & $\%$ & ن & $\%$ & ن & $\%$ & ن & \\
\hline غير دال & T.Y. & $\varepsilon 7 . V$ & $\leqslant r$ & N!.1 & 9 & $77 . \%$ & 7 & $\sum 7 . \wedge$ & $\varepsilon \varepsilon$ & التعرض لعروض وتخفيضات غير حقيقية \\
\hline 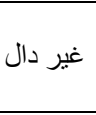 & r.V70 & $\varepsilon r . \varepsilon$ & rq & 7.9 & $\mathrm{v}$ & r ז. & r & $\leqslant \wedge .9$ & $\leqslant 7$ & 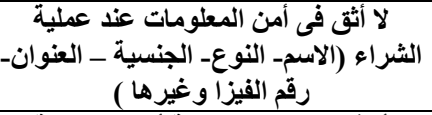 \\
\hline 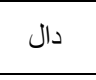 & *q. $r \wedge$ & rI. $\mathrm{V}$ & r. & $\varepsilon 0.0$ & - & $\varepsilon \varepsilon . \varepsilon$ & $\varepsilon$ & $1 \leqslant .9$ & $-1 \varepsilon$ & أخذوا منسي مبالغ مالية أكبر من قيمة المعروض المعرو \\
\hline 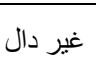 & r.r.t. & 7,0 & 7 & १. 1 & 1 & r.,, T & r & $7 . \varepsilon$ & 7 & تعرضت لاختراق بطاقتى الانتمانية وسحب \\
\hline غير دال & $\sum . V Y Y$ & $\leq \vee . \wedge$ & $\varepsilon \varepsilon$ & $11 . r$ & r & 00.7 & 0 & r9.气 & TV & بطء شبكة الاتترنت وصعوبة التبتل عبرونية \\
\hline 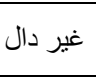 & $7 . \leqslant 91$ & r.. & $r \varepsilon$ & $r v . r$ & r & $7 . \mathrm{Y}$ & 1 & $r \cdot .9$ & rq & عدم وصول السلعة المطلوبة فى الموعد \\
\hline 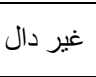 & r.人זr & 11.0 & IV & $r v . T$ & r & rז. & r & Ir.A & ir & تعرضت للسرقة و والنصبة عن طريق مواقع \\
\hline غير دال & $r . \wedge \wedge \varepsilon$ & $r 9.1$ & $r$ & $\leqslant 0.0$ & 0 & $77 . \mathrm{V}$ & 7 & $\leqslant 0 . Y$ & $\varepsilon r$ & عدم السماح بمعاينة المنتج قبل دفع المال \\
\hline 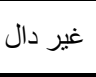 & $\cdot, 9 \vee 7$ & $\leq 7, V$ & $\varepsilon r$ & $\{0,0$ & - & 00.7 & 0 & trat & ○. & السلعة تكون غير مطابقة للمواصفات \\
\hline
\end{tabular}

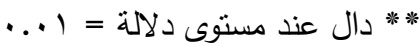

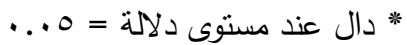

يتبين من جدول (Yr) عدم وجود فروق دالة إحصائية بين الأسر بمحافظتى البحيرة والإسكندرية

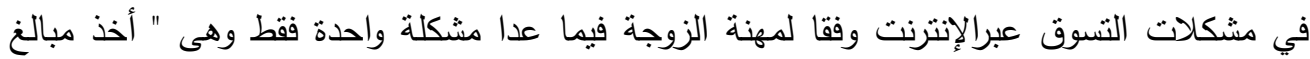




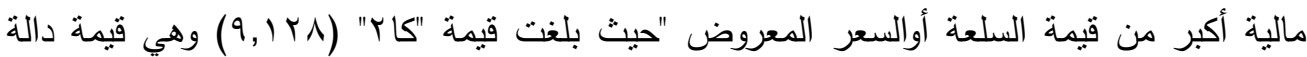
احصائياً عند مستوى دلالة ه. . . لصالح الزوجة التي "لا تعمل". وقد يرجع السبب في ذلك إلى أن المرأة غير العاملة قد تفتقر للخبرات والفرص المعرفية التى تتعرض لها المرأة العاملة وبالتالى قد تكون أكثر عرضة لمشكلات التسوق عبر الإنترنت مقارنة بالزوجة العاملة. وبالتالى يمكن رفض الفرض الرابع.

\section{النتائج فى ضوء الفرض الخامس:}

نص الفرض على أنه " توجد علاقة ارتباطية دالة إحصائياً بين بعض المتغيرات الإجتماعية والإقتصادية (عمرالزوج والزوجة- المستوى التعليمى للزوج والزوجة- مدة الزواج- عدد أفراد الأسرة- الاخل الشهرى للأسرة) ومميزات وعيوب التسوق عبر الإنترنت من وجهة نظر الأسر عينة البحث". وللتحقق من صحة الفرض تم استخدام معامل ارتباط سبيرمان. جدول (Yr): قيم معامل ارتباط سبيرمان لتحديد العلاقة الإرتباطية بين بعض المتغيرات الإجتماعية والإقتصادية ومميزات وعيوب التسوق عبر الإنترنت (ن = ج إ)

\begin{tabular}{|c|c|c|}
\hline \multicolumn{2}{|c|}{ اجمالي مميزات وعيوب التسوق عبر } & \multirow[t]{2}{*}{ بعض المتغير ات الإجتماعية و الإقتصادية } \\
\hline الدلالة & معامل الارتباط (rs) & \\
\hline غير دال & .1 & عمر الزوج \\
\hline غير دال & $\because 0$ & عمر الزوجة \\
\hline 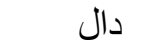 & **. YIA & المستوى التعليمى للزوج \\
\hline دال & ** ror & المستوى التعليمى للزوجة \\
\hline غير دال & $.94-$ & مدة الزواج بالأعوام \\
\hline غير دال &..$\vee V 7$ & عدد أفراد الأسرة \\
\hline 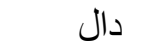 & **. & الدخل الشهرى للأسرة \\
\hline
\end{tabular}

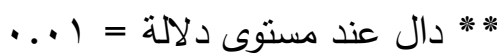

سبيرمان معامل الارتباط rs

يتضح من جدول (Tr) وجود علاقة إرتباطية طردية ذات دلالة إحصائية بين المستوى التعليمي للزوج وإجمالى الدرجة الدالة على مميزات وعيوب التسوق عبر الإنترنت،

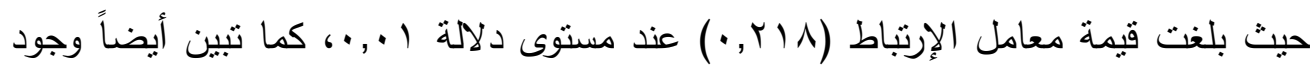


علاقة إرتباطية طردية ذات دلالة إحصائية بين المستوى التعليمي للزوجة وإجمالى الدرجة

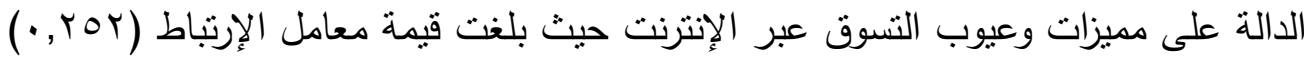
عند مستوى دلالة ا.,.•، أي أنه كلما إرتفع المستوى التعليمي لكل من الزوج والزوجة كلما

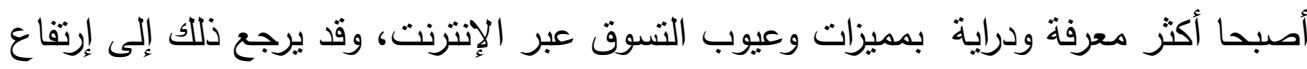
مستوى ثقافتهما وسعة إطلاعهما وادراكهما للمستجدات الإلكترونية الحديثة. وتتفق هذه النتيجة

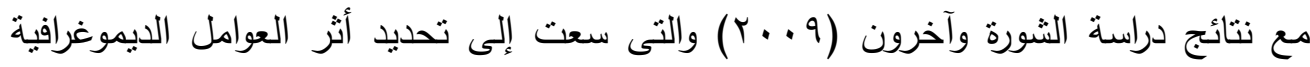
والمعوقات والمحفزات على إستخدام الإنترنت للتسوق، حيث أوضحت نتائجها وجود علاقة إرتباطية دالة إحصائياً بين متغير التعليم واستخدام المستهلك الأردني للإنترنت كوسيلة تسوق،

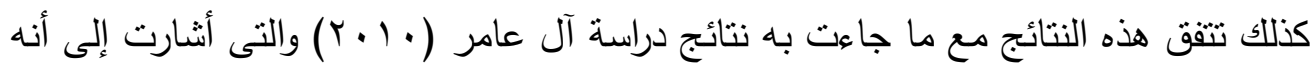
كلما إرتفع المستوى التعليمى كان هناك توجه إيجابى نحو إستخدام التسوق الإلكترونى، كما

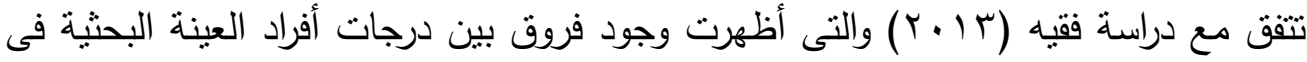

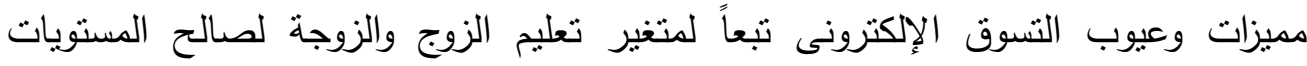

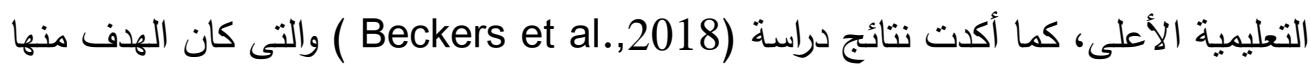
ثقييم أثر المنطقة الجغرافية والخصائص الإجتماعية والإقتصادية على التسوق عبر الإنترنت

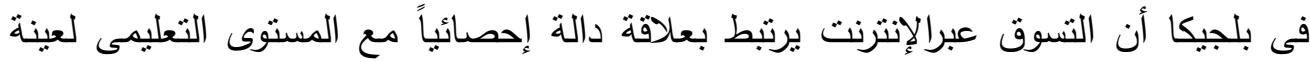
البحث التى انتنملت على ل . 10 بلجيكى. كما يتضح من جدول(Yr) وجود علاقة إرتباطية ذات دلالة احصائية بين الاخل الشهرى للأسرة وإجمالى الدرجة الدالة علي مميزات وعيوب التسوق الإلكتروني، حيث كانت

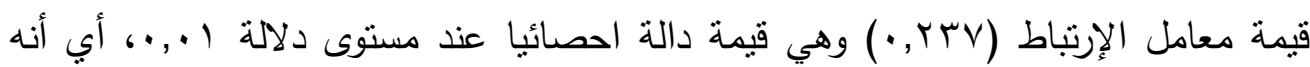

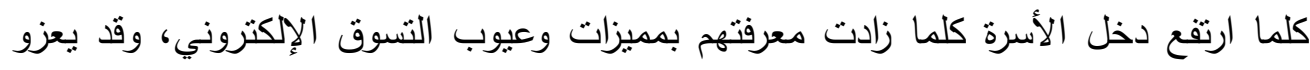
السبب في ذللك إلى أن إرتفاع مستوى الدخل الثهرى يتيح للفرد إمتالك الحديث من الأجهزة

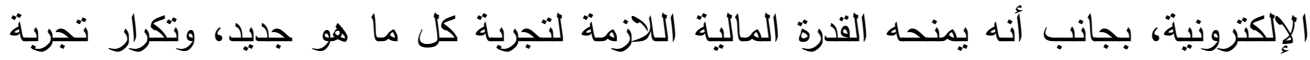
التسوق عبر الإنترنت لتوفر القدرة على تحمل تكاليف الإثتراك بخدمة الانترنت وتكاليف 
الحصول على السلع عبر الإنترنت مثل مصروفات الثحن والتوصيل وغيرها ويترتب على تكرار تلك التجربة إكتشاف المزيد من مميزات وعيوب التسوق عبر الإنترنت، كما أن أصحاب الدخل المرتفع كثيرا ما يسعون إلى التفرد والتميز خاصة فى إقتاء السلع وهذا ما يوفره لهم

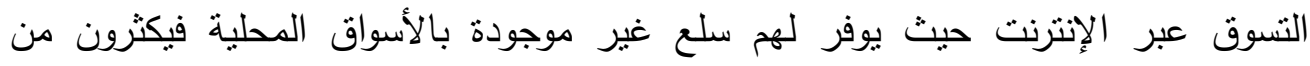

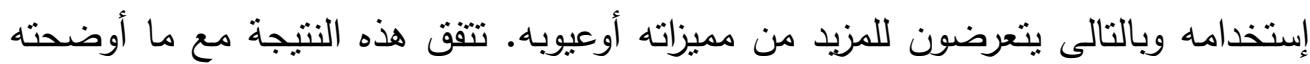

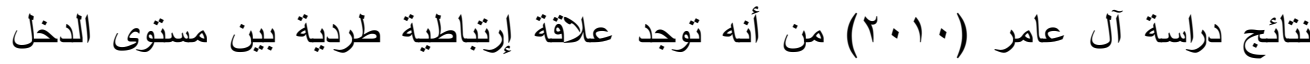

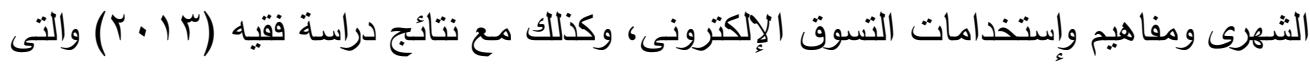

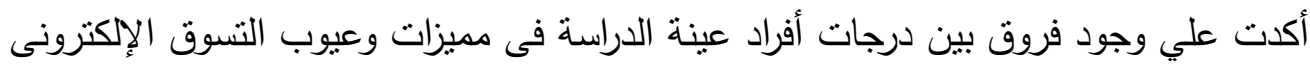

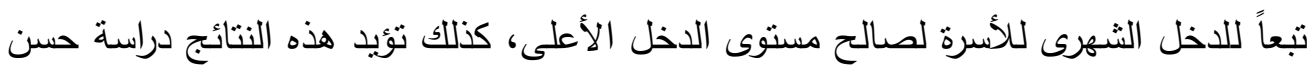

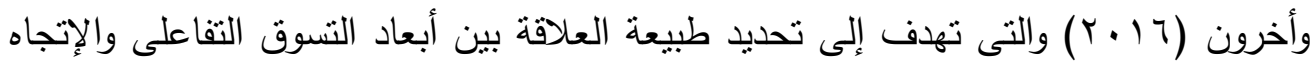
نحو التسوق الإلكترونى، حيث أظهرت نتائجها وجود فروق معنوية بين عملاء التسوق الإكترونى وفقاً للاخل الثهرى للأسرة حيث يزداد إدراكهم للتسوق الإلكترونى بإرتفاع الدخل الثهرى للأسرة، كما تدعم هذه النتيجه ما نوصلت إليه دراسة (Beckers et al.,2018 ) من أن متغير الدخل يرتبط بالتسوق عبر الإنترنت. بينما تختلف هذه النتائج مع نتائج دراسة (Clemes et al.,2014) والتى طبقت على عينة قوامها هبء مبر من المشترين الصنيين ببكين بهدف دراسة العوامل المؤثرة على سلوكهم الثرائى عبر الإنترنت، وقد بينت

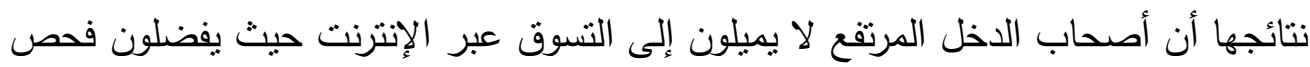

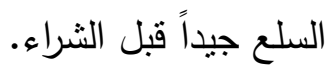

كما يتبين من جدول (Yr) عدم وجود علاقة ذات دلالة إحصائية بين كل من (عمر الزوج والزوجة ، مدة الزواج بالأعوام، و عدد أفراد الأسرة) و إجمالي الدرجة الدالة على دلى إلى

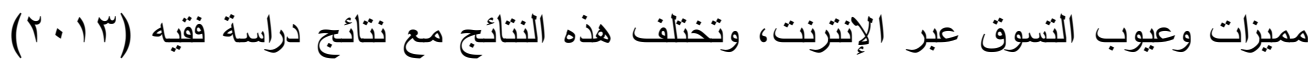

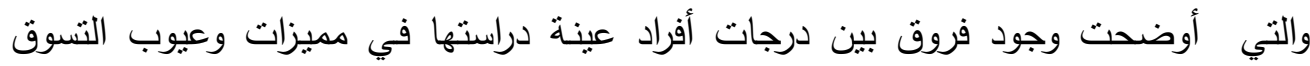


الالكتروني تبعا لمتغيرات (عمر الزوج، عمر الزوجة، وعدد أفراد الأسرة) بينما أوضحت عدم

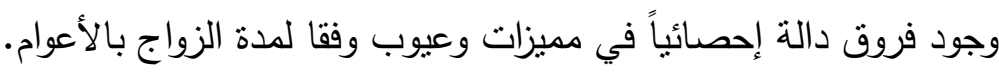

ومما سبق يمكننا القول أنه توجد علاقة إرتباطية موجبة دالة إحصائياً بين كل من فن

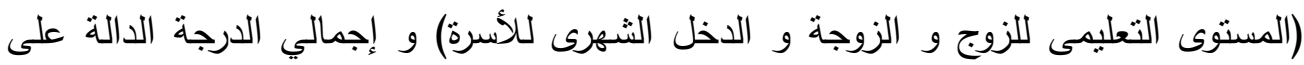
مميزات وعيوب التسوق عبر الإنترنت عند مستوى دلالة ا....، بينما لا توجد علاقة إرتباطبة

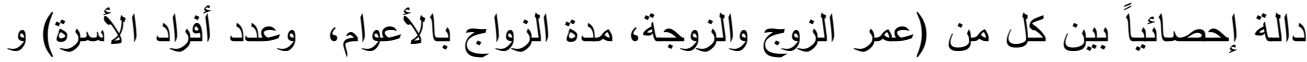

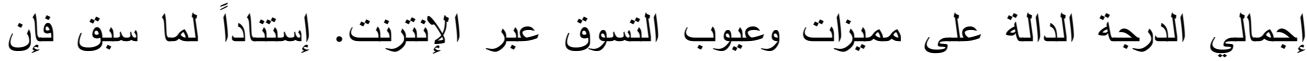
الفرض الخامس قد تحقق جزئياً. النتائج في ضوء الفرض السادس: نص الفرض على أنه "توجد فروق دالة إحصائياً بين الأسر عينة البحث بمحافظتى فئى

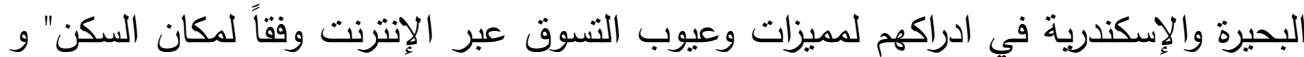
للتحقق من صحة الفرض تم استخدام اختبار "ت". جدول ( § Y): قيم "ت" لبيان دلالة الفروق بين مميزات وعيوب التسوق عبر الإنترنت وفقا

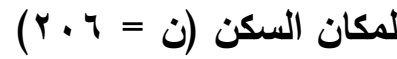

\begin{tabular}{|c|c|c|c|c|}
\hline \multirow{2}{*}{ 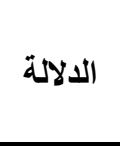 } & \multirow{2}{*}{ ت ت الجدوليه } & \multicolumn{2}{|c|}{ مكان السكن } & \multirow{2}{*}{ مميزات وعيوب التسوق عبر الإتترنت } \\
\hline & & الإسكندرية(ن = \& ـ 1) & البحيرة(ن = r · l ) & \\
\hline غير دال & $1 . \leqslant r q$ & $0 . r \pm 00 . r r$ & $0 . r \leqslant \pm 0 \leqslant . q_{q}$ & المتوسطد الانحراف المعياري \\
\hline
\end{tabular}

يتضح من الجدول (عا) عدم وجود فروق بين المبحوثين من محافظة البحيرة و محافظة الإسكندرية في إدراكهم لمميزات وعيوب التسوق عبر الإنترنت وفقاً لمكان السكن،

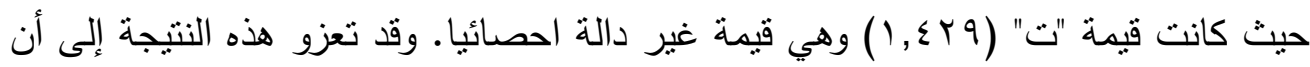
الإنترنت أصبح منتشراً فى كل المناطق فى مصر سواء الحضرية أوالريفية وأصبح استخدامه وهيه متاحاً للجميع بسهولة ويسر، كما أن تقارب خصائص العينة البحثية من حيث المستوى ستر 
التعليمى والدخل الثهرى (وفقا لجدول(() وجدول(0)) و نثابه أفراد العينة البحثية فى عدد مرات القيام بالثراء عير الإنترنت (وفقا لجدول (V)) والمواقع التى يدخلون عليها (كما ورد بجدول Y Y) كل ذللك يجعل الخبرات التى يتعرضون لها خلال الثراء عبر الإنترنت منقاربة نوعاً ما وبالتالى إدراكهم للمميزات والعيوب يكون متقارب وبالتالى لا يكون لمكان السكن أهمية فى التأثير على معرفتهم بالمميزات والعيوب للشراء عبر الإنترنت. وتتقق هذه النتيجة ما جاءت به نتائج دراسة النونو (Y. . . حيث بينت نتائجها عدم وجود فروق معنوية بين المتنبين وغير المتبنيين للتسوق عبر الإنترنت بإختلاف مكان السكن، فى المقابل إختلفت

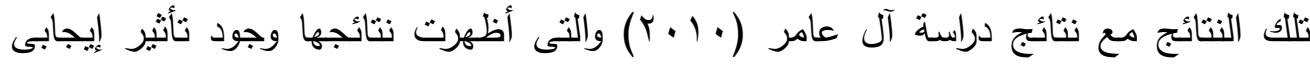

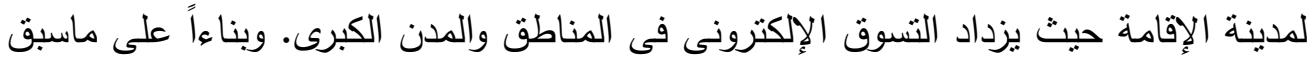
لم بتحقق الفرض السادس. النتائج في ضوء الفرض السابع: نص الفرض على أنه " توجد فروق دالة إحصائياً بين الأسر عينة البحث بمحافظتى البحيرة والإسكندرية في ادراكهم لمميزات وعيوب التسوق عبر الإنترنت وفقاً لمهنة الزوج".

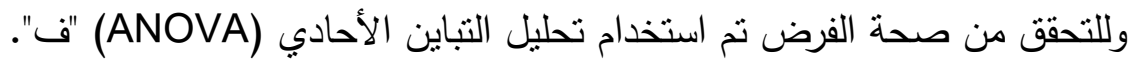
جدول (†): قيم "ف" لبيان الفروق بين مميزات وعيوب التسوق عبر الإنترنت وفقا لمهنة

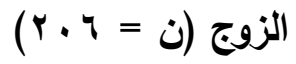

\begin{tabular}{|c|c|c|c|c|c|c|c|c|}
\hline \multirow[b]{2}{*}{ الدلاثل| } & \multirow[b]{2}{*}{ ف } & \multicolumn{6}{|c|}{ مهنة الزوج } & \multirow{2}{*}{ |لتسوق عميزب } \\
\hline & & $\begin{array}{l}\text { متوفى } \\
(Y=0)\end{array}$ & 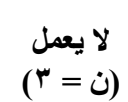 & 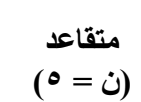 & 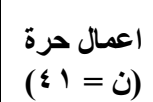 & 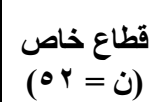 & (نيفه حكوميه & \\
\hline غال & & $\pm \leqslant 9.0$. & T.71 \pm 0 & $r . r 1 \pm 0$ & $\leqslant 99 \pm 00$. & $0.7 \wedge \pm 0 \leqslant .9$ & $0.1 \leq \pm 00$ & الانحتوسط اف المعياري \\
\hline
\end{tabular}

يتضح من جدول (Y0) عدم وجود فروق ذات دلالة احصائية في إدراكهم لمميزات وعيوب التسوق عبر الإنترنت وفقا لمهنة الزوج حيث كانت قيم "ف" (7 ....1) وهي قيمة 
غير دالة احصائيا. وقد يرجع ذلك إلى أن النسبة الأكبر من الأزواج عينة البحث يعملون

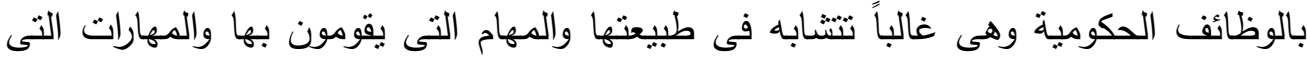
تحتاجها، وبالتالى تقل الإختلافات بين المبحوثين التى يمكن إرجاعها لطييعة المهنة. ويتفق

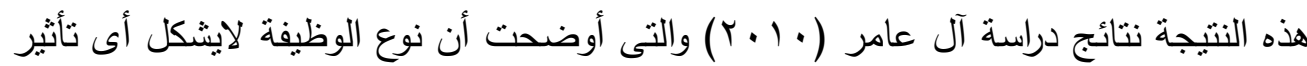

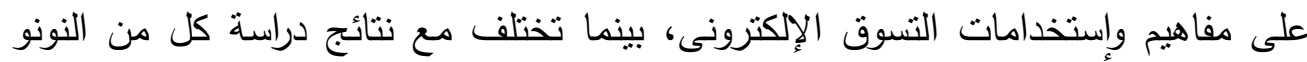

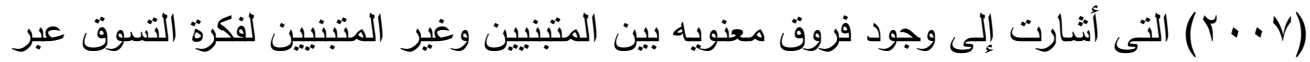

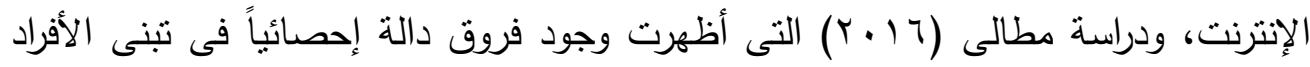
للتسوق عبر الإنترنت تعود إلى متغير الوظيفة. وبذلك لم يتحقق الفرض السابع. النتائج في ضوء الفرض الثامن: نص الفرض على أنه " نوجد فروق دالة إحصائياً بين الأسر بمحافظتى البحيرة والإسكندرية

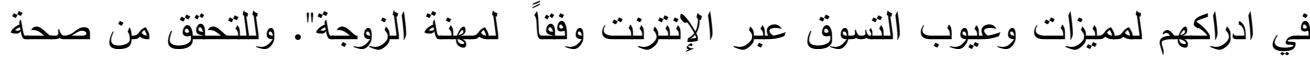

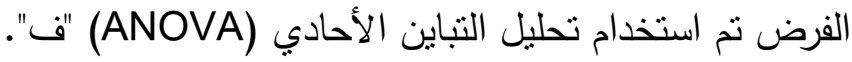
جدول(Y Y): قيم "ف" لبيان الفروق في مميزات وعيوب التسوق عبر الإنترنت وفقا لمهنة

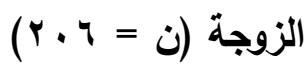

\begin{tabular}{|c|c|c|c|c|c|c|}
\hline \multirow[b]{2}{*}{ الدلالة } & \multirow[b]{2}{*}{ ف } & \multicolumn{4}{|c|}{ مهنة الزوجة } & \multirow[b]{2}{*}{ مميزات و عيوب التسوق } \\
\hline & & 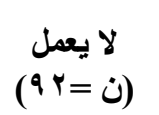 & 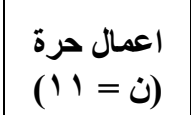 & 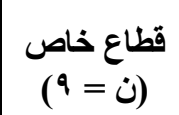 & وظيفه حكوميه & \\
\hline دال & & $, r \leqslant \pm \circ r, \wedge \varepsilon$ & $\varepsilon, \wedge v_{ \pm} \circ \vee, \cdot q$ & $r, \wedge ! \pm$ Or. & $0, \cdot v_{ \pm} 00, v N$ & المتوسطد الانحر اف \\
\hline
\end{tabular}

$$
\text { * دال عند مستوى دلالة = •. }
$$

يتضح من جدول (Tr) وجود فروق ذات دلالة إحصائية في إدراك العينة البحثية لمميزات

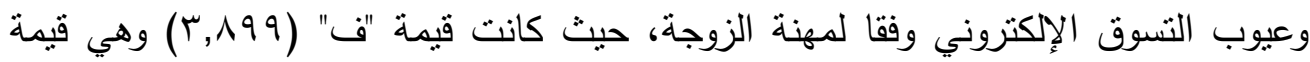


عدد خاص من مجلة "بحوث في العلوم والقنون النوعيه" المجيه

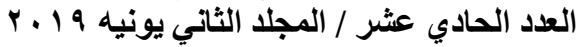

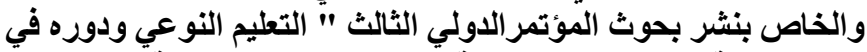

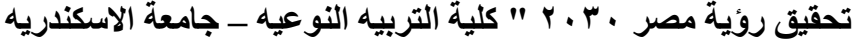

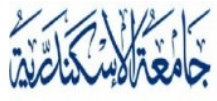

دالة إحصائيا عند مستوى دلالة ه.,.،، ولمعرفة إتجاه الدلالة تم تطبيق إختبار توكي للمقارنات المتعددة والجدول التالي يوضح ذللك:

جدول (†ץ) اختبار توكي للمقارنات المتعدة لمهنة الزوجة

\begin{tabular}{|c|c|c|c|c|}
\hline \multicolumn{4}{|c|}{ Tukey HSD } & \multirow{2}{*}{ مهنة الزوجة } \\
\hline لا يعمل & اعمال حرة & قطاع خاص & وظيفه حكوميه & \\
\hline & غير دال & غير دال & غير دال & قظيفه حكوميه \\
\hline
\end{tabular}

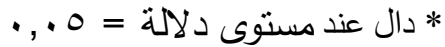

يتضح من جدول (†ץ+) وجود فروق في إدراك العينة البحثبة لمميزات وعيوب التسوق

الإلكتروني بين الزوجات في الوظائف المختلفة حيث كانت الفروق دالة لصالح الزوجات في الوظيفة الحكومية عند مستوى دلالة ه ., •. . وقد برجع السبب في ذلك لخصائص عينة البحث

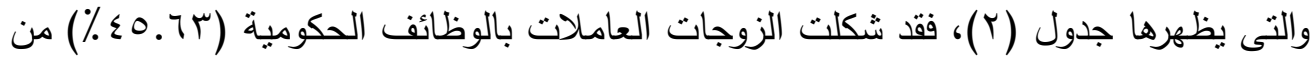

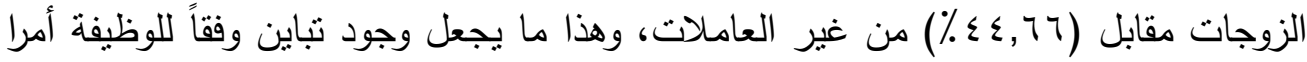
منطقياً خاصة حيث أن نزول المرأة للعمل يثقل معارفها ويزيد من خبراتها فى الحياة وتطلعها الدائم لنطوير نفسها كما يتيح لها التواصل مع زملاء العمل والإستفادة من خبراتهم ومعلوماتهم، وتكون أكثر تقبلاً لكل ماهو حديث ورغبة في الإستفادة منه فى حياتها اليومية.

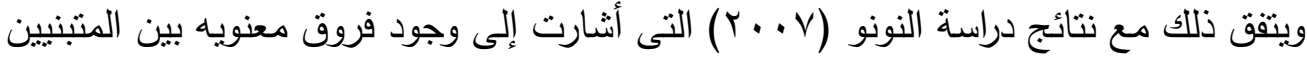

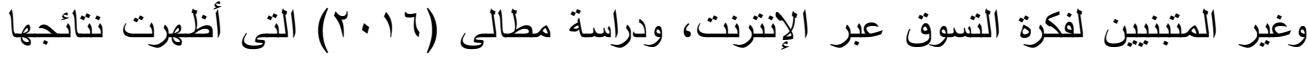
وجود فروق دالة إحصائيا فى تبنى الأفراد للتسوق عبر الإنترنت تعود إلى متغير الوظيفة. ويتضح من النتائج السابقة ثبوت صحة الفرض الثامن • بناءاً على ما سبق فإنه يمكن تلخيص النتائج التى توصل إليها البحث فى النقاط التالية: 


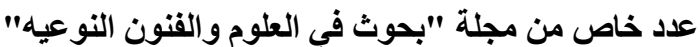

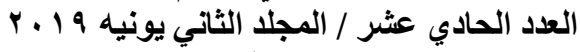

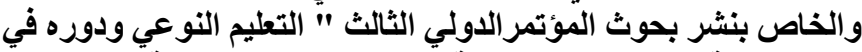

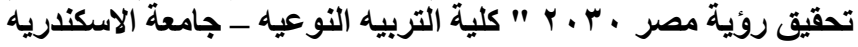

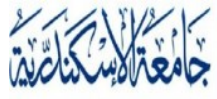

1- تبين أن (ع,rه\%) من المبحوثين بمحافظتى البحيرة والإسكندرية يقومون بالتسوق

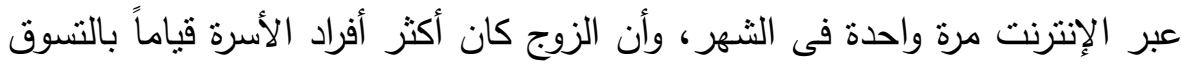

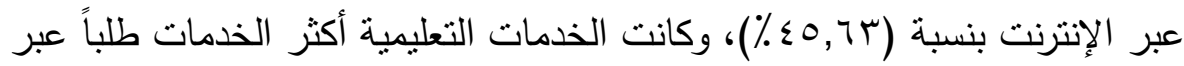

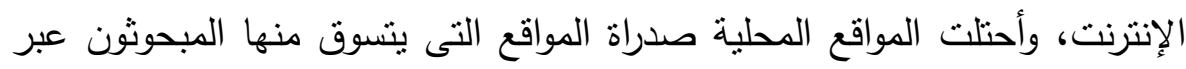
الإنترنت، كما شكلت الملابس أكثر السلع طلباً عبر الإنترنت بالنسبة، وكانت طريقة

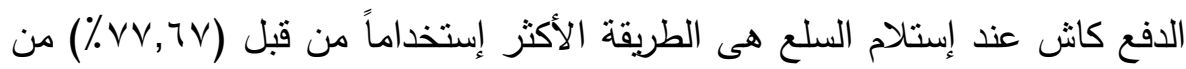

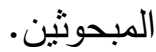

r- أظهرت نتائج البحث أن أكثر المشكلات التى تعرض لها المبحوثين كانت مشكلة بطء شبكة الإنترنت وصعوبة التقل بين مواقع التسوق عبر الإنترنت والتعرض للسرقة والنصب من مواقع وهمية، وعدم الثقة فى أمن المعلومات، وعدم السماح

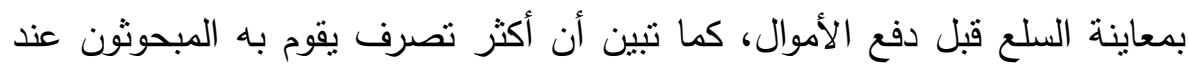
تعرضم لمشكلات عند التسوق عبر الإنترنت هو عدم التعامل مع الموقع مرة أخرى. r- أوضحت النتائج أن أهم مميزات التسوق عبر الإنترنت من وجهة نظر العينة البرت البحثية كانت (أن التسوق عبر الإنترنت يوفر الوقت والجهد، ويوفر التسوق عبر الإنترنت

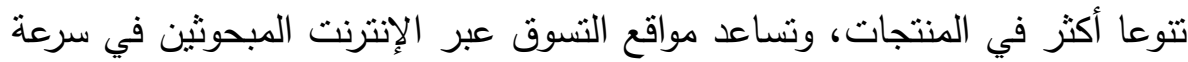
البحث عن المنتجات، ويتيح التسوق عبر الإنترنت فرصة الإختيار دون ضغط الإنط البائعين)، بينما تمنلت أكثر عيوب التسوق عبر الإنترنت فى أنه (يصعب معاينة

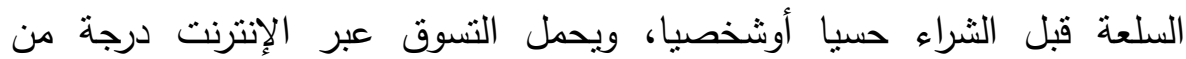
المخاطرة في عملية الثراء، وعدم ضمان المصداقية وصحة البيانات المعروضة عن

$$
\text { السلع، وعدم وجود قوانين تتظم عملية الثراء). }
$$

ع- تبين وجود علاقة ارتباطية قوية دالة إحصائياً بين (عمر الزوج والزوجة، مدة الزئة الزواج

$$
\text { بالأعوام) وبين مشكلات التسوق الإلكتروني. }
$$




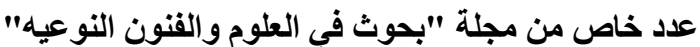

0- تبين وجود فروق ذات دلالة احصائية بين بعض مشكلات التسوق الإلكتروني منل" التعرض لعروض وتخفيضات وهمية"، "المبالغ المالية الكبيرة أكثر من قيمة السلعة أوالسعر المعروض"، "عدم وصول السلعة المعروضة في الموعد المحدد"، " التعرض فل للسرقة والنصب عن طريق مواقع وهمية وفقاً لمكان السكن لصالح المبحوثين

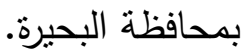

צ- تبين وجود فروق ذات دلالة إحصائية في بعض مشكلات التسوق الإكتروني "الببالغ المالية الكبيرة أكثر من قيمة السلعة والسعر المعروض"، "تعرضت لإختراق بطاقتي

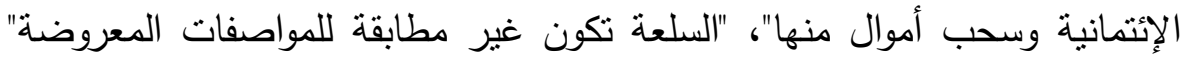

\section{وفقاً لمهنة الزوج لصالح الوظيفة الحكومية.}

V - اتضح عدم وجود فروق دالة إحصائياً بين الأسر بمحافظتى البحيرة والإسكندرية في

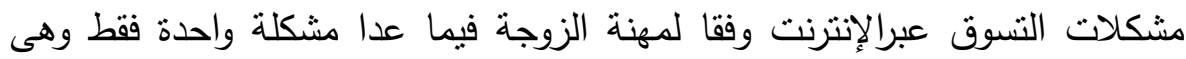

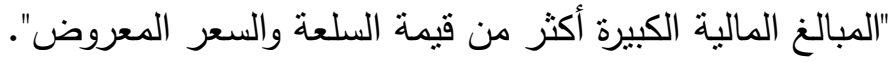
^- تنين وجود علاقة إرتباطية موجبة دالة إحصائياً بين كل من (المستوى التعليمى

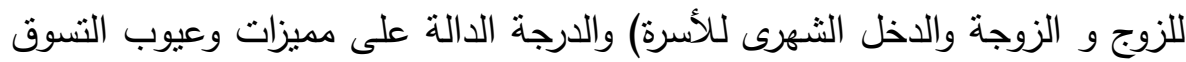
عبر الإنترنت عند مسنوى دلالة ا ....، بينما لا توجد علاقة إرتباطبة دالة إحصائياً

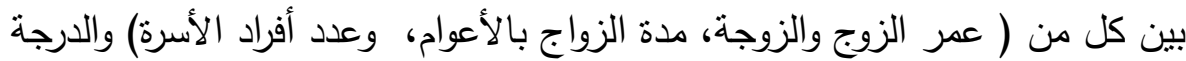
الدالة على مميزات وعيوب التسوق عبر الإنترنت. 9- تبين عدم وجود فروق بين المبحوثين من محافظة البحيرة ومحافظة الإسكندرية في مميزات وعيوب التسوق عبر الإنترنت وفقاً لمكان السكن ومهنة الزوج بينما توجد مند فروق دالة إحصائياً وفقاً لمهنة الزوجة لصالح الوظيفة الحكومية. 
عدد خاص من مجلة "بحوث في العلوم والقنون النوعيه"

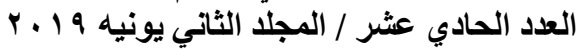

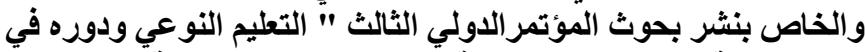

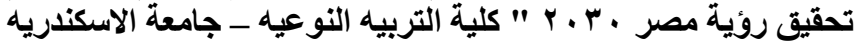

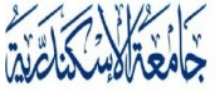

ALEXANDRIA

U N I V E R S I T Y

AlexUPress

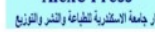

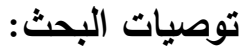

نظراً لان نتائج البحث الحالى قد أظهرت اتفاق غالبية العينة البحثية على مجموعة من

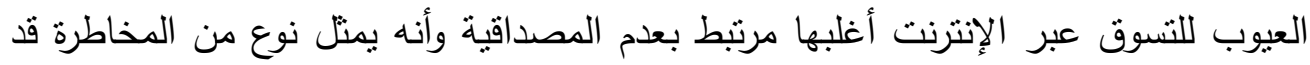

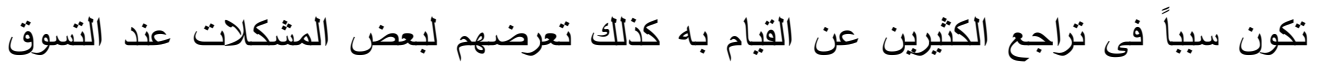
عبر الإنترنت لذا يمكن التوصية بالأتى : توصيات خاصة للأسرة :

1- التأكد من الموقع المراد الثراء منه قبل الثروع فى أى معاملة للشراء وعدم الإفصاح

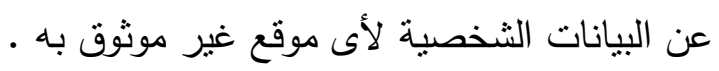

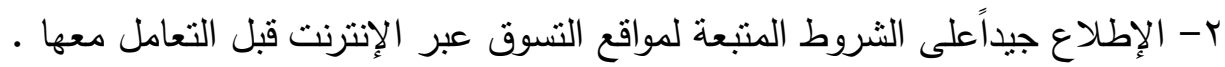
توصيات خاصة بمواقع التسوق عبر الإنترنت:

1- الإهتمام بتصميم الموقع بما يتيح سهولة الإستخدام مع الإهتمام بتوفير عدة لغات الإنرون مختلفة فى الموقع لتسهيل التعامل.

r-توفير خدمة ما بعد البيع مثل إمكانية إستبدال أوإسترجاع السلعة وكذللك الضمان

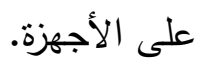
r- الحرص على إكتساب ثقة المشترى عن طريق تسليم السلع فى الموعد المحدد ووفقا للمواصفات التى نم الإتفاق عليها. ع - حماية خصوصية الموقع بكافة الطرق وخصوصية المتعاملين معه.

\section{توصيات عامة :}

1- يجب أن توفر وزارة التجارة والصناعة وجهاز حماية المستهلك كافة الضمانات

لحماية الأفراد من الغش التجارى أو النصب عبر مواقع التسوق الإكترونى. 
r- أن تكون للجامعات ووسائل الإعلام دوراً فى نشر نقافة التسوق عبر الإنترنت من خلال برامج التوعية والتى يعدها المتخصصون للعمل على نشر ثقافة التسوق عبر

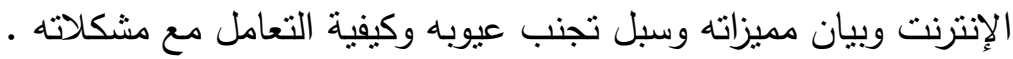
r- على الباحثين المتخصصين فى مجالات الإقتصاد المنزلى عامة وإدارة المنزل وإقتصاديات الأسرة خاصة الإهتمام بإجراء المزيد من الأبحاث التى تتناول التسوق الإنى عبر الإنترنت وأثزه على الأسرة ومواردها المختلفة. 


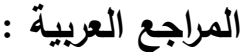

أبو المجد ، محمد جمال شحاته (0 . . ) ) ـ محددات الثراء عبر الإنترنت : دراسة تطبيقية

مقارنة لدوافع و إتجاهات و إدراكات و خصائص المشترين و غير المشترين من مواقع التسوق عبر الإنترنت ـ المجلة العلمية للإقتصاد و التجارة ، العدد الأول يناير

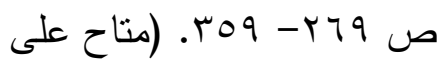

(https://search.mandumah.com/Record/111151

أبوجليل، محمد منصور ، هيكل ، إيهاب كمال ، عقل ، إبراهيم سعيد ، الطراونة ،خالد عطا

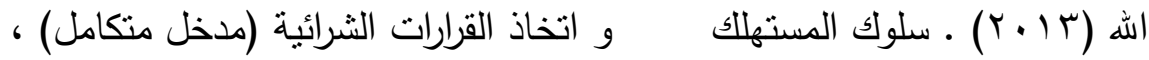
الطبعة الأولى ، عمان : دار الحامد للنشر والتوزيع ، الأردن.

آل عامر ، على بن سالم ( • • ( ) • إتجاهات مستخدمى شبكة الإنترنت فى المملكة العربية

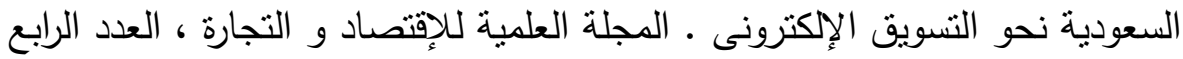

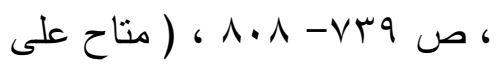

https://search.mandumah.com/Record/889926

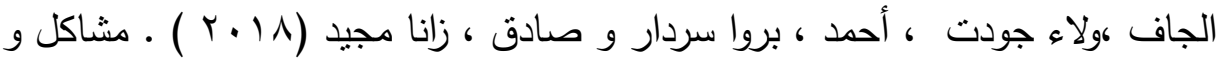

تحديات أستخدام التسوق الإكترونى - دراسة إستطلاعية لأراء عينة من الكوادر ، برد

التدريسية فى الجامعات الأهلية فى محافظة أربيل ـ مجلة جامعة جيهان - أربيل

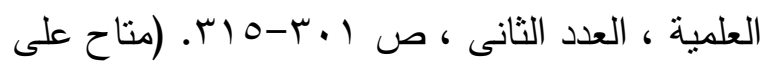

(http://cuesj.cihanuniversity.edu.iq

حسن ، عبد العزيز على ، عبد اللطيف ، محمد محمود و عبد العزيز ، الثيماء الاسوقى

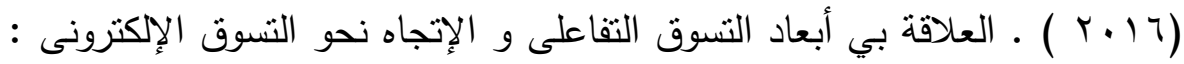
دراسة تطبيقية على عملاء التسوق الإلكترونى فى مصر . المجلة المصرية 
عدد خاص من مجلة "بحوث في العلوم والقنون النوعيه" التوديه

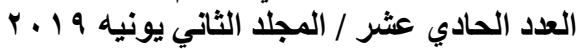

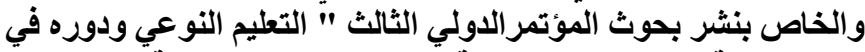

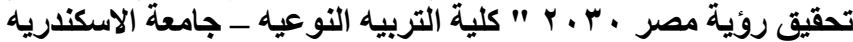

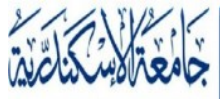

ALEXANDRIA

U N I VER S I T Y

AlexU Press

(ئ日)

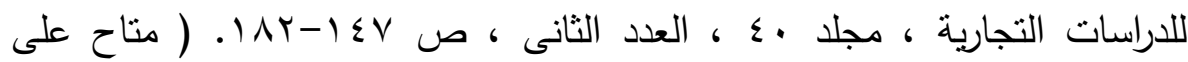
https://search.mandumah.com/Record/775646

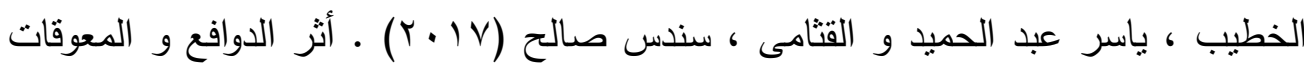
على تسوق الأفراد عبر الإنترنت فى محافظة جدة ـ المجلة العلمية للدراسات

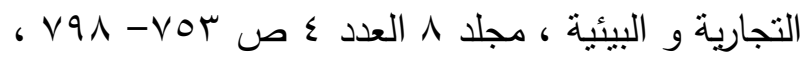

( https://search.mandumah.com/Record/889926 متاح على )

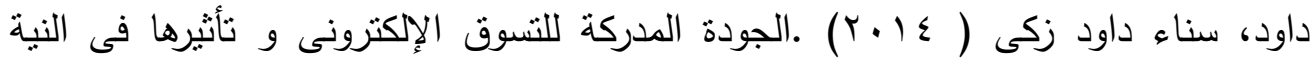
السلوكية المستمرة : دراسة ميدانية بإحدى المحافظات المصرية ــ مجلة الأكاديمية

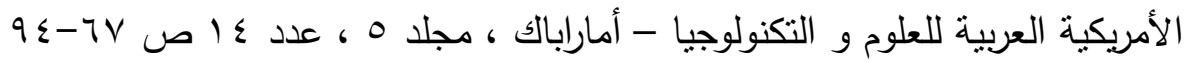

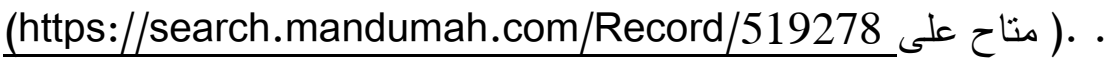
ديوب ، محمد عباس و خضر ، لورين (10 + ب) ـ تأثثير معوقات التسويق عبر الإنترنت على نبة الثراء الإككترونى - دراسة ميدانية على طلاب الكليات فى طرطوس . مجلة جامعة تشرين للبحوث و الدراسات العليا - سلسلة العلوم الإقتصادية و

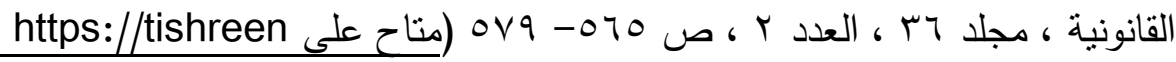

\section{(.edu.sy}

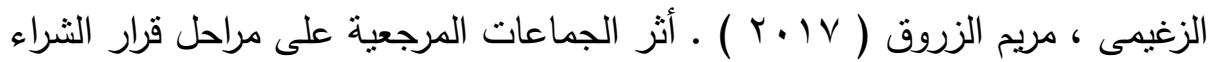
للمستهلك النهائى : دراسة ميدانية تحليلية ـ مجلة الحقوق و العلوم الإنسانية ، مجلد

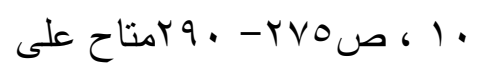

( https://search.mandumah.com/.com/Record/836694)

الثميمرى ، أحمد عبد الرحمن و أبو حمادة ،عبد الموجود عبد المقصود (T · . ؟) ـ استخدام

التسوق الإكترونى من وجهة نظر المستهلك النهائى فى جمهورية مصر العربية و

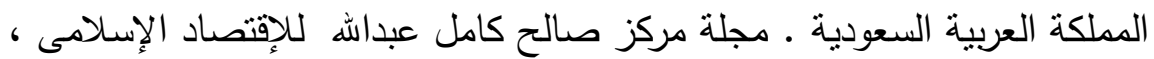




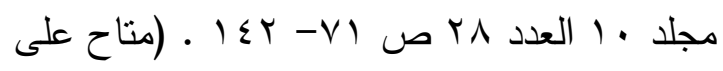

\section{( https://search.mandumah.com/Record/61973}

الثورة ، محمد سليم و كوكث ، حسام أحمد و الزامل ، أحمد محمود و العفيشات ، تيسيرى

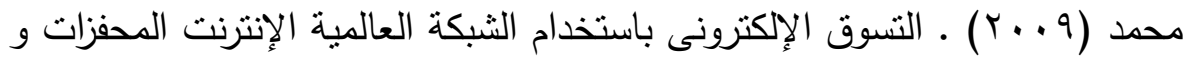

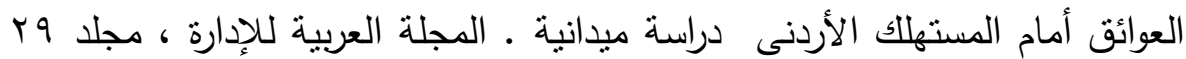

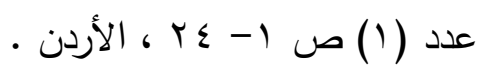

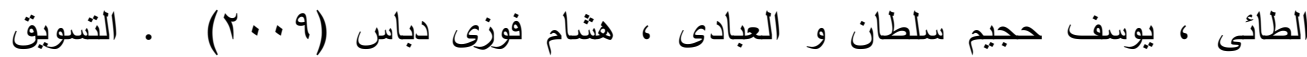

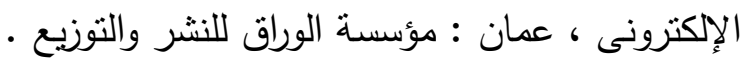

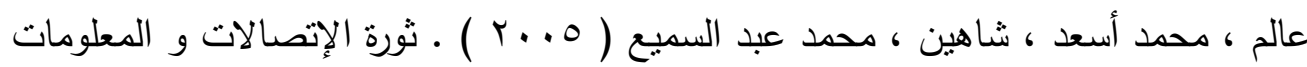

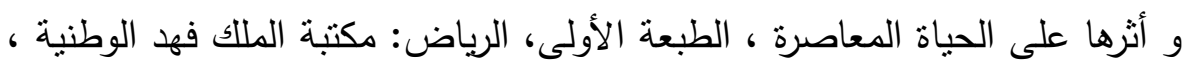

$$
\text { المملكة العربية السعودية. }
$$

عبد الحافظ ، نبيلة الوردانى ، العربى ، نفين ، نصر ، هبة محمد ، عبد الجواد ، أسماء

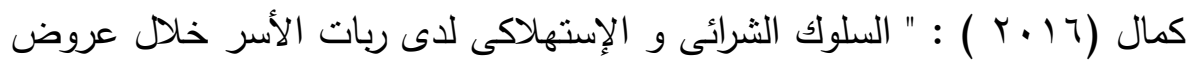
تخفيض الأسعار على السلع الإستهلاكية فى مدينة الإسماعيلية " مجلة الأسكندرية

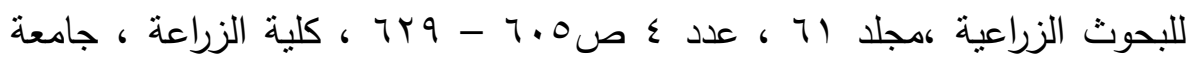

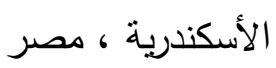

عبيدات ، ذوقان عبد الله ، عبد الحق ، كايد و عدس ،عبد الرحمن (1 . . ץ) ـ البحث العلمي

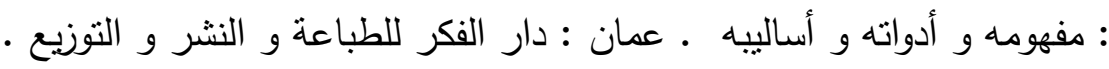

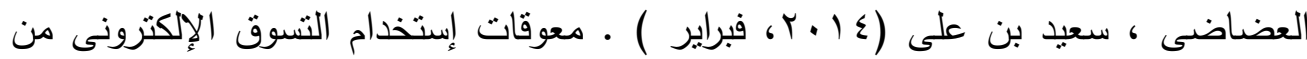
وجهة نظر المستهلك الخليجى - دراسة ميدانية ـ المؤتمر الأول لكليات إدارة الأعمال بجامعات دول مجلس التعاون لدول الخليج العربية ، كلية إدارة الأعمال ، لهال

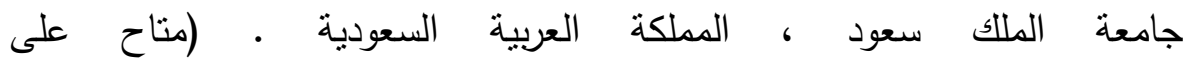
(https://cbagccu.ksu.edu.sa/ar/node/ 


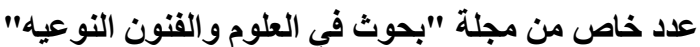

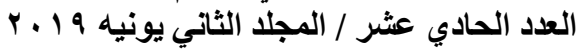

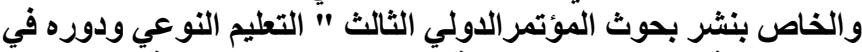

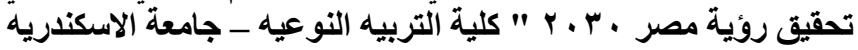

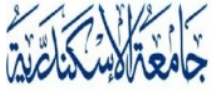

ALEXANDRIA

U N I V E R S I T Y

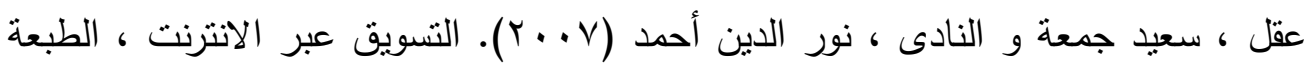
الأولى ، عمان : مكتبة المجتمع العربى للنشر والتوزيع. لون.

فقيه ، تهانى محمد عبد الرحمن ( rا ـ ץ) ـ التسوق الإلكترونى و أثره على اتجاهات الأسرة الإستهلاكية فى عصر المعلوماتية ( رسالة ماجستير) ، كلية الفنون و التصميم

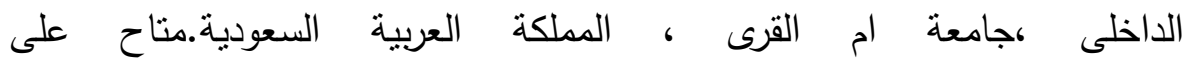
- ( http://libback.uqu.edu.sa/hipres/futxt/.pdf

القندوز ، أمنة محمد عبد القادر ( Y V ) ) ـ إتجاهات الثباب الليبى نحو التسوق عبر

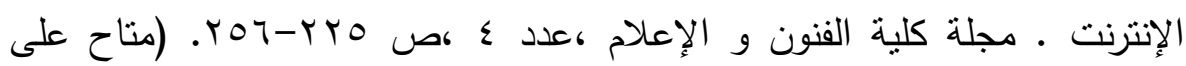
https://search.mandumah.com/Record/894977

الكردى ، أحمد السيد طه (ع ( ب) ـ المخاطر المدركة لاى المستهلك النهائى فى التسوق الإلكترونى تأثيرها فى إتخاذ قرار الشراء عبر الإنترنت بالتطبيق على مستخدمى

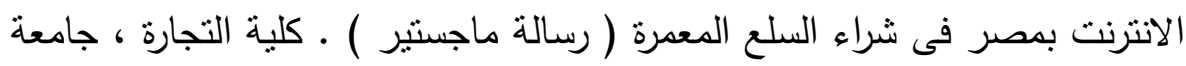

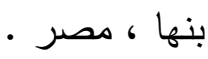

الكساسبه ، حمزة حمد مصطفى (Y V V ) ـ أثز العوامل الثقافية على تبنى قرارالشراء عبر

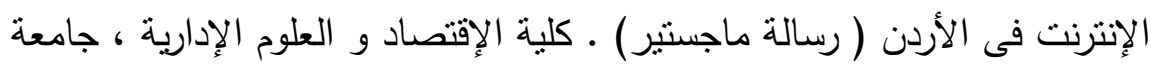

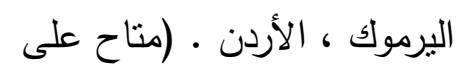
(https://search.mandumah.com/Record/61973

مطالى ، ليلى (7 ( + ) ). إتجاهات المستهلكين الجزائريين نحو التسوق عبر الإنترنت دراسة

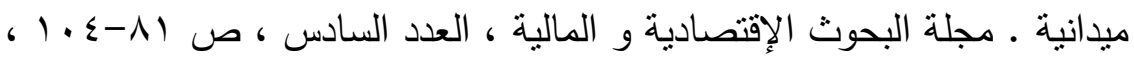

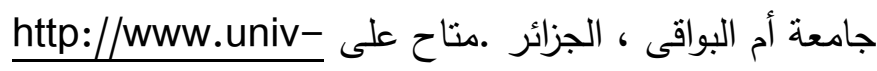
oeb.dz/JEFR/docs/num 
عدد خاص من مجلة "بحوث في العلوم والفنون النوعيه" التوبه

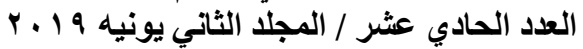

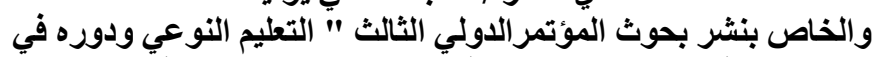

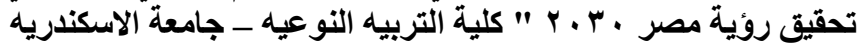

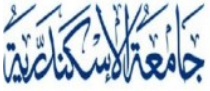

ALEXANDRIA

U N I V E R S I T Y

AlexUPress

منصور ، رشا رشاد محمود (7 ( ب ) ـ الشراء الرشيد لربة الأسرة العاملة و غبر العاملة .

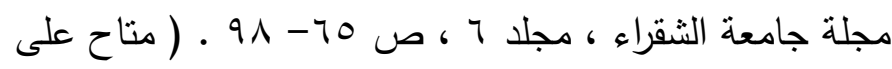
(https://search.mandumah.com/Record/843066

النونو،عماد أحمد إسماعيل (V . . r). التسوق عبر الانترنت - دوافع التبنى أو الرفض دراسة

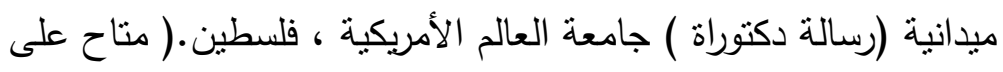
(https://search.mandumah.com/Record/544407

الوادى ، محمود و الوادى ، بلال (1) (1) .المعرفة و الإدارة الإكترونية وتطبيقاتها

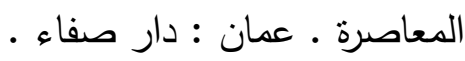

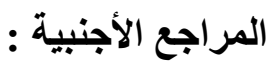

Beckers,J. \& Cardenas,I.\&Verhetsel,A. (2018). Identifying the geography of online shopping adoption in Belgium . Journal of Retailing and Consumer Services( 45) 33-41 avilable at : www.elsevier.com/locate/jretconser

Clemes,M. , Gan,Ch . \& Zhang ,J. (2014). An empirical analysis of online shopping adoption in Beijing, China, Journal of Retailing and Consumer Services (21) 364-375 available at https.www.sciencedirect.com

Haddadin ,M.(2017).The Impact of online services quality on customers'attitudes towards online shopping ( Master thesis ), Business College, Middle Eeast University, Jordan . Available online at https://search.mandumah.com/Record/843066

Javadi,M. ,Dolatabadi,H. ,Nourbakhsh,M. , Poursaeedi,A. and Asadollahi,A. (2012).An analysis of factors affecting on online shopping behavior of consumers . International Journal of Marketing Studies,4 (5),81 
Miyatake, K., Nemoto, T., Nakaharai, S., Hayashi, K.(2015 ). Reduction in consumers' purchasing cost by online shopping. The 9th International Conference on City Logistics, Tenerife, Canary Islands (Spain), 17-19 June 2015 Available online at www.sciencedirect.com

Ozkisi,H. and Topaloglu,M.(2016) . Identifying College Students'Feelings and Thoughts about Online Shopping .procedia Economics and Finance (39) 17-23 available at https.www.sciencedirect.com

Pandey,sh., Chawla, D . ( 2014 ) .E-lifestyles of Indian online shoppers: A scale validation. Journal of Retailing and Consumer Services( 21) 1068-1074 www.elsevier.com/locate/jretconser

Schultz ,D. and Block, M .(2015) . U.S. online shopping: Facts, fiction, hopes and dreams . Journal of Retailing and Consumer Services 23 (2015) 99-106 available at : www.elsevier.com/locate/jretconser

Vrechopoulos, A., Siomkos, G. \& Doukidis, G. (2001). Internet Shopping adoption by Greek consumer . European Journal of innovation Management, Vol: 4, No: 3, Greece 


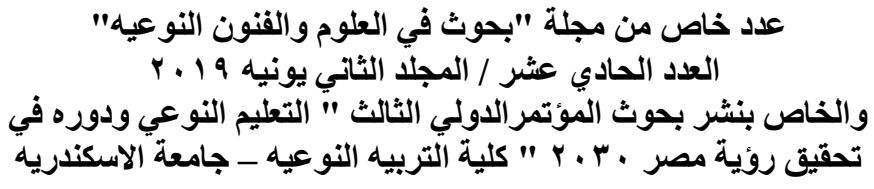

Advantages and Disadvantages of Online Shopping for Families in El-Beheira and Alexandria Governorates within some Socioeconomic Variables

\section{Prof.Faten Mostafa Kamal Lotfy Hemeida Soliman \\ Prof. Home Management \& Family Economics Lecturer of Home Management \& FamilyEconomics \\ Dean of Faculty of Specific Education \\ Home Economics Department}

Alexandria University

Faculty of Specific Education -Alexandria University

\section{Iman Mohamed Ibrahim Elargawy}

Faculty of Specific Education -Alexandria University

The research aimed to identify advantages and disadvantages of online shopping for families in the governorates of El-Beheira and Alexandria within some socioeconomic variables and Identify the most common problems which families faced when they shop online. The research sample included 206 families. The researchers used the descriptive analytical method and used questionnaire as a tool for data collection. The results are shown that the husband was the most member of the family doing online shopping, the more sites that used were the local sites and the most of the goods purchased online were clothing, Also the results showed the most problems faced was the problem of slow Internet and The privacy and sites security.

there is a statistically significant relationship between educational level of husband and wife and the family monthly income and the degree of advantages and disadvantages of online shopping, While there is no statistically significant relationship between the age of wife

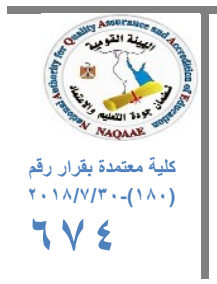

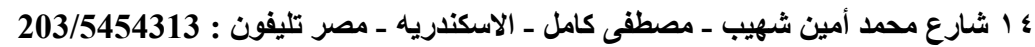

Alexandria - Egypt, Tel. : 203/5454313 - 203/5442776 Fax :203/5442776

E-mail : journal.edusp@alexu.edu.eg Web site: RSSA.edusp@lexu.edu.eg 
and husband, the marriage duration and the number of family members and the degree of advantages and disadvantages of online shopping

Also, there were no statistically significant differences between the respondents in the degree of the advantages and disadvantages of online shopping according to both the place of residence and the husband's job, while there were statistically significant differences in degree of advantages and disadvantages of online shopping for respondents according to the job of the wife. The study recommends the importance of introducing families the advantages of online shopping as well as its disadvantages to avoid them .

Keywords : Online shopping, Socioeconomic variables 